Electronic Supplementary Information

\title{
Discovery and Optimization of Small-Molecule Ligands for V-domain Ig Suppressor of T-cell Activation (VISTA)
}

\author{
Moustafa T. Gabr ${ }^{1,2^{*}}$ and Sanjiv S. Gambhir ${ }^{1,2,3 \neq}$ \\ ${ }^{1}$ Bio-X Program and Molecular Imaging Program at Stanford (MIPS), Stanford University, Stanford, CA, USA. \\ ${ }^{2}$ Department of Radiology, Stanford University, Stanford, CA, USA. \\ ${ }^{3}$ Department of Bioengineering, Department of Materials Science \& Engineering, Bio-X Program, Stanford University, Stanford, \\ CA, USA. \\ ${ }^{\ddagger}$ Deceased on July 18, 2020. \\ *Email: gabr2003@gmail.com
}

\section{Contents}

Linear correlation between TR-FRET ratio and various concentrations of CF647 labeled

S14

VISTA antibody

Effect of addition of various concentrations of VSIG-3 on the TR-FRET signal

Chemical structure of CA-170

S15

Dose-response curve for CA-170 in VISTA FRET assay

S15

Dose-response curve for CA-170 in VISTA-VSIG-3 competitive ELISA

S15

Sensogram for binding of CA-170 (50 $\mu \mathrm{M})$ to VISTA ECD in SPR screening

S16

Chemical structures for potential hits identified in VISTA TR-FRET assay

S17

COSY NMR of compound la

S18

${ }^{1} \mathrm{H}$ NMR STD experiment of compound la binding to VISTA

S19

Predicted binding sites in VISTA crystal structure (PDB ID: 6OIL) using DoGSiteScorer

Predicted binding sites in VISTA crystal structure (PDB ID: 6MVL) using DoGSiteScorer

Top 3 predicted binding sites in VISTA crystal structure (PDB ID: 6OIL) using LIBRA-WA

S21

Top 3 predicted binding sites in VISTA crystal structure (PDB ID: 6MVL) using LIBRA-WA

S21

Predicted binding sites in VISTA crystal structure (PDB ID: 6OIL) using FT site

S22

Predicted binding sites in VISTA crystal structure (PDB ID: 6MVL) using FT site

S22

Predicted binding site in VISTA crystal structure (PDB ID: 6OIL) using Prankweb

S23

A close-up to the predicted binding sites in VISTA crystal structure (PDB ID: 6OIL) using

Prankweb

Predicted binding site in VISTA crystal structure (PDB ID: 6MVL) using Prankweb

A close-up to the predicted binding sites in VISTA crystal structure (PDB ID: 6MVL) using 
Prankweb

Predicted binding sites in VISTA crystal structure (PDB ID: 6OIL) using Deepsite S25

Predicted binding sites in VISTA crystal structure (PDB ID: 6MVL) using Deepsite S26

Dose-response curve of compounds la-m, Ila,b and III in FRET assay S27

3D view of predicted binding pose of compound III to VISTA crystal structure S28

Evaluation of VISTA mutants in competitive ELISA in the presence of III S28

Luminescence signal in co-cultures of NanoGloTMIL-2/Jurkat VISTA cells with CHOK1 VISTA S29

cells and CHOK1 parental cells in the presence of different concentrations of VISTA antibody

Luminescence signal in co-cultures of NanoGloTMIL-2/Jurkat VISTA cells with CHOK1 VISTA S29

cells and CHOK1 parental cells in the presence of different concentrations of NSC622608

Flow cytometry analysis of human VISTA expression on the surface of cancer cell lines $\quad$ S30

Interferon gamma (IFN $\gamma$ ) concentration, determined by ELISA, in the supernatant of co- $\quad$ S31

culture of purified T cells and cancer cell lines

Tumor necrosis factor alpha (TNF $\alpha$ ), determined by ELISA, in the supernatant of co-culture S31

of purified T cells and cancer cell lines

Evaluation of VISTA mutants in competitive ELISA in the absence and presence of $100 \mathrm{nM}$ of $\quad$ S32

VISTA antibody (MAB71263-SP)

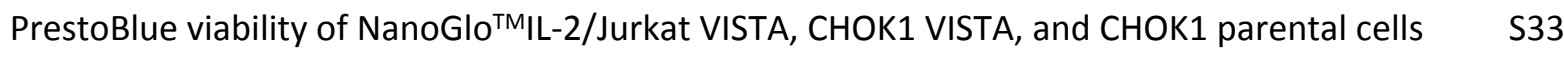

in the absence and presence of compound III (10 $\mu \mathrm{M})$

Inhibition percentages of the hits identified against VISTA in HTS FRET assay $\quad$ S34

GlideScores ( $\mathrm{kcal} / \mathrm{mol}$ ) of the hot compound (NSC622608) upon docking to all the predicted S35

binding sites in VISTA crystal structures PDB ID 6OIL and PDB ID 6MVL

$\begin{array}{ll}\text { References } & \text { S36 }\end{array}$

$\begin{array}{ll}\text { NMR of all compounds } & \text { S37 }\end{array}$

\section{Experimental:}




\section{General}

All commercially available starting materials, reagents, and solvents were used as supplied unless otherwise stated. CA-170 was purchased from MedChemExpress (Monmouth Junction, NJ, USA) CAS Number: 1673534-76-3. Proton $\left({ }^{1} \mathrm{H}\right)$ and carbon $\left({ }^{13} \mathrm{C}\right)$ NMR were collected on Agilent $400 \mathrm{MHz}$ WB NMR spectrometer. Chemical shifts $(\delta)$ are reported in parts-per million (ppm) relative to residual undeuterated solvent. High resolution mass spectra were obtained in positive ion mode using electrospray ionization (ESI) on Thermo Exactive Orbitrap LC/MS. The purity of all final compounds was $>99 \%$ as revealed by HPLC analysis using an Agilent system equipped with 1260 Infinity II quaternary pump and 1260 Infinity II diode array detector. Analytical HPLC reverse phase column (Phenomenex, Gemini, Hesperia, CA, C18, $5 \mu \mathrm{m}$, $250 \times 4.6 \mathrm{~mm}$ ) at a flow rate of $1 \mathrm{~mL} / \mathrm{min}$ was used for HPLC analysis.

\section{Synthetic procedures:}

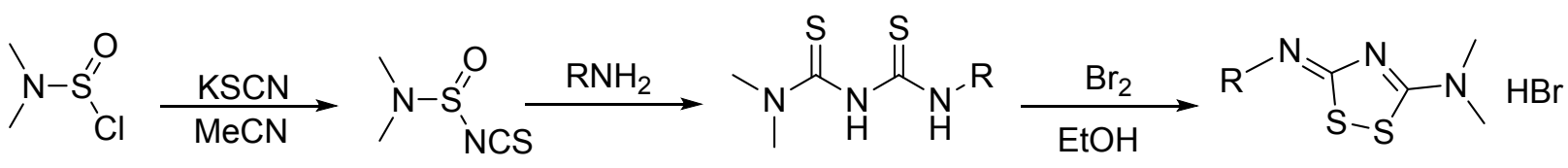

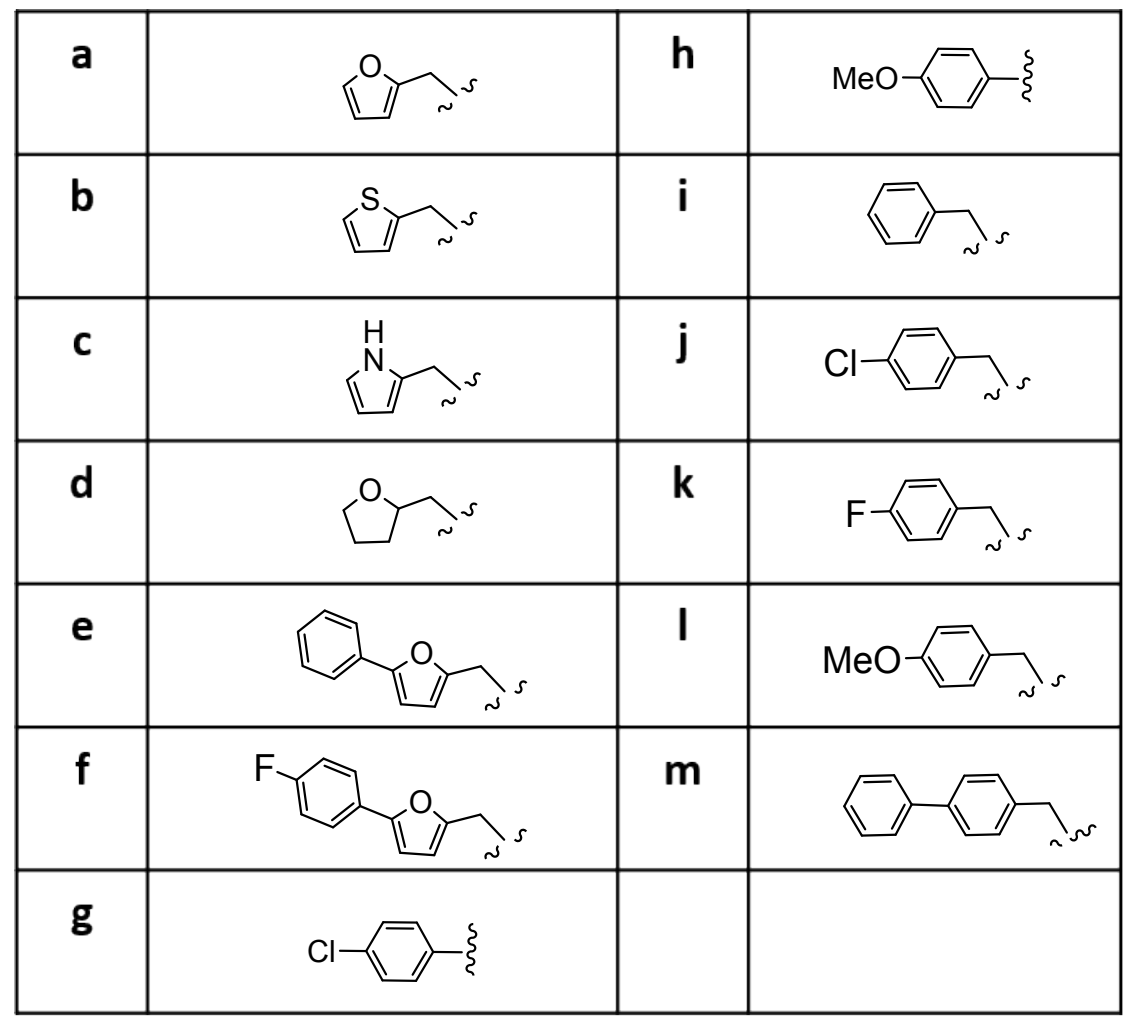

Scheme S1. General procedure for the synthesis of compounds la-m. 


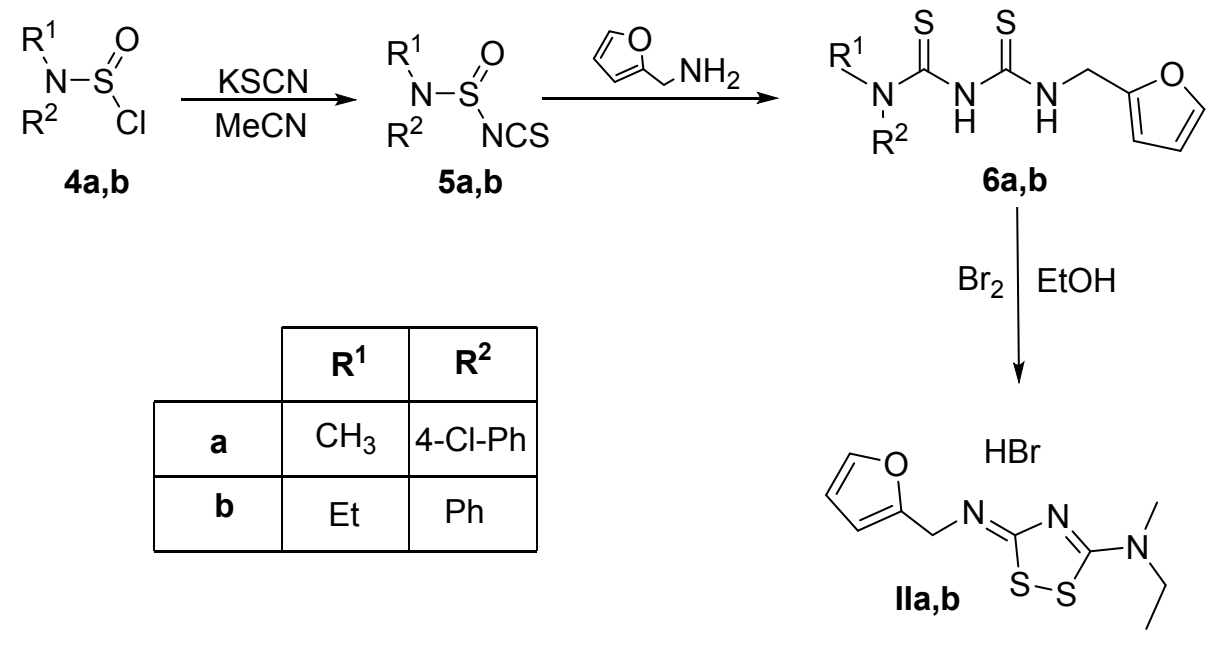

Scheme S2. Synthesis of compounds Ila,b.

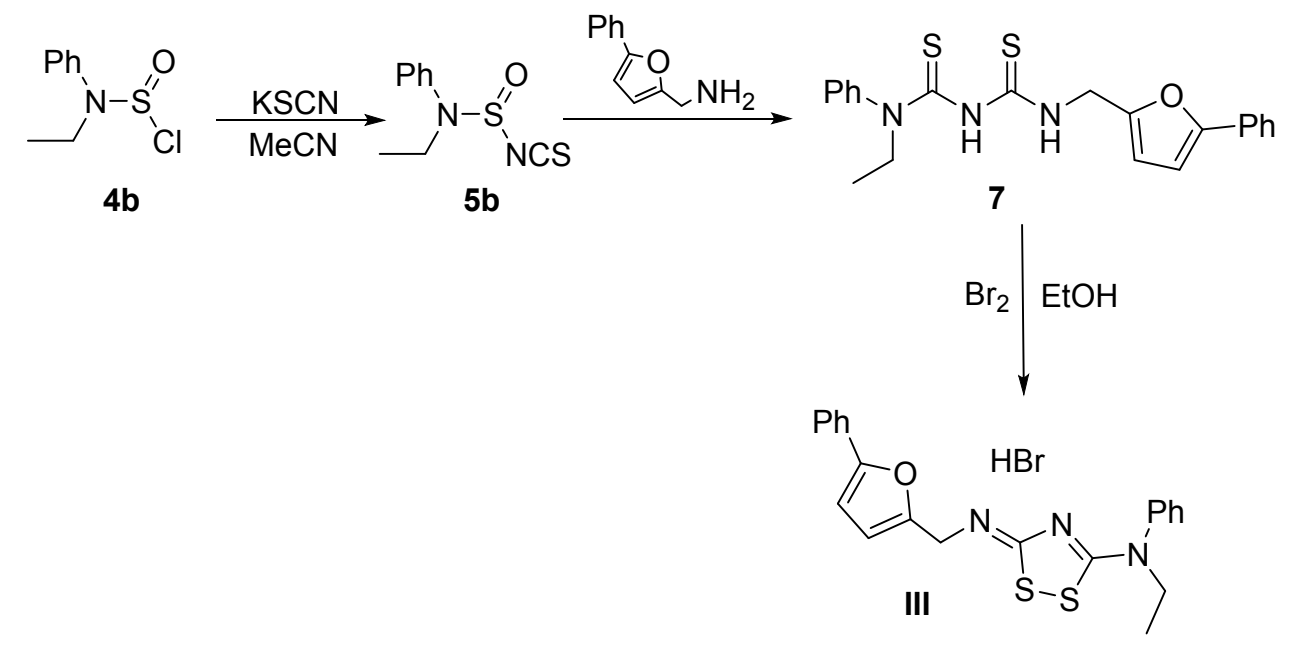

Scheme S3. Synthesis of compound III.

General procedure for the preparation of compounds $3 a-m, 6 a, b$ and 7:

A solution of aminosulphinyl chloride derivative $(10.0 \mathrm{mmol})$ and potassium thiocyanate $(0.98 \mathrm{~g}, 10.0$ $\mathrm{mmol})$ in dry acetonitrile $(25 \mathrm{~mL})$ was heated under reflux for $15 \mathrm{~min}$. A solution of the corresponding primary amine $(9 \mathrm{mmol})$ in dry acetonitrile $(10 \mathrm{~mL})$ was added to the reaction mixture and kept stirring under reflux for $1 \mathrm{hr}$. The crude reaction mixture was filtered over Celite and concentrated under vacuum. The crude mixture was purified by Teledyne CombiFlash Rf200 Flash Chromatography System (silica) using hexane-ethyl acetate gradient.

$\boldsymbol{N}, \boldsymbol{N}$-Dimethyl- $\boldsymbol{N}$ '-(furan-2-ylmethyl)-thioimidodicarbonic diamide (3a)

Purified using $10 \%$ ethyl acetate in hexane followed by $15 \%$ ethyl acetate in hexane, $\mathrm{Rf}=0.82$ in $1: 1$

ethyl acetate:hexane. Yield 87\%. ${ }^{1} \mathrm{H}$ NMR $\left(400 \mathrm{MHz}, \mathrm{CDCl}_{3}\right) \delta 3.27(\mathrm{~s}, 3 \mathrm{H}), 3.42(\mathrm{~s}, 3 \mathrm{H}), 4.76(\mathrm{~d}, \mathrm{~J}=5.4 \mathrm{~Hz}$, $2 \mathrm{H}), 6.26-6.29(\mathrm{~m}, 1 \mathrm{H}), 6.86(\mathrm{dd}, J=12.9,3.2 \mathrm{~Hz}, 1 \mathrm{H}), 6.91-6.97(\mathrm{~m}, 1 \mathrm{H}) .{ }^{13} \mathrm{C} \mathrm{NMR}\left(100 \mathrm{MHz}, \mathrm{DMSO}-d_{6}\right) \delta$ 
46.2, 46.7, 47.8, 127.0, 130.3, 137.1, 140.2, 177.2, 181.0. HRMS (ESI): calcd for $\mathrm{C}_{9} \mathrm{H}_{14} \mathrm{~N}_{3} \mathrm{OS}{ }_{2}[\mathrm{M}+\mathrm{H}]^{+}$, 244.0578; found, 244.0579.

$\mathbf{N}, \mathbf{N}$-Dimethyl- $\boldsymbol{N}^{\prime}$-( thiophen-2-ylmethyl)-thioimidodicarbonic diamide (3b)

Purified using $10 \%$ ethyl acetate in hexane followed by $20 \%$ ethyl acetate in hexane, $\mathrm{Rf}=0.75$ in $1: 1$ ethyl acetate:hexane. Yield 75\%. ${ }^{1} \mathrm{H}$ NMR $\left(400 \mathrm{MHz}, \mathrm{CDCl}_{3}\right) \delta 3.29(\mathrm{~s}, 3 \mathrm{H}), 3.33(\mathrm{~s}, 3 \mathrm{H}), 5.04(\mathrm{~d}, \mathrm{~J}=5.2 \mathrm{~Hz}, 2 \mathrm{H})$, 6.95 (ddd, $J=4.8,3.5,1.1 \mathrm{~Hz}, 1 \mathrm{H}), 7.07$ (dt, $J=3.5,1.1 \mathrm{~Hz}, 1 \mathrm{H}), 7.23$ (dd, $J=5.1,1.2 \mathrm{~Hz}, 1 \mathrm{H}), 8.47(\mathrm{~s}, 1 \mathrm{H}$ ), $12.51(\mathrm{~s}, 1 \mathrm{H}) .{ }^{13} \mathrm{C}$ NMR $\left(100 \mathrm{MHz}, \mathrm{CDCl}_{3}\right) \delta 40.1,40.6,44.9,125.3,126.4,126.8,140.7,177.9,182.0$. HRMS (ESI): calcd for $\mathrm{C}_{9} \mathrm{H}_{14} \mathrm{~N}_{3} \mathrm{~S}_{3}[\mathrm{M}+\mathrm{H}]^{+}, 260.0349$; found, 260.0355 .

\section{N,N-Dimethyl-N'-((1H-pyrrol-2-yl)methyl)-thioimidodicarbonic diamide (3c)}

Purified using $10 \%$ ethyl acetate in hexane followed by $15 \%$ ethyl acetate in hexane, $\mathrm{Rf}=0.88$ in $1: 1$ ethyl acetate:hexane. Yield 79\%. ${ }^{1} \mathrm{H}$ NMR $\left(400 \mathrm{MHz}, \mathrm{CDCl}_{3}\right) \delta 3.21(\mathrm{~s}, 3 \mathrm{H}), 3.25(\mathrm{~s}, 3 \mathrm{H}), 4.81(\mathrm{~d}, J=5.6 \mathrm{~Hz}, 2 \mathrm{H})$, 5.88-6.18 (m, 2H), 6.69-6.71 (m, 1H), $8.42(\mathrm{~s}, 1 \mathrm{H}), 9.34(\mathrm{~s}, 1 \mathrm{H}), 12.41(\mathrm{~s}, 1 \mathrm{H}) .{ }^{13} \mathrm{C} \mathrm{NMR}\left(100 \mathrm{MHz}, \mathrm{CDCl}_{3}\right) \delta$ 38.3, 40.7, 41.4, 110.0, 112.5, 130.3, 132.4, 175.6, 189.5. HRMS (ESI): calcd for $\mathrm{C}_{9} \mathrm{H}_{15} \mathrm{~N}_{4} \mathrm{~S}_{2}[\mathrm{M}+\mathrm{H}]^{+}$, 243.0738; found, 243.0742 .

\section{$\mathbf{N}, \mathbf{N}$-Dimethyl-N'-((tetrahydrofuran-2-yl)methyl)-thioimidodicarbonic diamide (3d)}

Purified using $5 \%$ ethyl acetate in hexane followed by $10 \%$ ethyl acetate in hexane, $\mathrm{Rf}=0.64$ in $1: 2$ ethyl acetate:hexane. Yield 68\%. ${ }^{1} \mathrm{H}$ NMR $\left(400 \mathrm{MHz}, \mathrm{CDCl}_{3}\right) \delta 1.54-2.04(\mathrm{~m}, 4 \mathrm{H}), 3.28(\mathrm{~s}, 6 \mathrm{H}), 3.66-3.92(\mathrm{~m}, 4 \mathrm{H})$, 4.11 (qd, $J=6.6,3.9 \mathrm{~Hz}, 1 \mathrm{H}), 8.43(\mathrm{~s}, 1 \mathrm{H}), 12.17(\mathrm{~s}, 1 \mathrm{H}) .{ }^{13} \mathrm{C} \mathrm{NMR}\left(100 \mathrm{MHz}, \mathrm{CDCl}_{3}\right) \delta 25.9,28.2,40.9,41.9$, 49.9, 68.3, 76.3, 175.3, 179.8. HRMS (ESI): calcd for $\mathrm{C}_{9} \mathrm{H}_{18} \mathrm{~N}_{3} \mathrm{OS}_{2}[\mathrm{M}+\mathrm{H}]^{+}, 248.0891$; found, 248.0894.

\section{$N, N$-Dimethyl-N'-((5-phenylfuran-2-yl)methyl)-thioimidodicarbonic diamide (3e)}

Purified using $5 \%$ ethyl acetate in hexane followed by $7.5 \%$ ethyl acetate in hexane, $\mathrm{Rf}=0.72$ in $1: 2$ ethyl acetate:hexane. Yield 65\%. ${ }^{1} \mathrm{H}$ NMR $\left(400 \mathrm{MHz}, \mathrm{CDCl}_{3}\right) \delta 3.12(\mathrm{~s}, 3 \mathrm{H}), 3.32(\mathrm{~s}, 3 \mathrm{H}), 4.48(\mathrm{~s}, 2 \mathrm{H}), 6.44(\mathrm{~d}, J=$ $3.2 \mathrm{~Hz}, 1 \mathrm{H}), 6.55(\mathrm{t}, J=3.0 \mathrm{~Hz}, 1 \mathrm{H}), 7.18-7.29(\mathrm{~m}, 1 \mathrm{H}), 7.29-2.47(\mathrm{~m}, 2 \mathrm{H}), 7.60(\mathrm{dd}, J=2.7,1.3 \mathrm{~Hz}, 1 \mathrm{H}), 7.61-$ $7.73(\mathrm{~m}, 1 \mathrm{H}) .{ }^{13} \mathrm{C} \mathrm{NMR}\left(100 \mathrm{MHz}, \mathrm{CDCl}_{3}\right) \delta 37.3,38.9,53.3,106.1,110.7,123.6,127.3,128.6,130.5,149.4$, 153.6, 168.8, 177.5. HRMS (ESI): calcd for $\mathrm{C}_{15} \mathrm{H}_{18} \mathrm{~N}_{3} \mathrm{OS}$ [ $[\mathrm{M}+\mathrm{H}]^{+}, 320.0891$; found, 320.0896 .

\section{$\mathbf{N}, \mathbf{N}$-Dimethyl-N'-((5-(4-fluorophenyl)furan-2-yl)methyl)-thioimidodicarbonic diamide (3f)}

Purified using $2.5 \%$ ethyl acetate in hexane followed by $5 \%$ ethyl acetate in hexane, $\mathrm{Rf}=0.81$ in $1: 2$ ethyl acetate:hexane. Yield 72\%. ${ }^{1} \mathrm{H}$ NMR $\left(400 \mathrm{MHz}, \mathrm{CDCl}_{3}\right) \delta 3.10(\mathrm{~s}, 3 \mathrm{H}), 3.32(\mathrm{~s}, 3 \mathrm{H}), 4.52(\mathrm{~s}, 2 \mathrm{H}), 6.41-6.49$ $(\mathrm{m}, 2 \mathrm{H}), 7.01-7.06(\mathrm{~m}, 2 \mathrm{H}), 7.57$ (ddd, $J=8.8,5.3,1.5 \mathrm{~Hz}, 2 \mathrm{H}) .{ }^{13} \mathrm{C} \mathrm{NMR}\left(100 \mathrm{MHz}, \mathrm{CDCl}_{3}\right) \delta 39.3,41.4,42.9$, 106.0, 110.4, 115.7, 126.0, 126.9, 148.9, 152.9, 160.8, 175.3, 179.2. HRMS (ESI): calcd for $\mathrm{C}_{15} \mathrm{H}_{17} \mathrm{FN}_{3} \mathrm{OS}_{2}$ $[\mathrm{M}+\mathrm{H}]^{+}, 338.0797$; found, 338.0799 .

\section{$\mathbf{N}, \mathbf{N}$-Dimethyl-N'-(4-chlorophenyl)-thioimidodicarbonic diamide (3g)}

Purified using $2.5 \%$ ethyl acetate in hexane followed by $5 \%$ ethyl acetate in hexane, $\mathrm{Rf}=0.74$ in $1: 2$ ethyl acetate:hexane. Yield 94\%. ${ }^{1} \mathrm{H}$ NMR $\left(400 \mathrm{MHz}, \mathrm{CDCl}_{3}\right) \delta 3.14(\mathrm{~s}, 3 \mathrm{H}), 3.24(\mathrm{~s}, 3 \mathrm{H}), 6.96(\mathrm{~d}, \mathrm{~J}=7.5 \mathrm{~Hz}, 2 \mathrm{H})$, $7.27(\mathrm{~d}, J=7.5 \mathrm{~Hz}, 2 \mathrm{H}) .{ }^{13} \mathrm{C} \mathrm{NMR}\left(100 \mathrm{MHz}, \mathrm{CDCl}_{3}\right) \delta 39.1,41.8,122.7,128.8,129.6,149.2,168.0,174.8$. HRMS (ESI): calcd for $\mathrm{C}_{10} \mathrm{H}_{13} \mathrm{ClN}_{3} \mathrm{~S}_{2}[\mathrm{M}+\mathrm{H}]^{+}, 274.0239$; found, 274.0241 .

\section{$\mathbf{N}, \mathbf{N}$-Dimethyl-N'-(4-methoxyphenyl)-thioimidodicarbonic diamide (3h)}

Purified using $7.5 \%$ ethyl acetate in hexane followed by $10 \%$ ethyl acetate in hexane, $R f=0.58$ in $1: 1$ ethyl acetate:hexane. Yield 91\%. ${ }^{1} \mathrm{H}$ NMR $\left(400 \mathrm{MHz}, \mathrm{CDCl}_{3}\right) \delta 3.20(\mathrm{~s}, 3 \mathrm{H}), 3.25(\mathrm{~s}, 3 \mathrm{H}), 3.77(\mathrm{~s}, 3 \mathrm{H}), 6.86(\mathrm{~d}, J=$ $8.3 \mathrm{~Hz}, 2 \mathrm{H}), 7.49(\mathrm{~d}, J=8.3 \mathrm{~Hz}, 2 \mathrm{H}), 8.54(\mathrm{~s}, 1 \mathrm{H}), 13.82(\mathrm{~s}, 1 \mathrm{H}) .{ }^{13} \mathrm{C} \mathrm{NMR}\left(100 \mathrm{MHz}, \mathrm{CDCl}_{3}\right) \delta$ 40.7, 41.8, 55.5, 
121.5, 125.7, 130.2, 143.6, 174.9, 177.6. HRMS (ESI): calcd for $\mathrm{C}_{11} \mathrm{H}_{16} \mathrm{~N}_{3} \mathrm{OS}$ [ $[\mathrm{M}+\mathrm{H}]^{+}, 270.0734$; found, 270.0739 .

$\mathbf{N}, \mathbf{N}$-Dimethyl-N'-benzyl-thioimidodicarbonic diamide (3i)

Purified using $2.5 \%$ ethyl acetate in hexane followed by $5 \%$ ethyl acetate in hexane, $\mathrm{Rf}=0.81$ in $1: 2$ ethyl acetate:hexane. Yield 95\%. ${ }^{1} \mathrm{H}$ NMR $\left(400 \mathrm{MHz}, \mathrm{CDCl}_{3}\right) \delta 3.22(\mathrm{~s}, 3 \mathrm{H}), 3.26(\mathrm{~s}, 3 \mathrm{H}), 4.89(\mathrm{~d}, \mathrm{~J}=2.9 \mathrm{~Hz}, 2 \mathrm{H})$, 7.29-7.41 (m, 5H), $8.50(\mathrm{~s}, 1 \mathrm{H}), 12.53(\mathrm{~s}, 1 \mathrm{H}) .{ }^{13} \mathrm{C} \mathrm{NMR}\left(100 \mathrm{MHz}, \mathrm{CDCl}_{3}\right) \delta 42.1,42.6,49.9,127.7,127.8$, 128.7, 136.2, 175.2, 179.2. HRMS (ESI): calcd for $\mathrm{C}_{11} \mathrm{H}_{16} \mathrm{~N}_{3} \mathrm{~S}_{2}[\mathrm{M}+\mathrm{H}]^{+}, 254.0785$; found, 254.0788 .

$\boldsymbol{N}, \boldsymbol{N}$-Dimethyl- $\boldsymbol{N}$-(4-chlorobenzyl)-thioimidodicarbonic diamide (3j)

Purified using $2.5 \%$ ethyl acetate in hexane followed by $5 \%$ ethyl acetate in hexane, $\mathrm{Rf}=0.72$ in $1: 3$ ethyl acetate:hexane. Yield 78\%. ${ }^{1} \mathrm{H}$ NMR $(400 \mathrm{MHz}, \mathrm{CDCl}) \delta 3.26(\mathrm{~s}, 3 \mathrm{H}), 3.29(\mathrm{~s}, 3 \mathrm{H}), 4.64(\mathrm{~d}, J=2.9 \mathrm{~Hz}, 2 \mathrm{H})$, $7.28(\mathrm{~d}, J=7.9 \mathrm{~Hz}, 2 \mathrm{H}), 7.39$ (d, $J=7.9 \mathrm{~Hz}, 2 \mathrm{H}) 10.75(\mathrm{~s}, 1 \mathrm{H}) .{ }^{13} \mathrm{C} \mathrm{NMR}\left(100 \mathrm{MHz}, \mathrm{CDCl}_{3}\right) \delta 42.3,42.8,49.0$, $128.8,129.2,133.3,134.8,175.1,179.4$. HRMS (ESI): calcd for $\mathrm{C}_{11} \mathrm{H}_{15} \mathrm{ClN}_{3} \mathrm{~S}_{2}[\mathrm{M}+\mathrm{H}]^{+}, 288.0395$; found, 288.0396.

$\mathbf{N}, \mathbf{N}$-Dimethyl-N'-(4-fluorobenzyl)-thioimidodicarbonic diamide (3k)

Purified using $2.5 \%$ ethyl acetate in hexane followed by $5 \%$ ethyl acetate in hexane, $\mathrm{Rf}=0.79$ in $1: 3$ ethyl acetate:hexane. Yield 86\%. ${ }^{1} \mathrm{H}$ NMR $\left(400 \mathrm{MHz}, \mathrm{CDCl}_{3}\right) \delta 3.24(\mathrm{~s}, 3 \mathrm{H}), 3.28(\mathrm{~s}, 3 \mathrm{H}), 4.85(\mathrm{~d}, \mathrm{~J}=5.3 \mathrm{~Hz}, 2 \mathrm{H})$, 6.84-7.05 (m, 2H), 7.26-7.47 (m, 2H), $8.49(\mathrm{~s}, 1 \mathrm{H}), 12.51(\mathrm{~s}, 1 \mathrm{H}) .{ }^{13} \mathrm{C} N M R\left(100 \mathrm{MHz}, \mathrm{CDCl}_{3}\right) \delta 42.8,43.6$, 49.1, 115.4, 129.6, 132.1, 163.4, 175.3, 179.3s. HRMS (ESI): calcd for $\mathrm{C}_{11} \mathrm{H}_{15} \mathrm{FN}_{3} \mathrm{~S}_{2}[\mathrm{M}+\mathrm{H}]^{+}, 272.0691$; found, 272.0690 .

\section{$\mathbf{N}, \mathbf{N}$-Dimethyl-N'-(4-methoxybenzyl)-thioimidodicarbonic diamide (3I)}

Purified using 5\% ethyl acetate in hexane followed by $10 \%$ ethyl acetate in hexane, $\mathrm{Rf}=0.66$ in $1: 2$ ethyl acetate:hexane. Yield 82\%. ${ }^{1} \mathrm{H}$ NMR $\left(400 \mathrm{MHz}, \mathrm{CDCl}_{3}\right) \delta 3.21(\mathrm{~s}, 3 \mathrm{H}), 3.24(\mathrm{~s}, 3 \mathrm{H}), 3.78(\mathrm{~s}, 3 \mathrm{H}), 4.80(\mathrm{~d}, \mathrm{~J}=$ $5.1 \mathrm{~Hz}, 2 \mathrm{H}), 6.85(\mathrm{~d}, J=8.9 \mathrm{~Hz}, 2 \mathrm{H}), 7.26(\mathrm{~d}, J=8.9 \mathrm{~Hz}, 2 \mathrm{H}), 8.46(\mathrm{~s}, 1 \mathrm{H}), 12.31(\mathrm{~s}, 1 \mathrm{H}) .{ }^{13} \mathrm{C} \mathrm{NMR}(100 \mathrm{MHz}$, $\left.\mathrm{CDCl}_{3}\right) \delta 40.1,40.6,49.5,55.3,114.1,128.2,129.2,159.1,175.3,178.9$. HRMS (ESI): calcd for $\mathrm{C}_{12} \mathrm{H}_{18} \mathrm{~N}_{3} \mathrm{OS}_{2}$ $[\mathrm{M}+\mathrm{H}]^{+}, 284.0891$; found, 284.0893 .

$N, N$-Dimethyl-N'-([1,1'-Biphenyl]-4-ylmethyl)-thioimidodicarbonic diamide (3m)

Purified using $2.5 \%$ ethyl acetate in hexane followed by $5 \%$ ethyl acetate in hexane, $\mathrm{Rf}=0.84$ in 1:3 ethyl acetate:hexane. Yield 70\%. ${ }^{1} \mathrm{H}$ NMR $\left(400 \mathrm{MHz}, \mathrm{CDCl}_{3}\right) \delta 3.28(\mathrm{~s}, 3 \mathrm{H}), 3.31(\mathrm{~s}, 3 \mathrm{H}), 4.98(\mathrm{~d}, \mathrm{~J}=5.4 \mathrm{~Hz}, 2 \mathrm{H})$, 7.34-7.49 (m, 5H), 7.56-7.61 (m, 4H), $8.54(\mathrm{~s}, 1 \mathrm{H}), 12.61(\mathrm{~s}, 1 \mathrm{H}) .{ }^{13} \mathrm{C} \mathrm{NMR}\left(100 \mathrm{MHz}, \mathrm{CDCl}_{3}\right) \delta 40.6,41.0$, 49.6, 127.0, 127.4, 127.5, 128.2, 128.8, 135.3, 140.5, 140.6, 175.3, 179.4. HRMS (ESI): calcd for $\mathrm{C}_{17} \mathrm{H}_{20} \mathrm{~N}_{3} \mathrm{~S}_{2}$ $[\mathrm{M}+\mathrm{H}]^{+}, 330.1098$; found, 330.1096.

\section{$\mathrm{N}$-(4-Chlorophenyl)-N-methyl-N'-(furan-2-ylmethyl)-thioimidodicarbonic diamide (6a)}

Purified using $2.5 \%$ ethyl acetate in hexane followed by $5 \%$ ethyl acetate in hexane, $\mathrm{Rf}=0.69$ in $1: 2$ ethyl acetate:hexane. Yield 92\%. ${ }^{1} \mathrm{H}$ NMR $\left(400 \mathrm{MHz}, \mathrm{CDCl}_{3}\right) \delta 3.28(\mathrm{~s}, 3 \mathrm{H}), 4.34(\mathrm{~d}, J=5.2 \mathrm{~Hz}, 2 \mathrm{H}), 4.61(\mathrm{~s}, 1 \mathrm{H})$, $5.67(\mathrm{~s}, 1 \mathrm{H}), 6.13(\mathrm{dt}, J=2.2,1.1 \mathrm{~Hz}, 1 \mathrm{H}), 6.26(\mathrm{dt}, J=3.1,1.5 \mathrm{~Hz}, 1 \mathrm{H}), 7.06(\mathrm{~d}, J=8.2 \mathrm{~Hz}, 1 \mathrm{H}), 7.16(\mathrm{~d}, J=$ $8.7 \mathrm{~Hz}, 2 \mathrm{H}), 7.30(\mathrm{~d}, J=8.7 \mathrm{~Hz}, 2 \mathrm{H}) .{ }^{13} \mathrm{C}$ NMR $\left(100 \mathrm{MHz}, \mathrm{CDCl}_{3}\right) \delta 37.8,43.9,106.8,110.3,127.3,128.6$, 130.1, 131.1, 141.9, 152.3, 179.5, 182.6. HRMS (ESI): calcd for $\mathrm{C}_{14} \mathrm{H}_{15} \mathrm{CIN}_{3} \mathrm{OS}_{2}[\mathrm{M}+\mathrm{H}]^{+}, 340.0345$; found, 340.0346 .

$N$-Ethyl-N-phenyl-N'-(furan-2-ylmethyl)-thioimidodicarbonic diamide (6b) 
Purified using $2.5 \%$ ethyl acetate in hexane followed by $5 \%$ ethyl acetate in hexane, $R f=0.71$ in $1: 2$ ethyl acetate:hexane. Yield 80\%. ${ }^{1} \mathrm{H}$ NMR $\left(400 \mathrm{MHz}, \mathrm{CDCl}_{3}\right) \delta 1.24(\mathrm{t}, J=7.1 \mathrm{~Hz}, 3 \mathrm{H}), 3.59(\mathrm{q}, J=7.2 \mathrm{~Hz}, 2 \mathrm{H}), 4.28$ $(\mathrm{d}, J=5.1 \mathrm{~Hz}, 2 \mathrm{H}), 6.75-6.81(\mathrm{~m}, 2 \mathrm{H}), 7.10-7.41(\mathrm{~m}, 6 \mathrm{H}) .{ }^{13} \mathrm{C} \mathrm{NMR}\left(100 \mathrm{MHz}, \mathrm{CDCl}_{3}\right) \delta 12.9,46.0,53.0,127.1$, $128.2,128.7,128.9,129.2,139.8,144.9,162.4,180.3,188.1$. HRMS (ESI): calcd for $\mathrm{C}_{15} \mathrm{H}_{18} \mathrm{~N}_{3} \mathrm{OS} \mathrm{S}_{2}[\mathrm{M}+\mathrm{H}]^{+}$, 320.0891; found, 320.0887 .

\section{$N$-Ethyl-N-phenyl-N'-((5-phenylfuran-2-yl)methyl)-thioimidodicarbonic diamide (7)}

Purified using $2.5 \%$ ethyl acetate in hexane followed by $5 \%$ ethyl acetate in hexane, $\mathrm{Rf}=0.86$ in $1: 2$ ethyl acetate:hexane. Yield 77\%. ${ }^{1 \mathrm{H}} \mathrm{NMR}\left(400 \mathrm{MHz}, \mathrm{CDCl}_{3}\right) \delta 1.25(\mathrm{t}, J=7.3 \mathrm{~Hz}, 3 \mathrm{H}), 3.59(\mathrm{q}, J=7.3 \mathrm{~Hz}, 2 \mathrm{H}), 4.27$ $(\mathrm{d}, J=5.4 \mathrm{~Hz}, 2 \mathrm{H}), 6.46-6.48(\mathrm{~m}, 1 \mathrm{H}), 6.73-6.84(\mathrm{~m}, 2 \mathrm{H}), 7.15-7.23(\mathrm{~m}, 2 \mathrm{H}), 7.25-7.39(\mathrm{~m}, 3 \mathrm{H}), 7.45-7.65(\mathrm{~m}$, 4H). ${ }^{13} \mathrm{C} \mathrm{NMR}\left(100 \mathrm{MHz}, \mathrm{CDCl}_{3}\right) \delta 12.9,46.0,53.0,119.4,120.5,127.1,128.2,128.7,128.9,129.0,129.2$, 139.8, 144.9, 152.0, 162.4, 176.9, 188.1. HRMS (ESI): calcd for $\mathrm{C}_{21} \mathrm{H}_{22} \mathrm{~N}_{3} \mathrm{OS}_{2}[\mathrm{M}+\mathrm{H}]^{+}, 396.1204$; found, 396.1208.

\section{General procedure for the preparation of compounds la-m, Ila,b and III:}

To a solution of thioimidodicarbonic diamide derivative $(1.00 \mathrm{mmol})$ in absolute ethanol $(10 \mathrm{~mL})$, bromine liquid $(2.00 \mathrm{mmol})$ was added dropwise at $0{ }^{\circ} \mathrm{C}$. The reaction mixture was warmed to room temperature and kept stirring for $6 \mathrm{hrs}$. The crude mixture was evaporated under vacuum and purified by Teledyne CombiFlash Rf200 Flash Chromatography System ( $C_{18}$ silica/reversed phase) using acetonitrilewater gradient.

\section{3-((Furan-2-ylmethyl)imino)- $\mathrm{N}, \mathrm{N}$-dimethyl-3H-1,2,4-dithiazol-5-amine hydrogen bromide (la)}

Purified using $5 \%$ acetonitrile in water followed by $8 \%$ acetonitrile in water, $\mathrm{Rf}=0.81$ in 7:3 water: acetonitrile. Yield 55\%. ${ }^{1} \mathrm{H}$ NMR $\left(400 \mathrm{MHz}, \mathrm{CD}_{3} \mathrm{OD}\right) \delta 3.37(\mathrm{~s}, 3 \mathrm{H}), 3.54(\mathrm{~s}, 3 \mathrm{H}), 4.45(\mathrm{~d}, \mathrm{~J}=5.2 \mathrm{~Hz}, 2 \mathrm{H}), 6.40-$ $6.49(\mathrm{~m}, 2 \mathrm{H}), 7.48-7.50(\mathrm{~m}, 1 \mathrm{H}) .{ }^{13} \mathrm{C} N M R\left(100 \mathrm{MHz}, \mathrm{CD}_{3} \mathrm{OD}\right) \delta$ 40.9, 42.1, 43.0, 108.9, 110.3, 143.1, 148.6, 177.7, 179.9. HRMS (ESI): calcd for $\mathrm{C}_{9} \mathrm{H}_{12} \mathrm{~N}_{3} \mathrm{OS}_{2}[\mathrm{M}+\mathrm{H}]^{+}, 242.0421$; found, 242.0425 .

\section{N,N-Dimethyl-3-((thiophen-2-ylmethyl)imino)-3H-1,2,4-dithiazol-5-amine hydrogen bromide (Ib)}

Purified using $5 \%$ acetonitrile in water followed by $10 \%$ acetonitrile in water, $\mathrm{Rf}=0.75$ in $7: 3$ water: acetonitrile. Yield 61\%. ${ }^{1} \mathrm{H}$ NMR $\left(400 \mathrm{MHz}, \mathrm{DMSO}-d_{6}\right) \delta 3.23(\mathrm{~s}, 3 \mathrm{H}), 3.27(\mathrm{~s}, 3 \mathrm{H}), 4.96(\mathrm{~d}, J=5.5 \mathrm{~Hz}, 2 \mathrm{H})$, $6.96(\mathrm{ddd}, J=4.9,3.5,1.2 \mathrm{~Hz}, 1 \mathrm{H}), 7.09$ (dd, $J=3.4,1.5 \mathrm{~Hz}, 1 \mathrm{H}), 7.41(\mathrm{dt}, J=5.2,1.3 \mathrm{~Hz}, 1 \mathrm{H}) .{ }^{13} \mathrm{C} \mathrm{NMR}(100$ $\mathrm{MHz}$, DMSO- $\left.d_{6}\right) \delta 42.1,43.1,43.5,126.2,127.0,127.1,140.1,177.3,179.7$. HRMS (ESI): calcd for $\mathrm{C}_{9} \mathrm{H}_{12} \mathrm{~N}_{3} \mathrm{~S}_{3}$ $[\mathrm{M}+\mathrm{H}]^{+}, 258.0193$; found, 258.0191 .

\section{3-(((1H-Pyrrol-2-yl)methyl)imino)- $\mathrm{N}, \mathrm{N}$-dimethyl-3H-1,2,4-dithiazol-5-amine hydrogen bromide (IC)} Purified using $5 \%$ acetonitrile in water followed by $15 \%$ acetonitrile in water, $\mathrm{Rf}=0.82$ in 7:3 water: acetonitrile. Yield 59\%. ${ }^{1} \mathrm{H}$ NMR $\left(400 \mathrm{MHz}, \mathrm{DMSO}-d_{6}\right) \delta 3.21(\mathrm{~s}, 3 \mathrm{H}), 3.24(\mathrm{~s}, 3 \mathrm{H}), 4.65(\mathrm{~d}, J=4.8 \mathrm{~Hz}, 2 \mathrm{H})$, $5.95(\mathrm{t}, J=2.8 \mathrm{~Hz}, 1 \mathrm{H}), 5.98-6.09(\mathrm{~m}, 1 \mathrm{H}), 6.61-6.72(\mathrm{~m}, 1 \mathrm{H}), 9.72(\mathrm{~s}, 1 \mathrm{H}) .{ }^{13} \mathrm{C} \mathrm{NMR}\left(100 \mathrm{MHz}, \mathrm{DMSO}-d_{6}\right) \delta$ 43.1, 45.7, 46.4, 107.3, 107.9, 118.1, 126.7, 177.0, 179.0. HRMS (ESI): calcd for $\mathrm{C}_{9} \mathrm{H}_{13} \mathrm{~N}_{4} \mathrm{~S}_{2}[\mathrm{M}+\mathrm{H}]^{+}$, 241.0581; found, 241.0576 .

\section{$\mathrm{N}, \mathrm{N}$-Dimethyl-3-(((tetrahydrofuran-2-yl)methyl)imino)-3H-1,2,4-dithiazol-5-amine hydrogen bromide (Id) \\ Purified using $2.5 \%$ acetonitrile in water followed by $5 \%$ acetonitrile in water, $\mathrm{Rf}=0.49$ in $7: 3$ water: acetonitrile. Yield 51\%. ${ }^{1} \mathrm{H}$ NMR $\left(400 \mathrm{MHz}\right.$, DMSO- $\left.d_{6}\right) \delta 1.24-1.65(\mathrm{~m}, 1 \mathrm{H}), 1.67-2.13(\mathrm{~m}, 3 \mathrm{H}), 3.22(\mathrm{~s}, 3 \mathrm{H})$, $3.26(\mathrm{~s}, 3 \mathrm{H}), 3.40-3.85(\mathrm{~m}, 4 \mathrm{H}), 3.89-4.09(\mathrm{~m}, 1 \mathrm{H}) .{ }^{13} \mathrm{C}$ NMR $\left(100 \mathrm{MHz}\right.$, DMSO- $\left.d_{6}\right) \delta 25.8,28.8,41.9,43.6$, 49.3, 67.9, 76.4, 176.8, 179.8. HRMS (ESI): calcd for $\mathrm{C}_{9} \mathrm{H}_{16} \mathrm{~N}_{3} \mathrm{OS}_{2}[\mathrm{M}+\mathrm{H}]^{+}, 246.0734$; found, 246.0735 .}


$\mathrm{N}, \mathrm{N}$-Dimethyl-3-(((5-phenylfuran-2-yl)methyl)imino)-3H-1,2,4-dithiazol-5-amine hydrogen bromide (le)

Purified using $2.5 \%$ acetonitrile in water followed by $5 \%$ acetonitrile in water, $\mathrm{Rf}=0.59$ in 7:3 water: acetonitrile. Yield 48\%. ${ }^{1} \mathrm{H}$ NMR $\left(400 \mathrm{MHz}\right.$, DMSO- $\left.d_{6}\right) \delta 3.17(\mathrm{~s}, 3 \mathrm{H}), 3.29(\mathrm{~s}, 3 \mathrm{H}), 4.52(\mathrm{~s}, 2 \mathrm{H}), 6.50(\mathrm{dd}, J=$ 3.4, $1.3 \mathrm{~Hz}, 1 \mathrm{H}), 6.86(\mathrm{dd}, J=3.4,1.3 \mathrm{~Hz}, 1 \mathrm{H}), 7.22-7.38(\mathrm{~m}, 3 \mathrm{H}), 7.56-7.67(\mathrm{~m}, 2 \mathrm{H}) .{ }^{13} \mathrm{C}$ NMR $(100 \mathrm{MHz}$, DMSO- $\left.d_{6}\right) \delta 43.0,44.1,44.9,107.3,111.1,123.6,127.9,129.3,130.5,150.5,153.0,168.0,176.7$. HRMS (ESI): calcd for $\mathrm{C}_{15} \mathrm{H}_{16} \mathrm{~N}_{3} \mathrm{OS}_{2}[\mathrm{M}+\mathrm{H}]^{+}, 318.0734$; found, 318.0737.

3-(((5-(4-Fluorophenyl)furan-2-yl)methyl)imino)- $\mathrm{N}, \mathrm{N}$-dimethyl-3H-1,2,4-dithiazol-5-amine hydrogen bromide (If)

Purified using $2.5 \%$ acetonitrile in water followed by $5 \%$ acetonitrile in water, $\mathrm{Rf}=0.62$ in $7: 3$ water: acetonitrile. Yield 58\%. ${ }^{1} \mathrm{H}$ NMR $\left(400 \mathrm{MHz}\right.$, DMSO- $\left.d_{6}\right) \delta 3.19(\mathrm{~s}, 3 \mathrm{H}), 3.29(\mathrm{~s}, 3 \mathrm{H}), 4.51(\mathrm{~s}, 2 \mathrm{H}), 6.49(\mathrm{dd}, J=$ $3.4,1.8 \mathrm{~Hz}, 1 \mathrm{H}), 6.83(\mathrm{t}, J=2.6 \mathrm{~Hz}, 1 \mathrm{H}), 7.15-7.26(\mathrm{~m}, 2 \mathrm{H}), 7.59-7.71(\mathrm{~m}, 2 \mathrm{H}) .{ }^{13} \mathrm{C}$ NMR $(100 \mathrm{MHz}$, DMSO$\left.d_{6}\right) \delta 43.5,44.4,45.7,107.1,111.1,116.4,125.7,127.2,150.5,152.2,160.6,168.0$, 176.7. HRMS (ESI): calcd for $\mathrm{C}_{15} \mathrm{H}_{15} \mathrm{FN}_{3} \mathrm{OS}_{2}[\mathrm{M}+\mathrm{H}]^{+}$, 336.0640; found, 336.0637 .

3-((4-Chlorophenyl)imino)- $\mathrm{N}, \mathrm{N}$-dimethyl-3H-1,2,4-dithiazol-5-amine hydrogen bromide (Ig)

Purified using $2.5 \%$ acetonitrile in water followed by $5 \%$ acetonitrile in water, $\mathrm{Rf}=0.55$ in $7: 3$ water: acetonitrile. Yield 71\%. ${ }^{1} \mathrm{H}$ NMR $\left(400 \mathrm{MHz}, \mathrm{DMSO}-d_{6}\right) \delta 3.25(\mathrm{~s}, 3 \mathrm{H}), 3.53(\mathrm{~s}, 3 \mathrm{H}), 6.95(\mathrm{~d}, J=7.9 \mathrm{~Hz}, 2 \mathrm{H})$, $7.51(\mathrm{~d}, J=7.9 \mathrm{~Hz}, 2 \mathrm{H}) .{ }^{13} \mathrm{C} \mathrm{NMR}\left(100 \mathrm{MHz}\right.$, DMSO- $\left.d_{6}\right) \delta 41.8,42.6,123.5,128.8,130.0,144.2,158.9,174.0$. HRMS (ESI): calcd for $\mathrm{C}_{10} \mathrm{H}_{11} \mathrm{ClN}_{3} \mathrm{~S}_{2}[\mathrm{M}+\mathrm{H}]^{+}, 272.0082$; found, 272.0083.

3-((4-Methoxyphenyl)imino)- $\mathrm{N}, \mathrm{N}$-dimethyl-3H-1,2,4-dithiazol-5-amine hydrogen bromide (Ih)

Purified using $10 \%$ acetonitrile in water followed by $15 \%$ acetonitrile in water, $\mathrm{Rf}=0.73$ in $7: 3$ water: acetonitrile. Yield 66\%. ${ }^{1} \mathrm{H}$ NMR $\left(400 \mathrm{MHz}\right.$, DMSO- $\left.d_{6}\right) \delta 3.25(\mathrm{~s}, 3 \mathrm{H}), 3.28(\mathrm{~s}, 3 \mathrm{H}), 3.68(\mathrm{~s}, 3 \mathrm{H}), 6.96(\mathrm{~d}, J=$ $8.1 \mathrm{~Hz}, 2 \mathrm{H}), 7.49(\mathrm{~d}, J=8.1 \mathrm{~Hz}, 2 \mathrm{H}) .{ }^{13} \mathrm{C}$ NMR $\left(100 \mathrm{MHz}\right.$, DMSO-d $d_{6} \delta 42.1,43.3,55.7,114.2,115.2,122.4$, 144.3, 166.9, 174.6. HRMS (ESI): calcd for $\mathrm{C}_{11} \mathrm{H}_{14} \mathrm{~N}_{3} \mathrm{OS}_{2}[\mathrm{M}+\mathrm{H}]^{+}, 268.0578$; found, 268.0573 .

\section{3-(Benzylimino)- $\mathbf{N}, \mathbf{N}$-dimethyl-3H-1,2,4-dithiazol-5-amine hydrogen bromide (li)}

Purified using $2.5 \%$ acetonitrile in water followed by $5 \%$ acetonitrile in water, $\mathrm{Rf}=0.44$ in $7: 3$ water: acetonitrile. Yield $62 \%$. ${ }^{1} \mathrm{H}$ NMR $\left(400 \mathrm{MHz}\right.$, DMSO- $\left.d_{6}\right) \delta 3.16(\mathrm{~s}, 3 \mathrm{H}), 3.30(\mathrm{~s}, 3 \mathrm{H}), 4.72(\mathrm{~s}, 2 \mathrm{H}), 7.15-7.42(\mathrm{~m}$, $5 \mathrm{H}) .{ }^{13} \mathrm{C}$ NMR $\left(100 \mathrm{MHz}\right.$, DMSO-d $\left.d_{6}\right) \delta 45.0,45.7,57.0,124.4,125.2,130.2,136.7,165.4,172.2$. HRMS (ESI): calcd for $\mathrm{C}_{11} \mathrm{H}_{14} \mathrm{~N}_{3} \mathrm{~S}_{2}[\mathrm{M}+\mathrm{H}]^{+}, 252.0629$; found, 252.0633 .

3-((4-Chlorobenzyl)imino)- $\mathrm{N}, \mathrm{N}$-dimethyl-3H-1,2,4-dithiazol-5-amine hydrogen bromide (lj) Purified using $2.5 \%$ acetonitrile in water followed by $5 \%$ acetonitrile in water, $\mathrm{Rf}=0.41$ in $7: 3$ water: acetonitrile. Yield 78\%. ${ }^{1} \mathrm{H}$ NMR $\left(400 \mathrm{MHz}\right.$, DMSO- $\left.d_{6}\right) \delta 3.29(\mathrm{~s}, 3 \mathrm{H}), 3.32(\mathrm{~s}, 3 \mathrm{H}), 4.71(\mathrm{~s}, 2 \mathrm{H}) 7.23(\mathrm{~d}, J=7.2$ $\mathrm{Hz}, 2 \mathrm{H}), 7.96(\mathrm{~d}, J=7.2 \mathrm{~Hz}, 2 \mathrm{H}) .{ }^{13} \mathrm{C}$ NMR $\left(100 \mathrm{MHz}\right.$, DMSO- $\left.d_{6}\right) \delta 45.8,46.9,53.5,128.9,129.8,132.3,136.5$, 159.8, 178.7. HRMS (ESI): calcd for $\mathrm{C}_{11} \mathrm{H}_{13} \mathrm{ClN}_{3} \mathrm{~S}_{2}[\mathrm{M}+\mathrm{H}]^{+}$, 286.0239; found, 286.0238 .

\section{3-((4-Fluorobenzyl)imino)- $\mathbf{N , N}$-dimethyl-3H-1,2,4-dithiazol-5-amine hydrogen bromide (Ik)}

Purified using $2.5 \%$ acetonitrile in water followed by $5 \%$ acetonitrile in water, $\mathrm{Rf}=0.37$ in $7: 3$ water: acetonitrile. Yield 81\%. ${ }^{1} \mathrm{H} N M R\left(400 \mathrm{MHz}\right.$, DMSO- $\left.d_{6}\right) \delta 3.25(\mathrm{~s}, 3 \mathrm{H}), 3.31(\mathrm{~s}, 3 \mathrm{H}), 4.71(\mathrm{~s}, 2 \mathrm{H}), 7.09-7.21(\mathrm{~m}$, $2 \mathrm{H}), 7.33-7.46(\mathrm{~m}, 2 \mathrm{H}) .{ }^{13} \mathrm{C} \mathrm{NMR}\left(100 \mathrm{MHz}\right.$, DMSO- $\left.d_{6}\right) \delta 42.1,43.7,52.2,116.5,120.2,130.2,133.3,171.5$, 177.2. HRMS (ESI): calcd for $\mathrm{C}_{11} \mathrm{H}_{13} \mathrm{FN}_{3} \mathrm{~S}_{2}[\mathrm{M}+\mathrm{H}]^{+}, 270.0534$; found, 270.0537 . 
3-((4-Methoxybenzyl)imino)-N,N-dimethyl-3H-1,2,4-dithiazol-5-amine hydrogen bromide (II)

Purified using $5 \%$ acetonitrile in water followed by $7.5 \%$ acetonitrile in water, $\mathrm{Rf}=0.54$ in 7:3 water: acetonitrile. Yield 85\%. ${ }^{1} \mathrm{H}$ NMR $\left(400 \mathrm{MHz}\right.$, DMSO- $\left.d_{6}\right) \delta 3.22(\mathrm{~s}, 3 \mathrm{H}), 3.25(\mathrm{~s}, 3 \mathrm{H}), 3.72(\mathrm{~s}, 3 \mathrm{H}), 4.71(\mathrm{~d}, J=$ $5.3 \mathrm{~Hz}, 2 \mathrm{H}), 6.91(\mathrm{~d}, J=8.1 \mathrm{~Hz}, 2 \mathrm{H}), 7.28(\mathrm{~d}, J=8.1 \mathrm{~Hz}, 2 \mathrm{H}) .{ }^{13} \mathrm{C}$ NMR $\left(100 \mathrm{MHz}\right.$, DMSO- $\left.d_{6}\right) \delta 44.5,45.4,48.3$, $53.5,114.3,129.5,129.6,159.0,177.1,179.7$. HRMS (ESI): calcd for $\mathrm{C}_{12} \mathrm{H}_{16} \mathrm{~N}_{3} \mathrm{OS} \mathrm{S}_{2}[\mathrm{M}+\mathrm{H}]^{+}, 282.0734$; found, 282.0735 .

3-(([1,1'-Biphenyl]-4-ylmethyl)imino)- $\mathrm{N}, \mathrm{N}$-dimethyl-3H-1,2,4-dithiazol-5-amine hydrogen bromide (Im) Purified using $2.5 \%$ acetonitrile in water followed by $5 \%$ acetonitrile in water, $\mathrm{Rf}=0.47$ in $7: 3$ water: acetonitrile. Yield 48\%. ${ }^{1} \mathrm{H}$ NMR $\left(400 \mathrm{MHz}\right.$, DMSO- $\left.d_{6}\right) \delta 3.23(\mathrm{~s}, 3 \mathrm{H}), 3.26(\mathrm{~s}, 3 \mathrm{H}), 4.88(\mathrm{~s}, 2 \mathrm{H}), 7.28-7.49(\mathrm{~m}$, $4 \mathrm{H}), 7.56-7.72(\mathrm{~m}, 5 \mathrm{H}) .{ }^{13} \mathrm{C}$ NMR $\left(100 \mathrm{MHz}\right.$, DMSO- $\left.d_{6}\right) \delta 42.7,43.8,48.4,127.0,127.2,127.8,128.6,129.3$, 137.1, 139.5, 140.2, 177.2, 180.2. HRMS (ESI): calcd for $\mathrm{C}_{17} \mathrm{H}_{18} \mathrm{~N}_{3} \mathrm{~S}_{2}[\mathrm{M}+\mathrm{H}]^{+}, 328.0942$; found, 328.0939.

\section{$\mathrm{N}$-(4-Chlorophenyl)-3-((furan-2-ylmethyl)imino)- $\mathrm{N}$-methyl-3H-1,2,4-dithiazol-5-amine hydrogen} bromide (Ila)

Purified using $2.5 \%$ acetonitrile in water followed by $5 \%$ acetonitrile in water, $\mathrm{Rf}=0.49$ in $7: 3$ water: acetonitrile. Yield 76\%. ${ }^{1} \mathrm{H}$ NMR $\left(400 \mathrm{MHz}\right.$, DMSO- $\left.d_{6}\right) \delta 3.16(\mathrm{~s}, 3 \mathrm{H}), 4.17(\mathrm{~d}, J=5.7 \mathrm{~Hz}, 2 \mathrm{H}), 6.10-6.14(\mathrm{~m}$, $1 \mathrm{H}), 6.34(\mathrm{dt}, J=3.3,1.6 \mathrm{~Hz}, 1 \mathrm{H}), 6.67(\mathrm{t}, J=5.8 \mathrm{~Hz}, 1 \mathrm{H}), 7.27(\mathrm{~d}, J=8.6 \mathrm{~Hz}, 2 \mathrm{H}), 7.72(\mathrm{~d}, J=8.6 \mathrm{~Hz}, 2 \mathrm{H}) .{ }^{13} \mathrm{C}$ NMR $\left(100 \mathrm{MHz}\right.$, DMSO-d $\left.d_{6}\right) \delta 42.8,49.3,106.5,110.8,128.5,129.4,129.8,129.9,143.4,154.1,156.8$, 182.6. HRMS (ESI): calcd for $\mathrm{C}_{14} \mathrm{H}_{13} \mathrm{CIN}_{3} \mathrm{OS}_{2}[\mathrm{M}+\mathrm{H}]^{+}, 338.0188$; found, 338.0191 .

\section{$\mathrm{N}$-Ethyl-3-((furan-2-ylmethyl)imino)- $\mathrm{N}$-phenyl-3H-1,2,4-dithiazol-5-amine hydrogen bromide (IIb)}

Purified using $5 \%$ acetonitrile in water followed by $7.5 \%$ acetonitrile in water, $\mathrm{Rf}=0.36$ in $7: 3$ water: acetonitrile. Yield 63\%. ${ }^{1} \mathrm{H}$ NMR $\left(400 \mathrm{MHz}\right.$, DMSO- $\left.d_{6}\right) \delta 1.11(\mathrm{t}, J=7.3 \mathrm{~Hz}, 3 \mathrm{H}), 3.51(\mathrm{q}, J=7.3 \mathrm{~Hz}, 2 \mathrm{H}), 4.17$ $(\mathrm{d}, J=5.5 \mathrm{~Hz}, 2 \mathrm{H}), 6.79-6.91(\mathrm{~m}, 2 \mathrm{H}), 7.17-7.47(\mathrm{~m}, 6 \mathrm{H}) .{ }^{13} \mathrm{C}$ NMR $\left(100 \mathrm{MHz}\right.$, DMSO- $\left.d_{6}\right) \delta 13.1,46.0,52.3$, $127.4,128.9,129.1,129.6,129.8,139.9,144.6,154.6,161.3,187.7$. HRMS (ESI): calcd for $\mathrm{C}_{15} \mathrm{H}_{16} \mathrm{~N}_{3} \mathrm{OS}_{2}$ $[\mathrm{M}+\mathrm{H}]^{+}, 318.0734$; found, 318.0737.

\section{N-Ethyl-N-phenyl-3-(((5-phenylfuran-2-yl)methyl)imino)-3H-1,2,4-dithiazol-5-amine hydrogen bromide}

(III)

Purified using $3 \%$ acetonitrile in water followed by $7 \%$ acetonitrile in water, $\mathrm{Rf}=0.45$ in $7: 3$ water: acetonitrile. Yield 73\%. ${ }^{1} \mathrm{H}$ NMR $\left(400 \mathrm{MHz}\right.$, DMSO- $\left.d_{6}\right) \delta 1.11(\mathrm{t}, J=7.2 \mathrm{~Hz}, 3 \mathrm{H}), 3.48(\mathrm{q}, J=7.2 \mathrm{~Hz}, 2 \mathrm{H}), 4.19$ $(\mathrm{d}, J=5.3 \mathrm{~Hz}, 2 \mathrm{H}), 6.17-6.21(\mathrm{~m}, 1 \mathrm{H}), 6.72-6.79(\mathrm{~m}, 2 \mathrm{H}), 6.98-7.21(\mathrm{~m}, 4 \mathrm{H}), 7.24-7.58(\mathrm{~m}, 5 \mathrm{H}) .{ }^{13} \mathrm{C} \mathrm{NMR}(100$ $\left.\mathrm{MHz}, \mathrm{DMSO}-d_{6}\right) \delta 13.1,46.0,52.9,125.8,127.4,128.0,128.5,128.9,129.1,129.6,129.8,140.0,144.6$, 151.7, 161.3, 166.9, 187.7. HRMS (ESI): calcd for $\mathrm{C}_{21} \mathrm{H}_{20} \mathrm{~N}_{3} \mathrm{OS}{ }_{2}[\mathrm{M}+\mathrm{H}]^{+}$, 394.1047; found, 394.1049.

\section{Validation of the VISTA TR-FRET assay for high-throughput screening (HTS):}

$Z$ factor was calculated based on five independent runs. Each run consisted of six 384-well plates. the following equation was used to determine $Z^{\prime}$ factor: ${ }^{1}$

$Z^{\prime}$ factor $=1-\frac{(S . D .+v e)+(S . D .-v e)}{(\text { mean }+v e)-(\text { mean }-v e)}$

Where, S.D. +ve : Standard deviation of the positive control ( $2 \mathrm{nM}$ Tb cryptate-VISTA as donor $+20 \mathrm{nM}$ CF647-VISTA antibody as acceptor).

S.D. - ve: Standard deviation of the negative control (only $2 \mathrm{nM}$ of Tb cryptate-VISTA as donor). 
Mean +ve : mean of the positive controls

Mean -ve : mean of the negative controls

\section{Saturation-transfer difference (STD) NMR spectroscopy:}

Samples for STD NMR experiments were prepared using la $(10 \mathrm{mM})$ prepared in phosphate buffer solution, $\mathrm{pH}$ 7.0. Samples had final concentrations of $1 \% \mathrm{DMSO}-\mathrm{d}_{6}$ and $\mathrm{D}_{2} \mathrm{O}(10 \% \mathrm{v} / \mathrm{v})$. Each sample was made up to a final volume of $500 \mu \mathrm{L}$ with PBS buffer $(20 \mathrm{mM}, \mathrm{pH} 7.0)$ and $\mathrm{NaCl}(20 \mathrm{mM})$. The experiments were performed at a final concentration of la (1 mM) on Agilent $400 \mathrm{MHz}$ WB NMR spectrometer at 298 $\mathrm{K}$ and $\mathrm{pH} 7.0$ in the presence and absence of VISTA extracellular domain $(20 \mu \mathrm{m})$. The protein was saturated on-resonance at $-0.5 \mathrm{ppm}$ and off-resonance at $33 \mathrm{ppm}$ with a cascade of 40 selective Gaussian shaped pulses, of 50 ms duration with a $100 \mu \mathrm{sec}$ delay between each pulse. The total duration of the saturation time was set to $2 \mathrm{~s}$. A total of 256 scans per STD NMR experiment were acquired and a WATERGATE sequence was used to suppress the residual $\mathrm{H}_{2} \mathrm{O}$ signal.

\section{Time-resolved fluorescence resonance energy transfer (TR-FRET) assay:}

Human recombinant VISTA ECD (10XHis Tag), catalogue number: 13482-H08H, was obtained from Sino biological and labeled with MAb Anti-6HIS Tb cryptate from Cisbio. VISTA antibody (MAB71263-SP) was obtained from Novus Biologicals and labeled using Mix-n-Stain ${ }^{\mathrm{TM}} \mathrm{CF}^{\mathrm{TM}} 647$ Antibody Labeling Kit (Sigma Aldrich). The assay plates were medium binding Greiner white 384-well plates. The assay buffer was phosphate buffer solution (PBS, pH 7.0). TR-FRET measurements were done using excitation ( $\lambda_{\mathrm{ex}}=340$ $\mathrm{nm})$. The emission was collected with a lag time of $40 \mu$ s and integration time of $150 \mu \mathrm{s}$ at $620 \mathrm{~nm}$ and $665 \mathrm{~nm}$ corresponding to donor and acceptor emission, respectively. VISTA Tb cryptate $(50 \mu \mathrm{M})$ and CF647-labeled VISTA antibody (3.2 $\mu \mathrm{M})$ stock solutions were prepared in PBS (pH7.0).

The assay mixture consisting of VISTA Tb cryptate and CF647-labeled VISTA antibody was mixed prior to the assay to a final concentration of: His-tagged VISTA (20 nM), MAb Anti-6HIS Tb cryptate Gold ( $2 \mathrm{nM}$ ), and CF647-labeled VISTA antibody (20 nM). Stock solutions of tested compounds in DMSO (40 nL) from the chemical libraries were applied to 384 -well plates. The assay mixture $(10 \mu \mathrm{L})$ was added to the plated compounds and incubated for $2 \mathrm{hrs}$ at room temperature. Measurements were performed as described above and TR-FRET signals were derived by dividing the emission intensity value at $665 \mathrm{~nm}$ by the emission value at $620 \mathrm{~nm}$. The $\mathrm{IC}_{50}$ values were calculated by plotting compound concentrations versus TR-FRET signals. The dose-response curves were analyzed by nonlinear regression using GraphPad Prism 8.0.2 (GraphPad Software, Inc., La Jolla, CA, USA). The dose-response screening was performed in triplicates in three independent runs. Error bars represent standard deviation.

\section{Competitive VISTA-VSIG-3 enzyme-linked Immunosorbent assay (ELISA):}

Human recombinant VISTA (ECD, Fc Tag), catalogue number: 13482-H02H, was obtained from Sino Biological. Biotinylated human VSIG3 protein ( $\mathrm{Fc}$, Avitag) was obtained from Acro Biosystems. VISTA ECD $(2 \mu \mathrm{g} / \mathrm{mL}$ ) in PBS (pH 7.0) was immobilized on 96-well clear polystyrene plates from R\&D systems (Part \# 991427) by addition of $50 \mu \mathrm{L}$ of stock solution for $12 \mathrm{hrs}$ at $4{ }^{\circ} \mathrm{C}$. The ELISA plates were washed three times with PBS, then blocked with 1\% bovine serum albumin (BSA) in PBS at room temperature for 2 hrs. The blocking buffer was removed, and plates were washed by PBS three times. The wells were then incubated for $2 \mathrm{hrs}$ at room temperature with $50 \mu \mathrm{L}$ solutions containing various concentrations of tested compounds (obtained by diluting from a $1 \mathrm{mg} / \mathrm{mL}$ stock solution of each molecule dissolved in PBS 
containing 1\% DMSO) and a fixed concentration of biotinylated human VSIG3 protein (2 $\mathrm{nM}$ ) in proteinfree blocking buffer. VISTA-VSIG-3 binding was detected by adding streptavidin-horseradish peroxidase (HRP) followed by substrate color reagents (R\&D Systems, Minneapolis, MN). The reactions were stopped after 15 min with $2 \mathrm{M}$ sulfuric acid, and absorbance at $450 \mathrm{~nm}$ was measured on microplate reader (BioTek Synergy4). Absorbance values of control wells with no coated protein were subtracted from sample wells and corrected values were plotted against compound concentrations and fit to a one-site specific binding curve on GraphPad Prism 8.0.2 (GraphPad Software, Inc., La Jolla, CA, USA). The assay was performed in triplicates in three independent runs. Error bars represent standard deviation.

\section{Surface plasmon resonance (SPR) screening:}

The kinetic analysis for the interaction of tested small molecules with VISTA was performed on a Biacore T200 (GE Healthcare Bio-sciences, Sweden) using Series S Sensor Chip NTA (GE Healthcare Bio-sciences, Sweden, catalog \# 28-9949-51). Human recombinant VISTA Protein (His Tag), catalogue number: 13482$\mathrm{HO8H}$, obtained from Sino Biological was captured in PBS (pH 7.0) on sensor chip using NTA reagent kit (GE Healthcare Bio-sciences, Sweden, catalog \# 28-9950-43).

Stock solution of tested compounds were prepared in DMSO at $1 \mathrm{mM}$ final concentration. Samples were then serially diluted while maintaining final DMSO concentration to $5 \%$ in all tested samples. Tested compounds in PBS ( $\mathrm{pH} 7.0$ ) containing 5\% DMSO and 0.05\% Tween20 were allowed to flow through both ligand-captured flow cells and reference flow cells at the same rate $(30 \mu \mathrm{l} / \mathrm{min})$ and contact time $(120$ sec). Solvent correction was included to avoid the impact of DMSO on surface plasmon effect during binding analysis. Extra wash of the flow system using 50\% DMSO in PBS buffer was then performed following each run. Kinetic analysis was performed at $25^{\circ} \mathrm{C}$. Equilibrium dissociation rate constant $\left(K_{D}\right)$ values were calculated using Biacore T200 Evaluation software following the 1:1 Langmuir binding model with global fit parameters for solvent-corrected sensograms. SPR screening for all tested compounds was performed in three independent runs.

\section{Cell culture:}

SKOV3 ovarian cancer, RL952 endometrial cancer, HEC1A endometrial cancer, AN3CA endometrial cancer, and Jurkat T cell lines were obtained from American Type Culture Collection (ATCC). COV504 ovarian cancer and A2780 ovarian cancer cell lines were obtained from European Collection of Authenticated Cell Cultures (ECACC). OVKATE ovarian cancer and Ishikawa endometrial cancer cell lines were obtained from Prof. Wendy Fantl lab, Stanford University. Cells were cultured in RPMI1640 medium with $10 \%$ Fetal Bovine Serum (FBS), 100 units $/ \mathrm{mL}$ penicillin and $100 \mu \mathrm{g} / \mathrm{mL}$ streptomycin. All cells were grown at $37^{\circ} \mathrm{C}$ in a humidified atmosphere containing $5 \% \mathrm{CO}_{2}$.

\section{Expression and purification of VISTA mutants:}

VISTA mutants were expressed and purified using previously reported method (with minor modifications) for expression and purification of VISTA mutants. ${ }^{2}$ Expi293 cells were acquired from ThermoFisher Scientific and grown in Expi293 Expression Medium according to the manufacturer's protocol. The extracellular domain of human VISTA (residues 1 to 161) provided by Integrated DNA Technologies (Coralville, IA) was cloned into a pcDNA3.4 vector (Thermo Fisher) with an $\mathrm{N}$-terminal signal peptide from CRYP $\alpha$ and a C-terminal Mpro protease site and His6-tag. Plasmids were transfected into Expi293 cells (Thermo Fisher) using manufacturer's protocol but with the addition of $20 \mu \mathrm{M}$ swainsonine (Cayman Chemical) at the time of transfection. Secreted protein in the supernatant was harvested, dialyzed into Ni-NTA binding buffer (50 mM Tris $\mathrm{pH} 8.0,300 \mathrm{mM} \mathrm{NaCl})$, and purified using Ni-NTA affinity 
chromatography (Qiagen). Binding of the mutants to the VISTA antibody (MAB71263-SP) was retained with no significant difference in binding from WT VISTA (Fig. S30).

\section{Flow cytometry analysis:}

For the analysis of the expression of human VISTA on the surface of selected ovarian and endometrial cancer cells, flow cytometry analysis was performed. The cells were seeded on 6-well plates and cultured till sub-confluency. The cells were detached from the plates with Cellstripper (Corning, Cat. No. 25-056$\mathrm{Cl}$ ), placed on ice, washed 2 times with Flow Cytometry Staining Buffer (eBioscience, Waltham, MA, USA) and stained with Human VISTA/B7-H5/PD-1H Alexa Fluor ${ }^{\circledR}$ 647-conjugated Antibody (R\&D systems, Cat. No. FAB71261R). Non-viable cells were stained with propidium iodide (PI) and gated out. The cells were analyzed with the BD Biosciences LSRII cytometer.

\section{Promega VISTA bioluminescent cell-based T-cell activation assay:}

The assay is based on coculturing NanoGlo ${ }^{\text {TM }}$ IL2-NLP/Jurkat VISTA cells and CHOK1 VISTA cells. VISTAVISTA interaction that results from co-culturing stimulates IL2 signaling which is detected by a luminescence signal. Compounds with VISTA binding affinity are identified by their ability to impede VISTA-VISTA interaction and consequently result in reduced IL2 signaling. The assay kit including

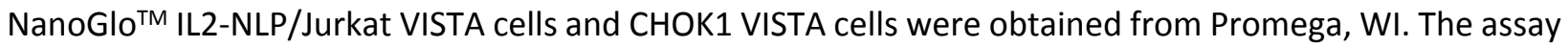
was then performed according to provider's protocol. Briefly, Jurkat cells $\left(5 \times 10^{4}\right.$ cells) and $3 \times 10^{4}$ cells of CHOK1 cells (CHOK1 parentral or CHOK1 VISTA cells) were co-cultured overnight in RPMI1640 medium with $10 \%$ Fetal Bovine Serum (FBS). Antihuman CD3 antibody $(1000 \mathrm{ng} / \mathrm{mL})$ was then added and the cocultures were incubated for $6 \mathrm{hrs}$ at $37^{\circ} \mathrm{C}$ in a humidified atmosphere containing $5 \% \mathrm{CO}_{2}$. Promega Nano$\mathrm{Glo}^{\mathrm{TM}}$ Reagent was then reconstituted and used at the end of the incubation time according to the manufacturer's instructions. Each data point from this assay represents the average of three independent measurements. Error bars represent standard deviation.

\section{PrestoBlue cell viability assay:}

Briefly, $3 \times 10^{4}$ Jurkat T cells were cultured alone or co-cultured with $1.5 \times 10^{5}$ of 8 cancer cell lines used in the assay in 24-well plates as previously reported. ${ }^{3}$ After incubation with compound III ( $\left.5 \mu \mathrm{M}\right)$ or VISTA antibody (MAB71263-SP) $(1 \mu \mathrm{M})$ for $24 \mathrm{~h}$, Jurkat T cells were harvested from the supernatant. Presto Blue ${ }^{\circledR}$ Viability Assay (Thermo Fisher Scientific Inc., Waltham, MA) was then performed. The assay was performed in triplicates in three independent runs. Error bars represent standard deviation.

\section{Assessment of cytokines production by ELISA:}

Human Pan-T Cell Isolation Kit (Miltenyi Biotec) was used to isolate human T cells from peripheral blood mononuclear cells (PBMCs) cultured in RPMI1640 medium supplemented with $10 \%$ FBS and $1 \%$ pencillin/streptomycin. Human IFN- $\gamma$, and TNF $\alpha$ ELISA kits (Qiagen, Valencia, CA, USA) were used to analyze cytokine production in co-incubation experiments with OVKATE and RL952 cells cultured in RPMI1640 medium with $10 \%$ FBS. The assay was performed in triplicates in three independent runs. Error bars represent standard deviation.

\section{Statistical analyses:}


Statistical significance was determined using a 2-tailed Student t test, with $P$ values of less than 0.05 being considered significant. For analysis across multiple samples, 1- or 2-way ANOVA was used, followed by multiple comparisons of means with Bonferroni adjustment.

\section{Molecular modeling:}

The crystal structure of human VISTA ECD (PDB ID: 6OIL) and human VISTA in complex with antibody Fab fragment (PDB ID: 6MVL) were obtained from protein data bank (PDB). Refinement of crude PDB structure of receptor was performed. Polar hydrogens were added, Kollman charges were assigned and atomic solvation parameters were added. The optimized receptors were then used for docking simulation.

The 2D structures of the compounds were built and then converted into 3D using vLife MDS 3.0 software. The 3D structures were energetically minimized up to the rms gradient of 0.01 using CHARM22 force field. Glide docking was performed using Maestro 12.0 (Schrodinger). 10 poses were generated for each docking run to a given site. GlideScore, an empirical scoring function that approximates ligand binding free energy, was used to evaluate the binding. ${ }^{4}$ All visualizations of ligand-protein interactions were done using Maestro 12.0 (Schrodinger). 


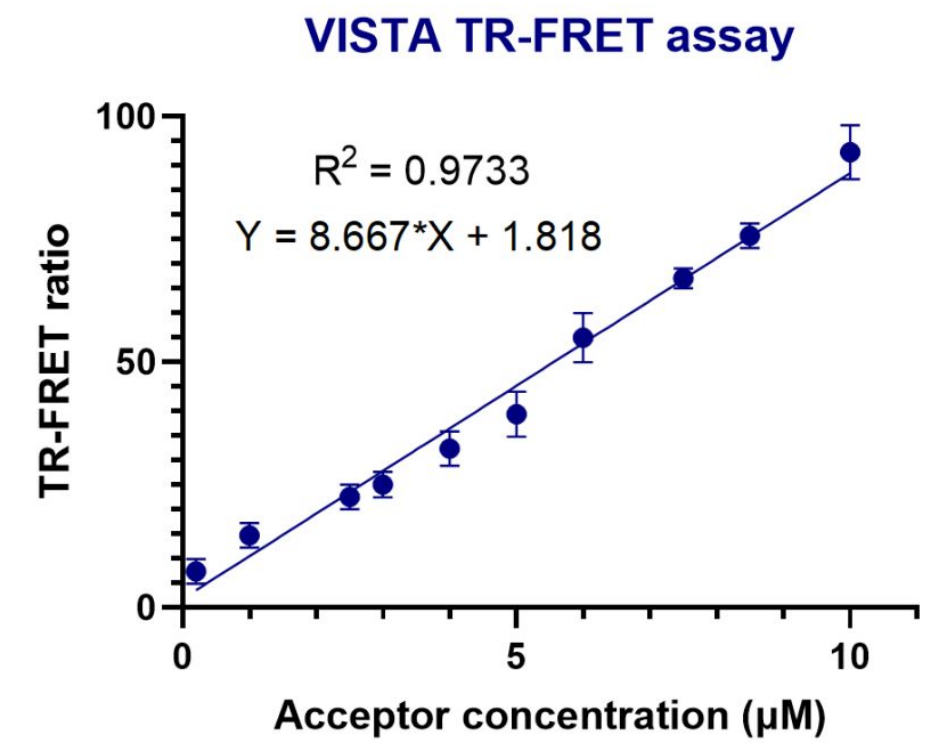

Figure S1. Linear correlation between TR-FRET ratio and various concentrations (0-10 $\mu \mathrm{M})$ of CF647 labeled VISTA antibody (acceptor). Straight line represents linear regression of the data. Error bars represent standard deviation $(n=3)$.

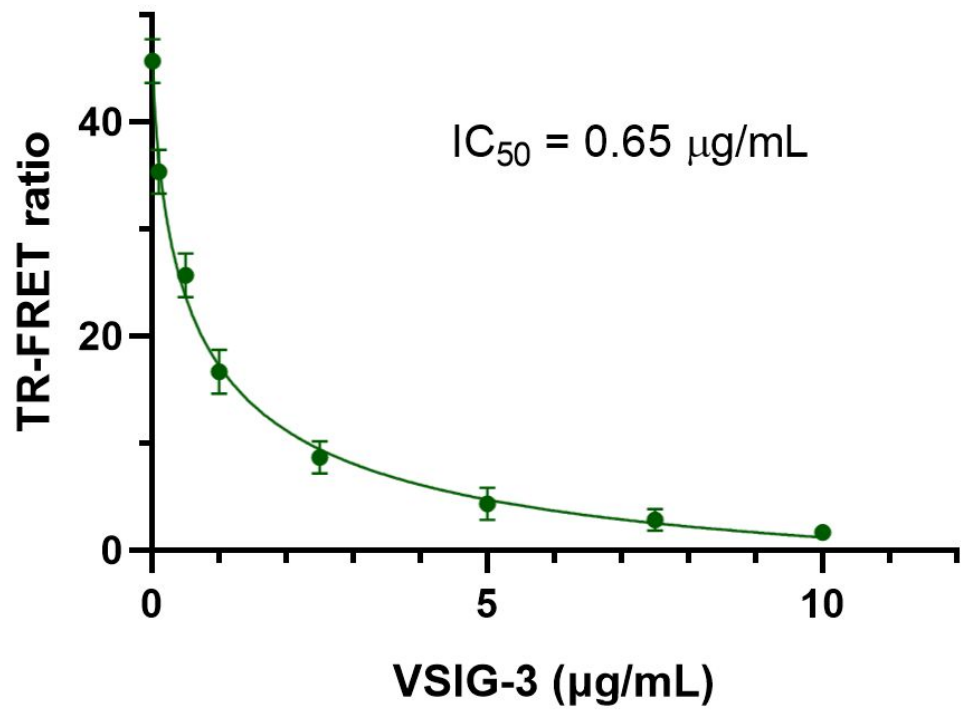

Figure S2. Effect of addition of various concentrations of VSIG-3 on the TR-FRET ratios in VISTA FRET assay. Error bars represent standard deviation $(n=3)$. 


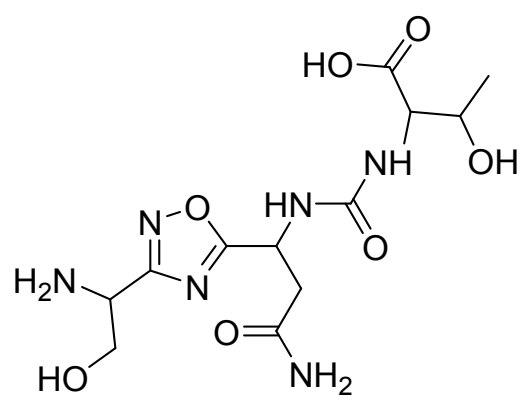

Figure S3. Chemical structure of CA-170.

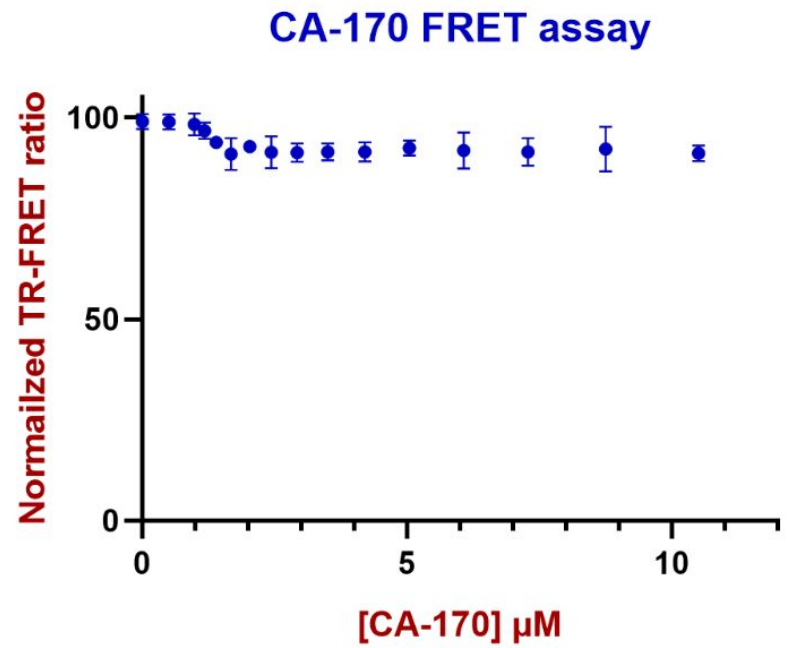

Figure S4. Dose-response curve for CA-170 in VISTA FRET assay. Error bars represent standard deviation $(n=3)$.

\section{CA-170 ELISA assay}

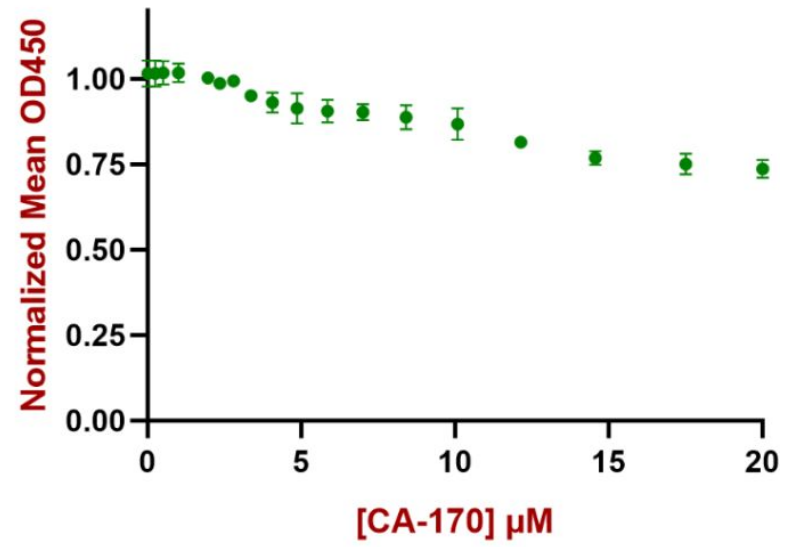

Figure S5. Dose-response curve for CA-170 in VISTA-VSIG-3 competitive ELISA. Error bars represent standard deviation $(n=3)$. 


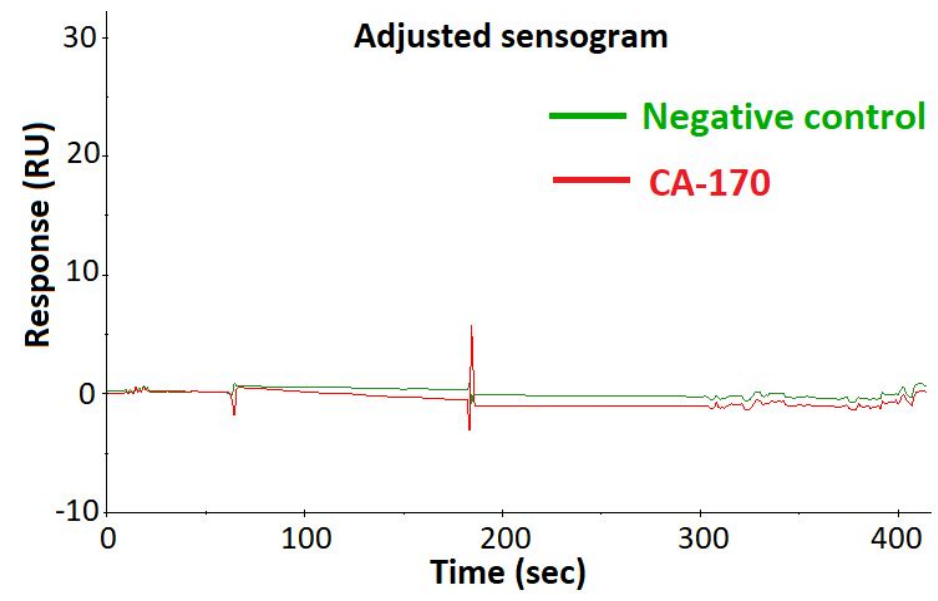

Figure S6. Sensogram for binding of CA-170 $(50 \mu \mathrm{M})$ to VISTA ECD immobilized on a chip in SPR screening. 


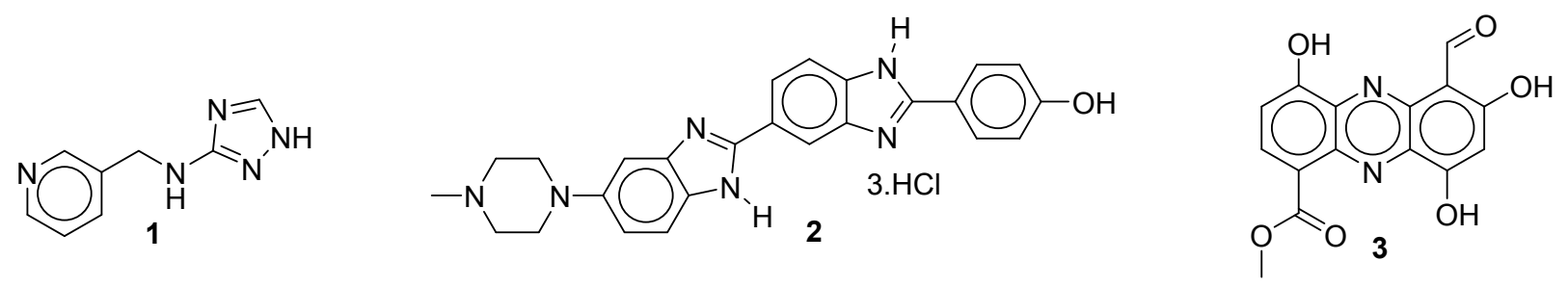

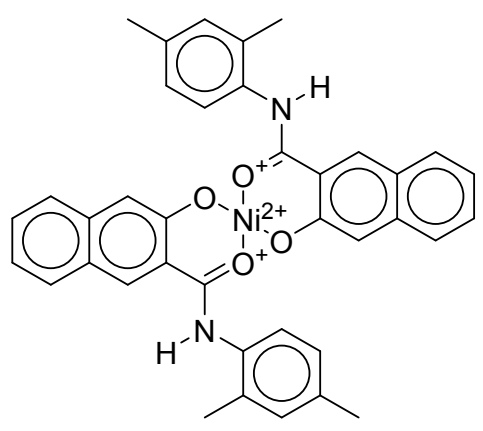

4<smiles>[3H]SSC(=NC1N=C(Br)SS1)N(C)C</smiles><smiles>C[N+]1(C)CCc2cc(O)c(O)cc2C1Cc1ccc(O)c(O)c1</smiles><smiles>O=[N+]([O-])c1cccc2c(N=Nc3ccc4ccccc4c3O)c(O)cc(S(=O)(=O)O)c12</smiles>

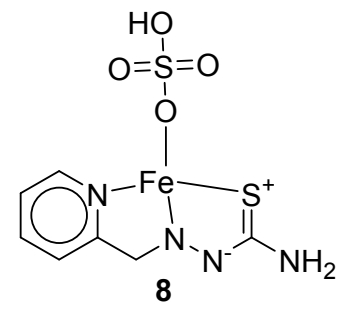<smiles>O=[N+]([O-])c1ccccc1S(=O)(=O)c1ccccc1[N+](=O)[O-]</smiles><smiles>Cc1cc(C)cc(C(=N)c2ccccc2Cc2cccc3ccccc23)c1</smiles>

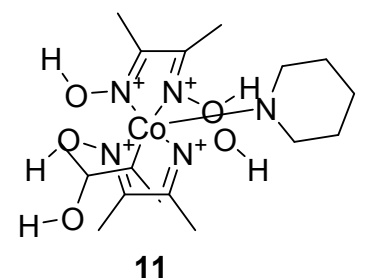

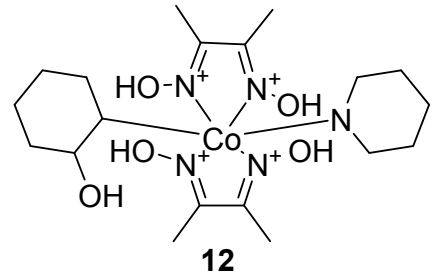<smiles>[Y4]OC(=O)C(C(=O)O)C(Br)c1ccc(OC)cc1</smiles> 

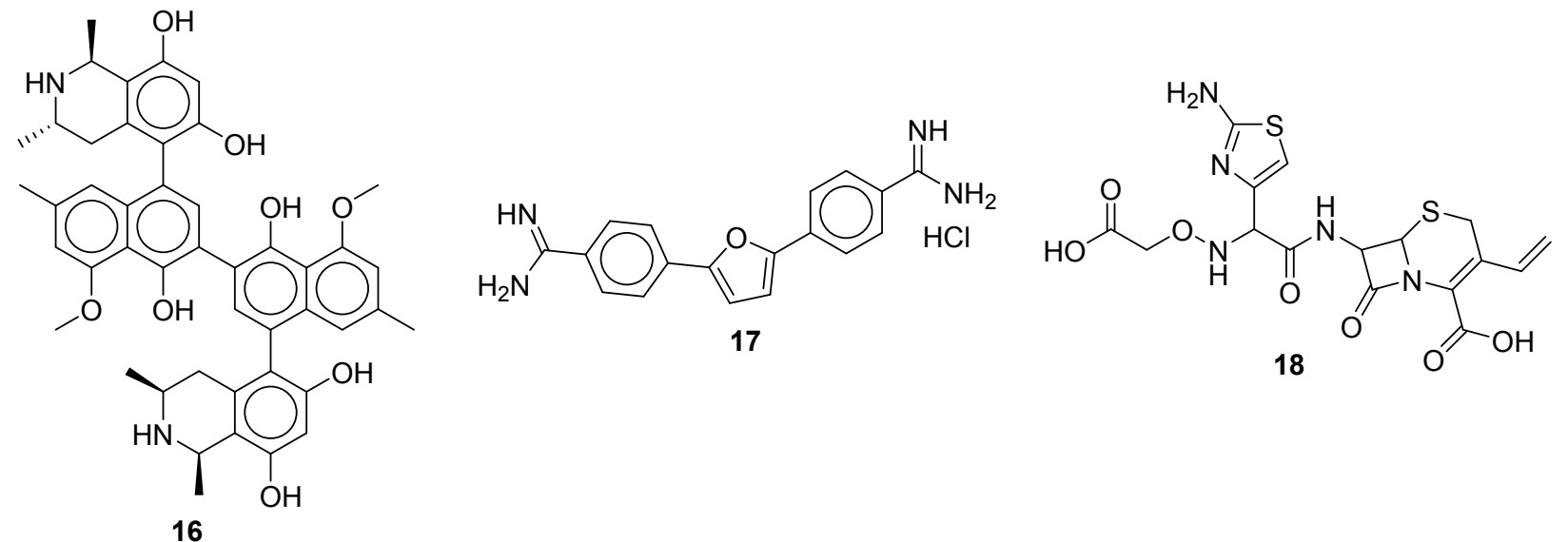

Figure S7. Chemical structures for potential hits identified in VISTA TR-FRET assay.

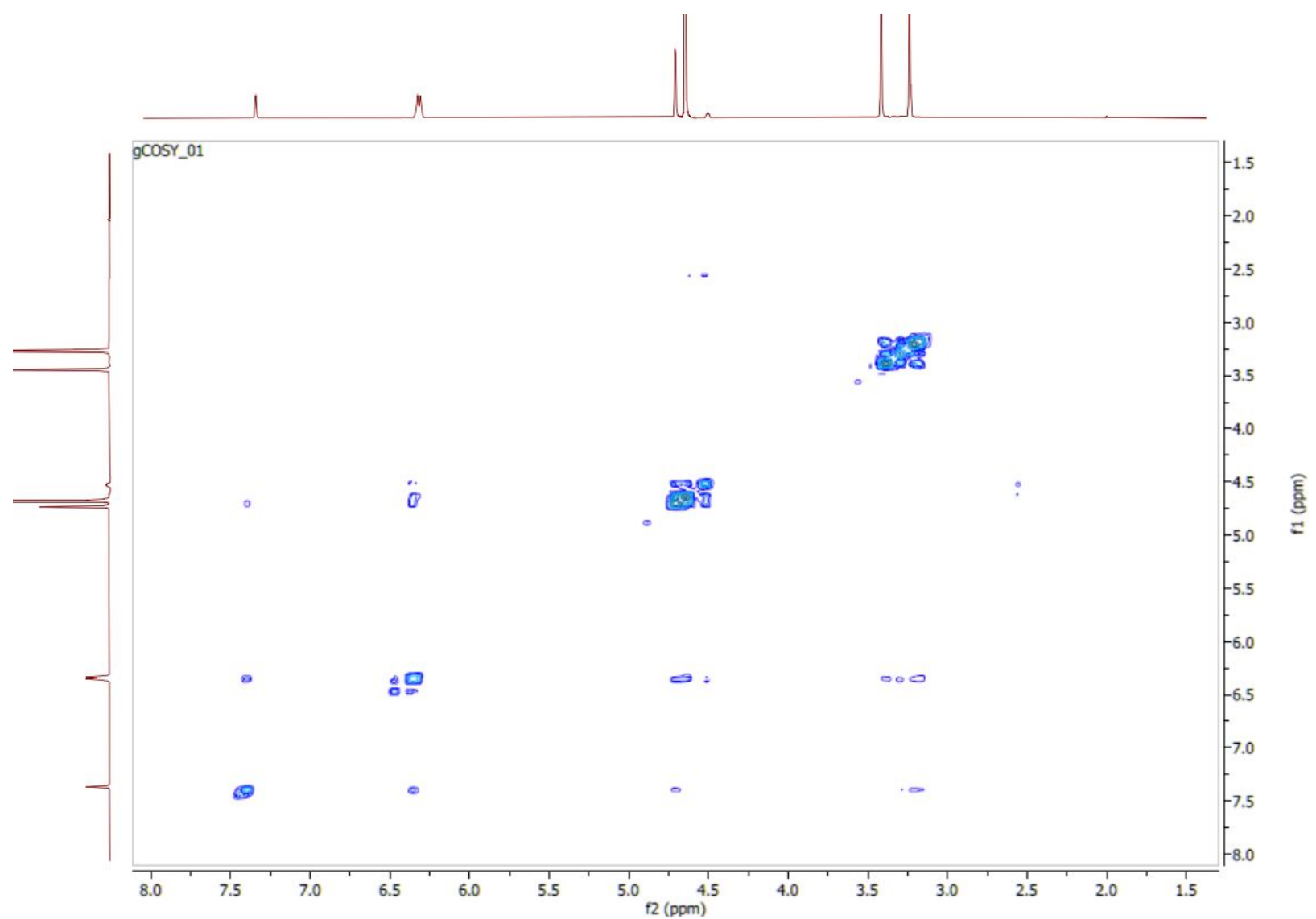

Figure S8. COSY NMR of compound la. 


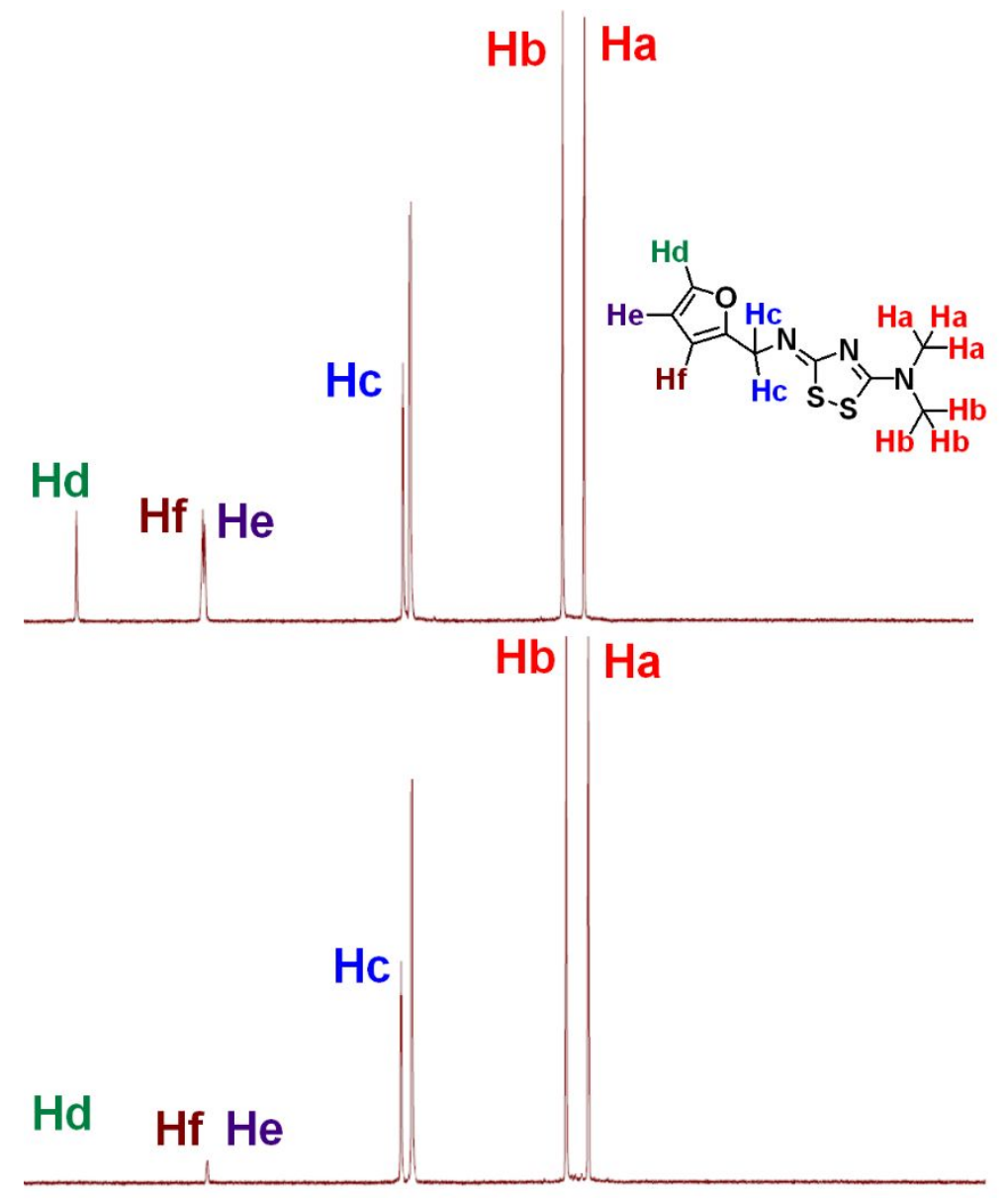

$\begin{array}{llllllllllllllllllllllllll}7.5 & 7.0 & 6.5 & 6.0 & 5.5 & 5.0 & 4.5 & 4.0 & 3.5 & 3.0 & 2.5 & 2.0 & 1.5 & 1.0 & 0.5 & 0.0\end{array}$ (ppm)

Figure S9. ${ }^{1} \mathrm{H}$ NMR STD experiment of compound la binding to VISTA. Reference ${ }^{1} \mathrm{H}$ NMR spectrum for compound la (top). Corresponding STD-NMR spectrum (bottom). Compound la (1 mM) and VISTA extracellular domain $(20 \mu \mathrm{M})$ were used in the experiment. 


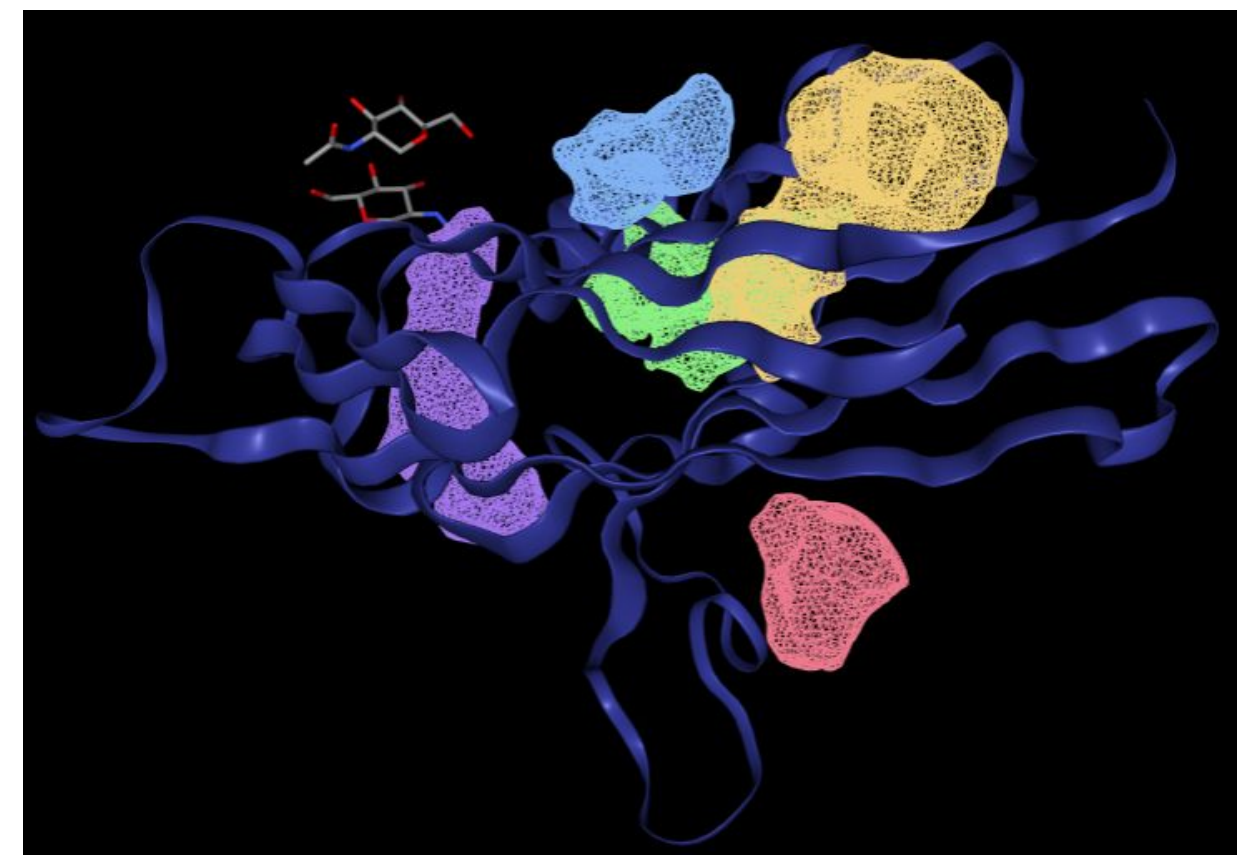

Figure S10. Predicted binding sites (shown in blue, yellow, green, red, and violet) in VISTA crystal structure (PDB ID: 6OIL) using DoGSiteScorer.

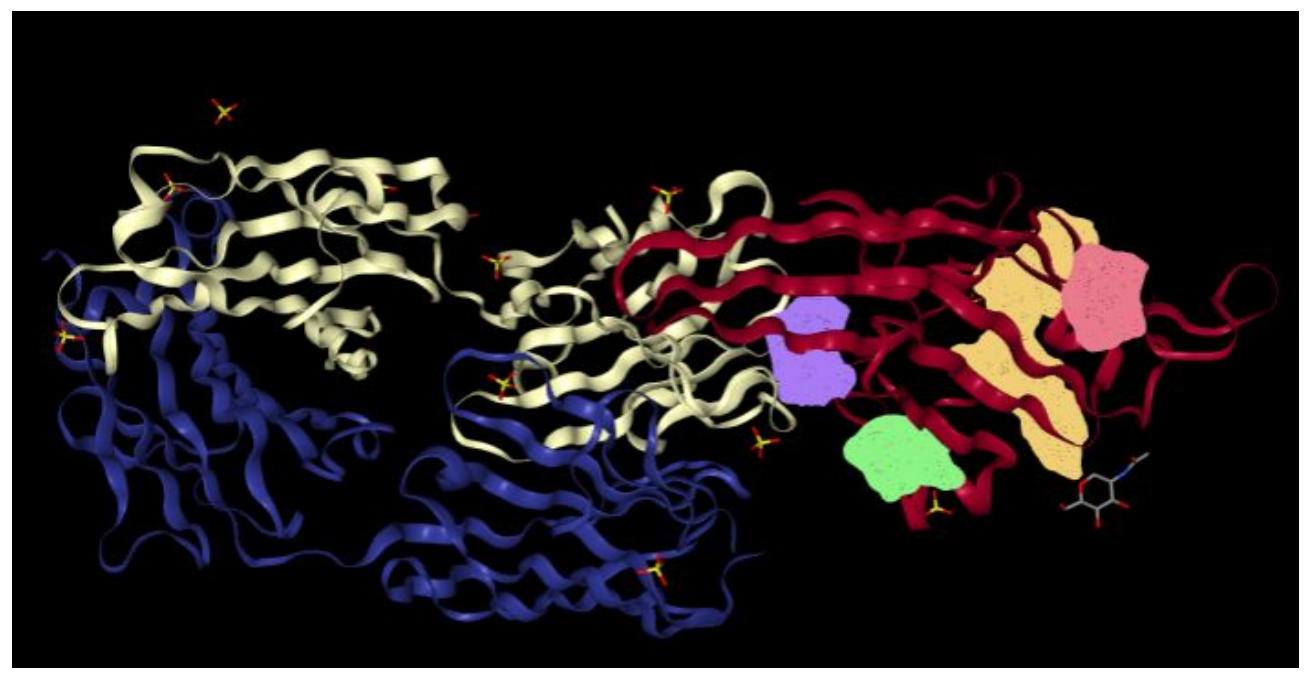

Figure S11. Predicted binding sites (shown in red, yellow, green, and violet) in VISTA crystal structure (PDB ID: 6MVL) using DoGSiteScorer. 


\begin{tabular}{|c|c|c|c|c|c|c|c|c|c|c|c|c|c|c|}
\hline \multirow[b]{2}{*}{1} & \multicolumn{2}{|l|}{ protein } & \multirow[b]{2}{*}{$\begin{array}{l}\text { residues } \\
\text { THR } 21 \mathrm{~A} \\
\text { TRP } 40 \mathrm{~A} \\
\text { CYS } 22 \mathrm{~A} \\
\text { LEU } 20 \mathrm{~A} \\
\text { GLY } 130 \mathrm{~A} \\
\text { CYS } 114 \mathrm{~A} \\
\text { TYR } 112 \mathrm{~A}\end{array}$} & \multicolumn{2}{|l|}{ residues } & \multicolumn{2}{|c|}{ size } & \multicolumn{2}{|c|}{ size } & & \multicolumn{2}{|l|}{ Score } & \multicolumn{2}{|l|}{ context } \\
\hline & $\begin{array}{l}\text { 9C2 TCR DE } \\
\text { LTA CHAIN }\end{array}$ & ACT & & $\begin{array}{l}\text { THR } 25 \mathrm{G} \\
\text { TRP } 38 \mathrm{G} \\
\text { CYS } 26 \mathrm{G} \\
\text { ILE } 24 \mathrm{G} \\
\text { GLY } 116 \mathrm{G} \\
\text { CYS } 98 \mathrm{G} \\
\text { TYR } 96 \mathrm{G}\end{array}$ & $\begin{array}{l}\text { THR } 25 \mathrm{G} \\
\text { ASP } 27 \mathrm{G} \\
\text { TYR } 96 \mathrm{G} \\
\text { CYS } 98 \mathrm{G} \\
\text { GLY } 116 \mathrm{G} \\
\text { GLY } 118 \mathrm{G}\end{array}$ & 6 & 0.54 & 7 & 1.201 & $\begin{array}{l}\text { Cluster } \\
\text { ACT } \\
\text { Size: } 4 \\
\text { Matches: } 1\end{array}$ & 0.8 & Open JMol & Open JMol & Info \\
\hline 2 & $\begin{array}{l}\text { TRANSCRIP } \\
\text { TIONAL RE } \\
\text { GULATOR, T } \\
\text { ETR FAMILY }\end{array}$ & STE & $\begin{array}{l}\text { VAL } 3 \text { A } \\
\text { GLY } 70 \text { A } \\
\text { VAL } 34 \mathrm{~A} \\
\text { VAL } 116 \mathrm{~A} \\
\text { PHE } 1 \mathrm{~A} \\
\text { VAL } 28 \mathrm{~A} \\
\text { SER } 98 \mathrm{~A}\end{array}$ & $\begin{array}{l}\text { LEU } 70 \mathrm{~A} \\
\text { GLY } 178 \mathrm{~B} \\
\text { ILE } 176 \mathrm{~B} \\
\text { LEU } 133 \mathrm{~A} \\
\text { PHE } 67 \mathrm{~A} \\
\text { LEU } 111 \mathrm{~A} \\
\text { SER } 94 \mathrm{~A}\end{array}$ & $\begin{array}{l}\text { LEU } 70 \mathrm{~A} \\
\text { SER } 94 \mathrm{~A} \\
\text { LEU } 111 \mathrm{~A} \\
\text { PHE } 112 \mathrm{~A} \\
\text { LEU } 160 \mathrm{~A} \\
\text { ARG } 175 \mathrm{~B} \\
\text { SER } 177 \mathrm{~B}\end{array}$ & 7 & 0.35 & 7 & 2.167 & $\begin{array}{c}\text { Cluster } \\
\text { 14V } \\
\text { Size: } 75 \\
\text { Matches: } 6\end{array}$ & 0.63 & Open JMol & Open JMol & Info \\
\hline 3 & $\begin{array}{l}\text { TRANSLATI } \\
\text { ON ELONGA } \\
\text { TION FACT } \\
\text { OR SELB }\end{array}$ & CMH & $\begin{array}{l}\text { ILE } 99 \mathrm{~A} \\
\text { SER } 109 \mathrm{~A} \\
\text { LEU } 134 \mathrm{~A} \\
\text { LEU } 104 \mathrm{~A} \\
\text { LEU } 20 \mathrm{~A} \\
\text { GLY } 110 \mathrm{~A} \\
\text { VAL } 136 \mathrm{~A}\end{array}$ & $\begin{array}{l}\text { ILE } 283 \mathrm{~A} \\
\text { SER } 334 \mathrm{~A} \\
\text { ILE } 333 \mathrm{~A} \\
\text { LEU } 329 \mathrm{~A} \\
\text { ILE } 285 \mathrm{~A} \\
\text { GLY } 335 \mathrm{~A} \\
\text { VAL } 332 \mathrm{~A}\end{array}$ & $\begin{array}{l}\text { ILE } 283 \text { A } \\
\text { VAL } 332 \text { A } \\
\text { GLY } 335 \text { A } \\
\text { GLU } 337 \text { A } \\
\text { TYR } 339 \text { A }\end{array}$ & 5 & 0.54 & 7 & 2.432 & $\begin{array}{c}\text { Cluster } \\
\text { 31Q } \\
\text { Size: } 2 \\
\text { Matches: } 2\end{array}$ & 0.53 & Open JMol & Open JMol & Info \\
\hline
\end{tabular}

Figure S12. Top 3 predicted binding sites in VISTA crystal structure (PDB ID: 6OIL) using LIBRA-WA.

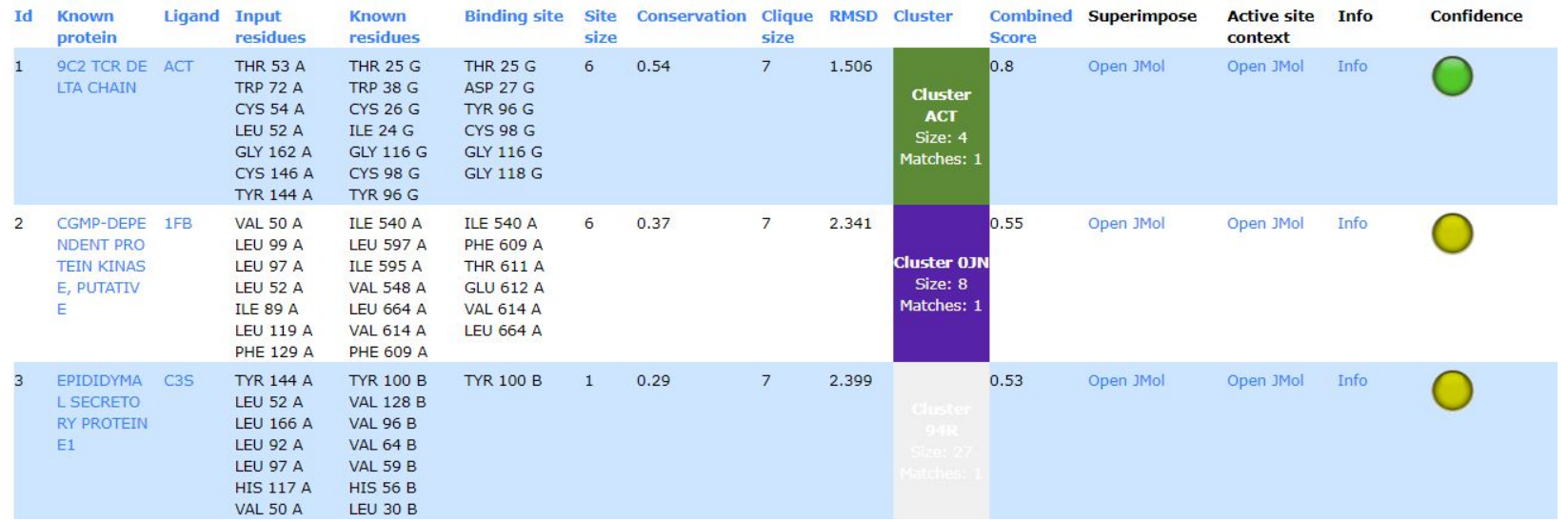

Figure S13. Top 3 predicted binding sites in VISTA crystal structure (PDB ID: 6MVL) using LIBRA-WA. 


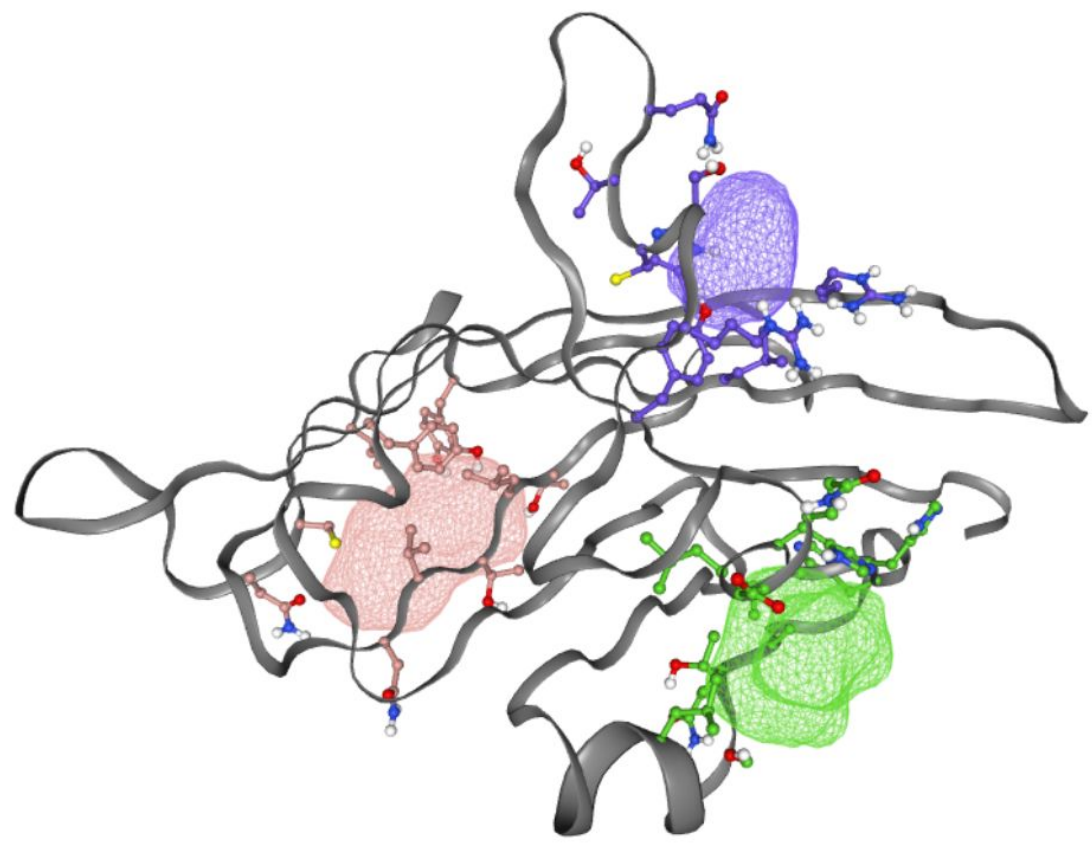

Figure S14. Predicted binding sites (shown in green, pink, and violet) in VISTA crystal structure (PDB ID: 6OIL) using FT site.

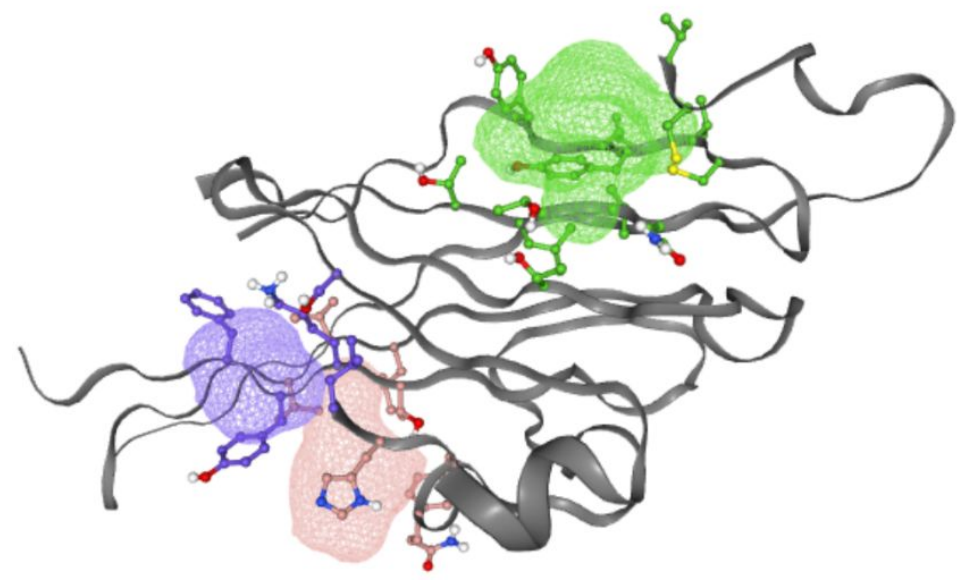

Figure S15. Predicted binding sites (shown in green, violet, and pink) in VISTA crystal structure (PDB ID: 6MVL) using FT site. 


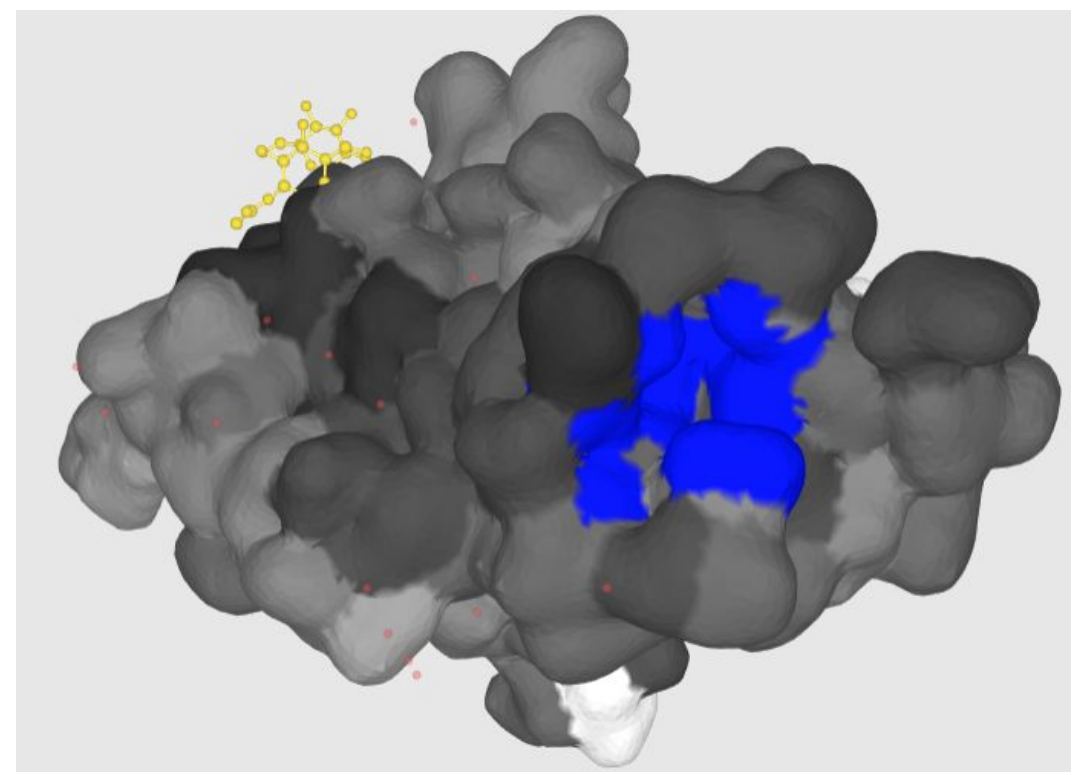

Figure S16. Predicted binding site (shown in blue) in VISTA crystal structure (PDB ID: 6OIL) using Prankweb.

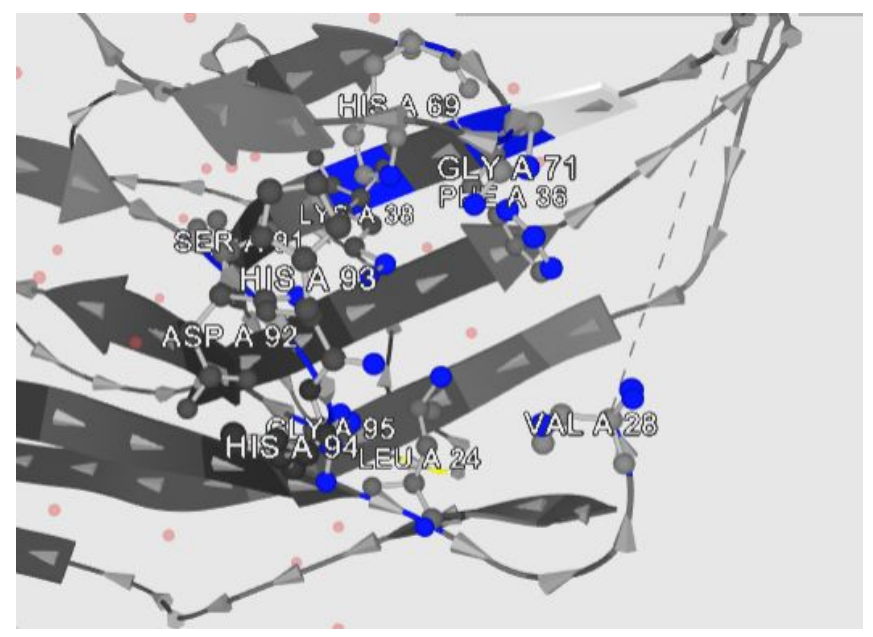

Figure S17. A close-up to the predicted binding sites (shown in blue) in VISTA crystal structure (PDB ID: 6OIL) using Prankweb. 


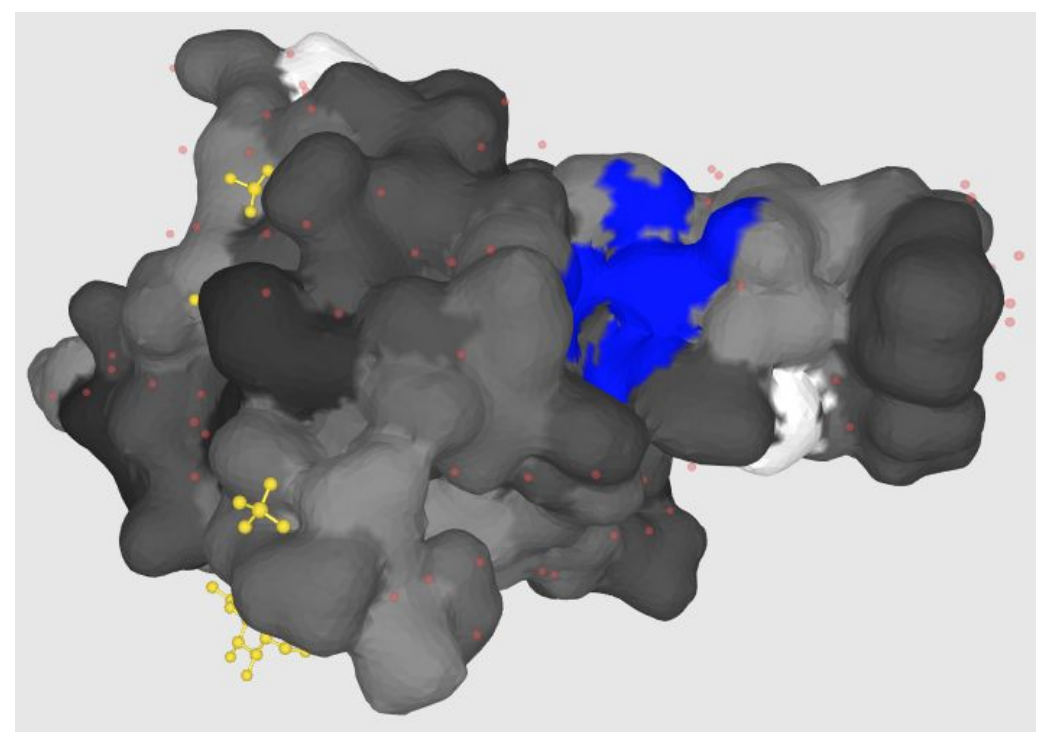

Figure S18. Predicted binding site (shown in blue) in VISTA crystal structure (PDB ID: 6MVL) using Prankweb.

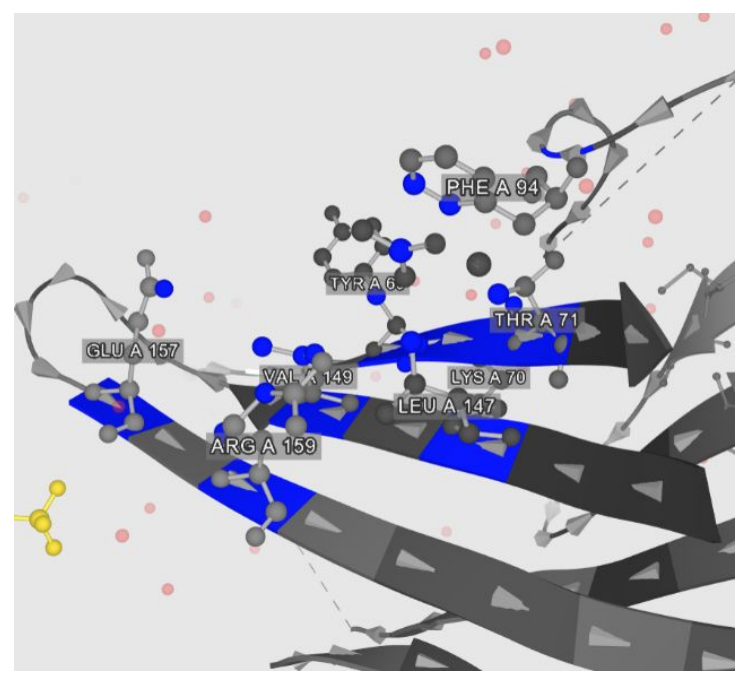

Figure S19. A close-up to the predicted binding sites (shown in blue) in VISTA crystal structure (PDB ID: 6MVL) using Prankweb. 


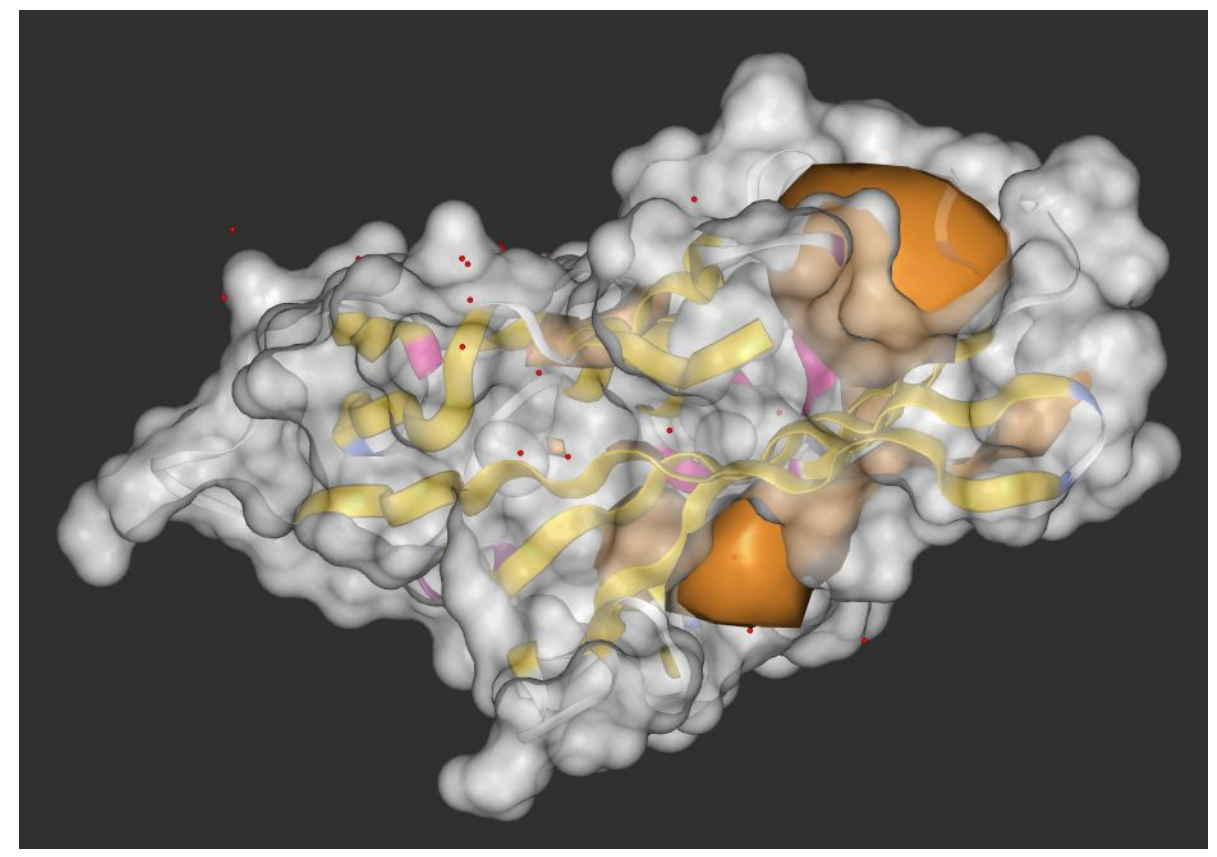

$\checkmark$ Deepsite prediction results

\begin{tabular}{ccc}
\hline id & centers & score \\
\hline 1 & {$[16.9,42.5,43.7]$} & 0.99 \\
\hline 2 & {$[22.9,26.5,37.7]$} & 0.93 \\
\hline 3 & {$[20.9,32.5,19.7]$} & 0.8 \\
\hline 4 & {$[28.9,40.5,43.7]$} & 0.85 \\
\hline 5 & {$[22.9,42.5,31.7]$} & 0.45 \\
\hline 6 & {$[10.9,32.5,31.7]$} & 0.54 \\
\hline
\end{tabular}

Figure S20. Predicted binding sites (displayed as orange spheres) in VISTA crystal structure (PDB ID: 6OIL) using Deepsite. 


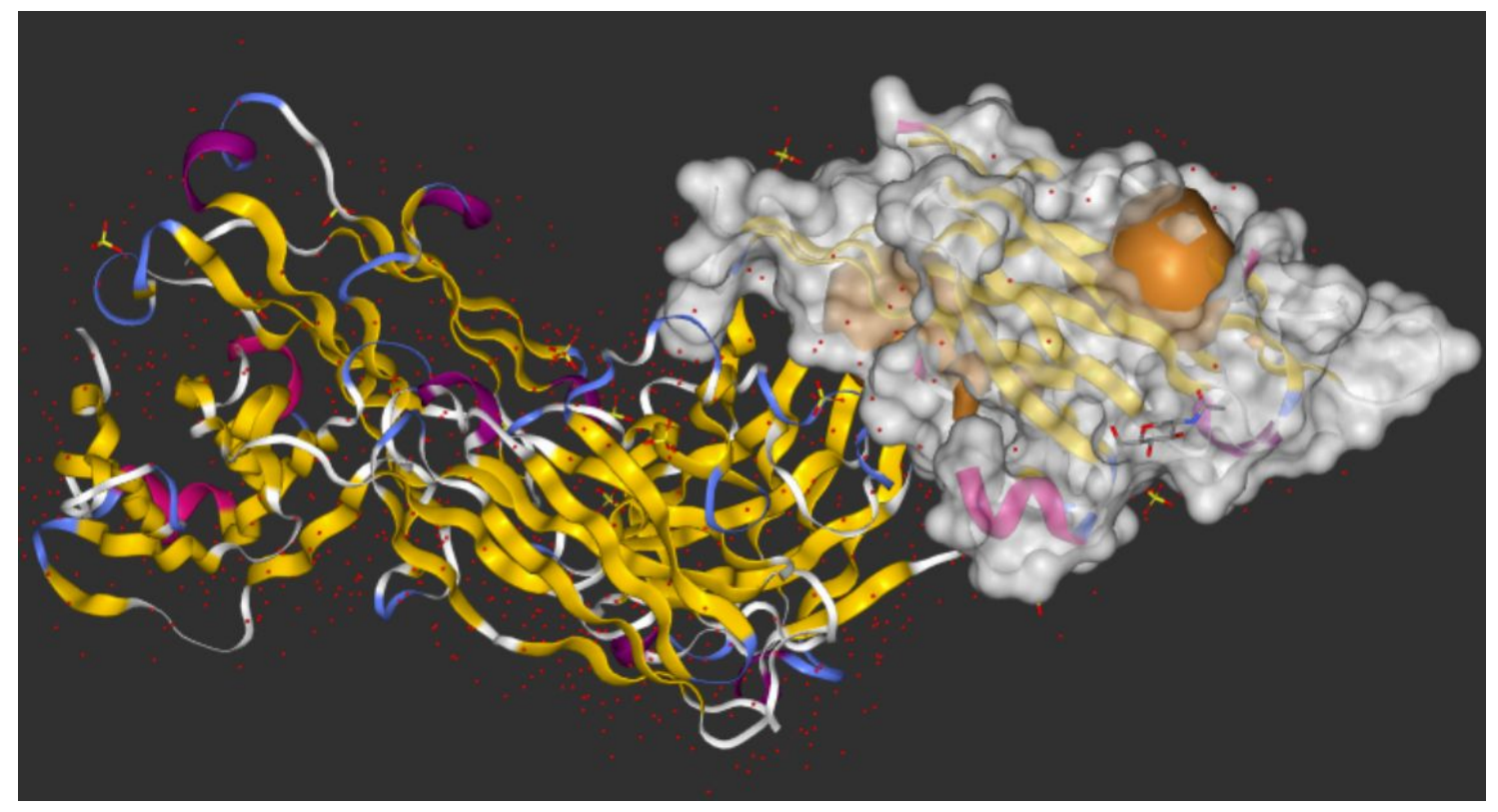

\begin{tabular}{ccc}
\multicolumn{3}{c}{$\checkmark$ Deepsite prediction results } \\
\hline id & centers & score \\
\hline 1 & {$[-27.2,16.2,17.8]$} & 1.0 \\
\hline 2 & {$[-45.2,16.2,3.8]$} & 0.99 \\
\hline 3 & {$[-31.2,12.2,15.8]$} & 0.81 \\
\hline
\end{tabular}

Figure S21. Predicted binding sites (shown as orange spheres) in VISTA crystal structure (PDB ID: 6MVL) using Deepsite. 

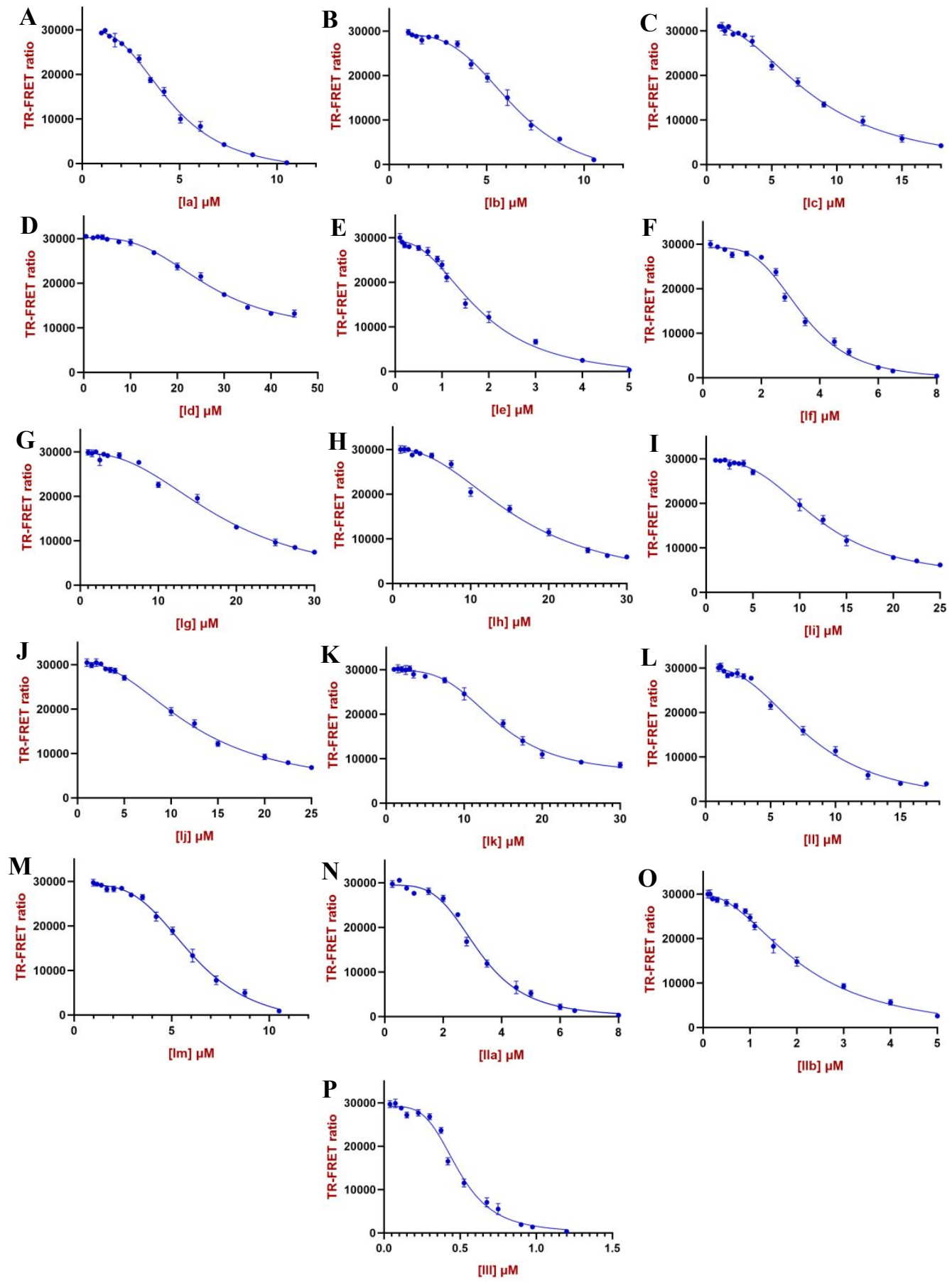

Figure S22. Dose-response curves of la (A), Ib (B), Ic (C), Id (D), le (E), If (F), Ig (G), Ih (H), li (I), lj (J), Ik (K), II (L), Im (M), IIa (N), IIb (O) and III (P) in VISTA FRET assay. Error bars represent standard deviation ( $n=3)$. 


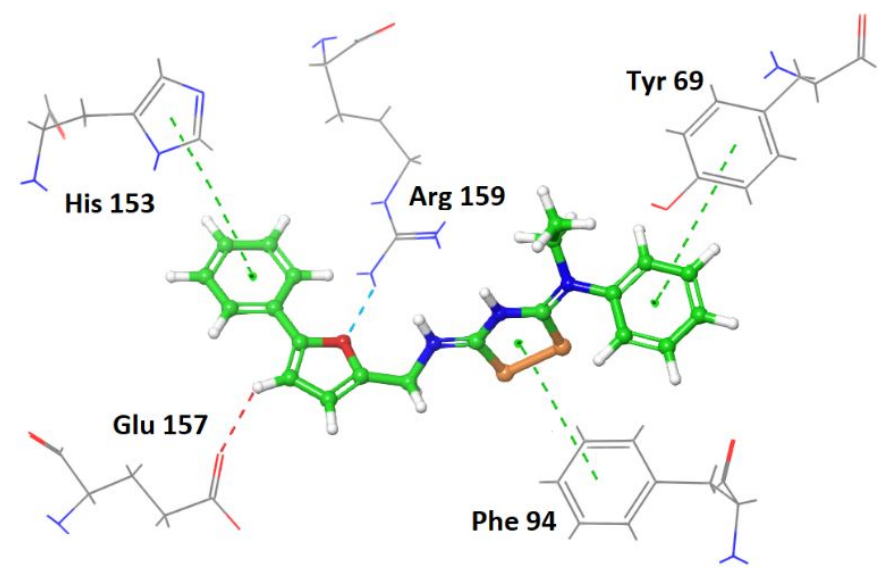

Figure S23. 3D view of predicted binding pose of compound III to VISTA crystal structure (PDB ID: 6MVL). Dotted green lines represent hydrophobic interaction, dotted cyan lines represent $\mathrm{H}$-bonding, and dotted red lines represent aromatic-hydrogen bonding.

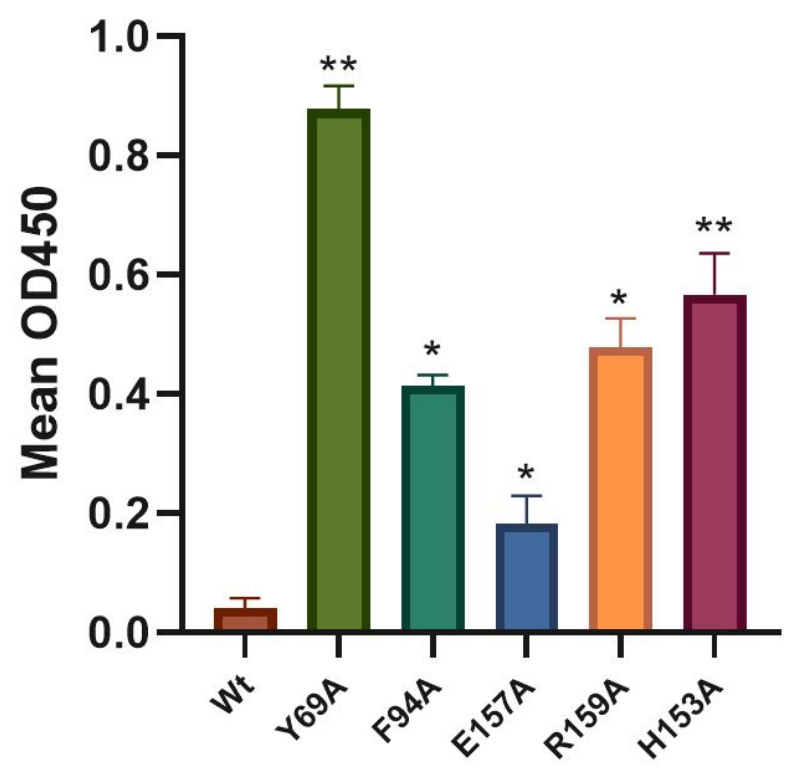

Figure S24. Evaluation of VISTA mutants in competitive ELISA in the presence of III ( $20 \mu \mathrm{M})$. Error bars represent standard deviation $(\mathrm{n}=6) .\left({ }^{* *} p<0.05 ;{ }^{* * *} p<0.005\right.$ relative to Wt VISTA). 


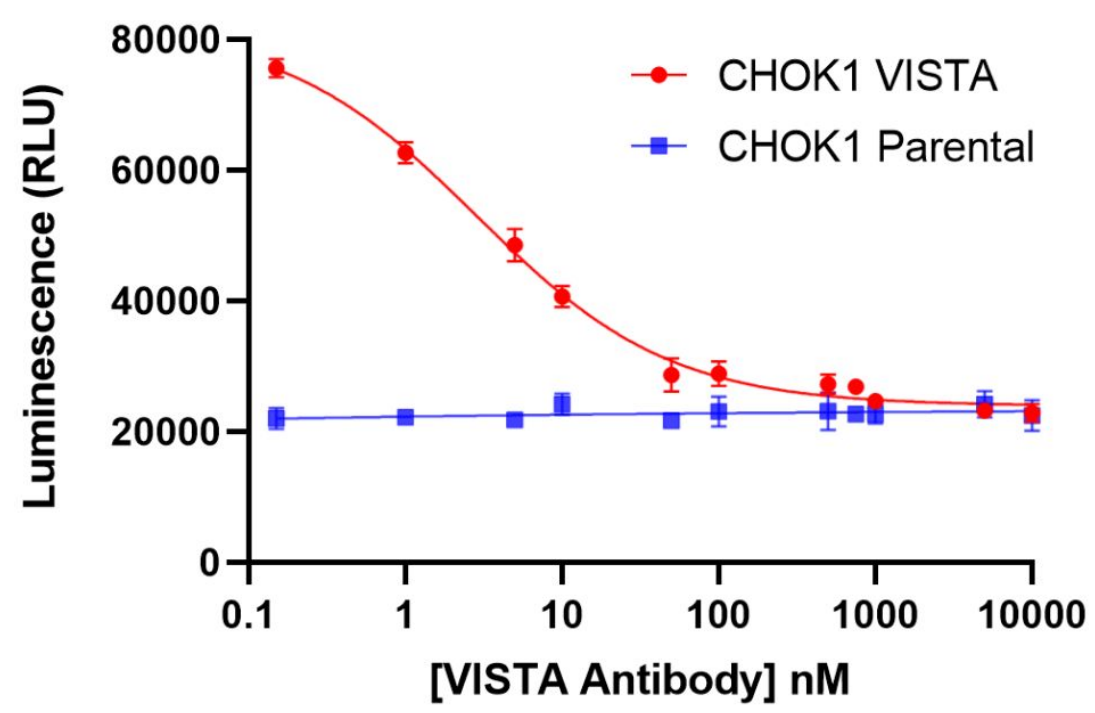

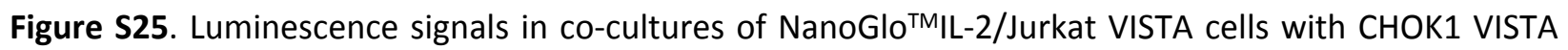
cells and CHOK1 parental cells in the presence of different concentrations of VISTA antibody. Error bars represent standard deviation $(n=3)$.

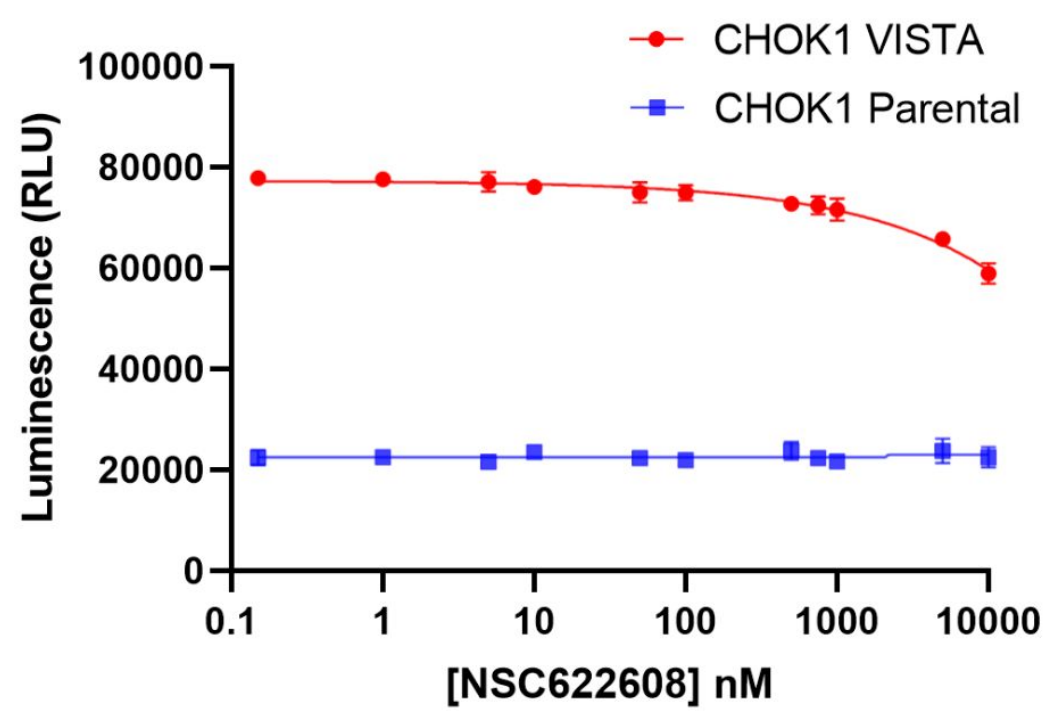

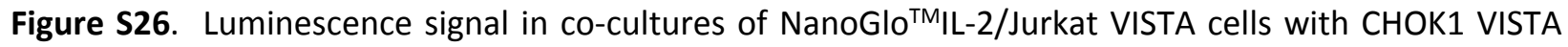
cells and CHOK1 parental cells in the presence of different concentrations of NSC622608. Error bars represent standard deviation $(n=3)$. 

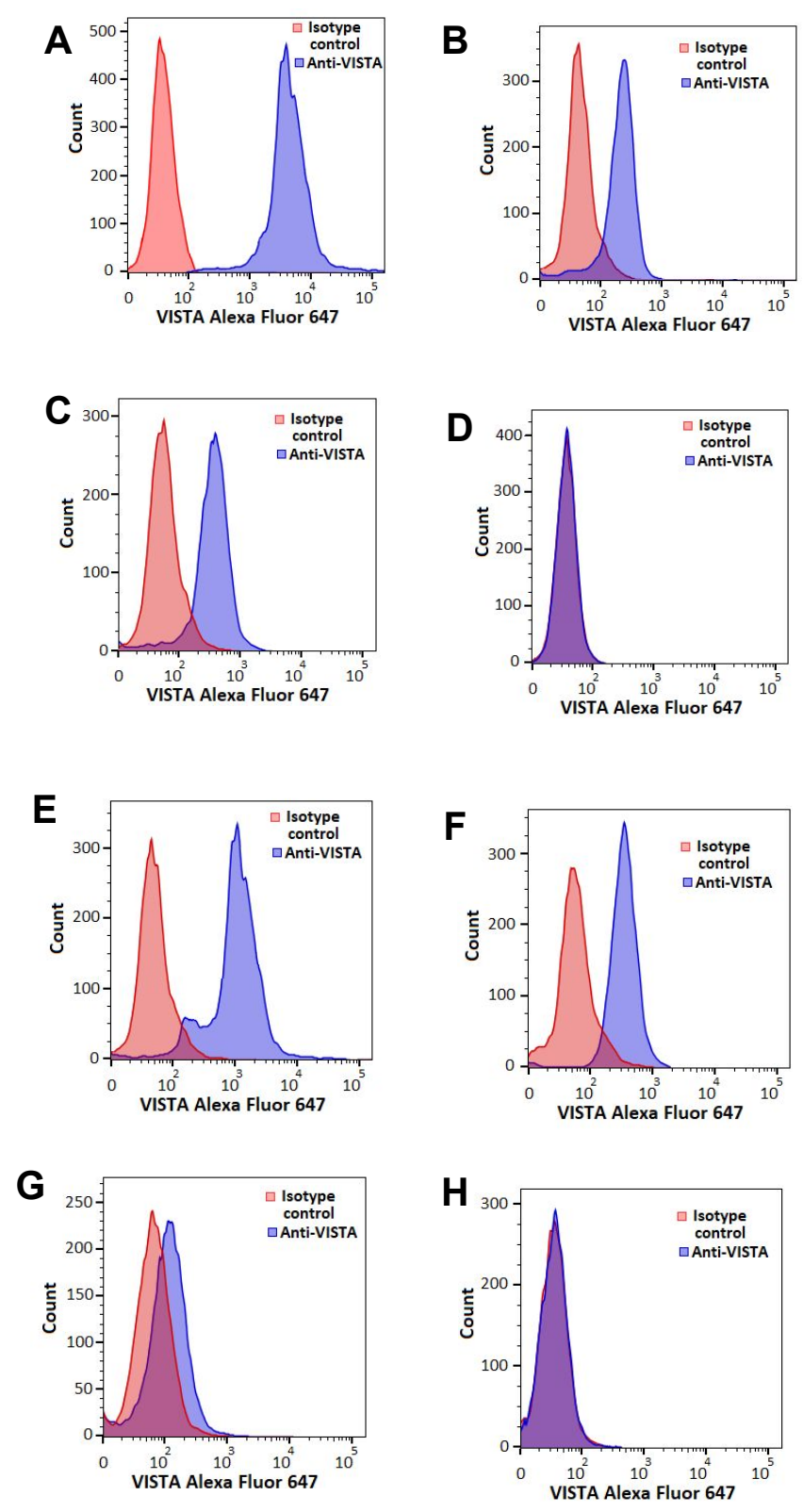

Figure S27. Flow cytometry analysis of human VISTA expression on the surface of (A) OVKATE cancer cell line, (B) SKOV3 cancer cell line, (C) COV504 cancer cell line, (D)A2780 cancer cell line, (E) RL952 cancer cell line ,(F) HEC1A cancer cell line, (G) AN3CA cancer cell line and (H) Ishikawa cancer cell line. 


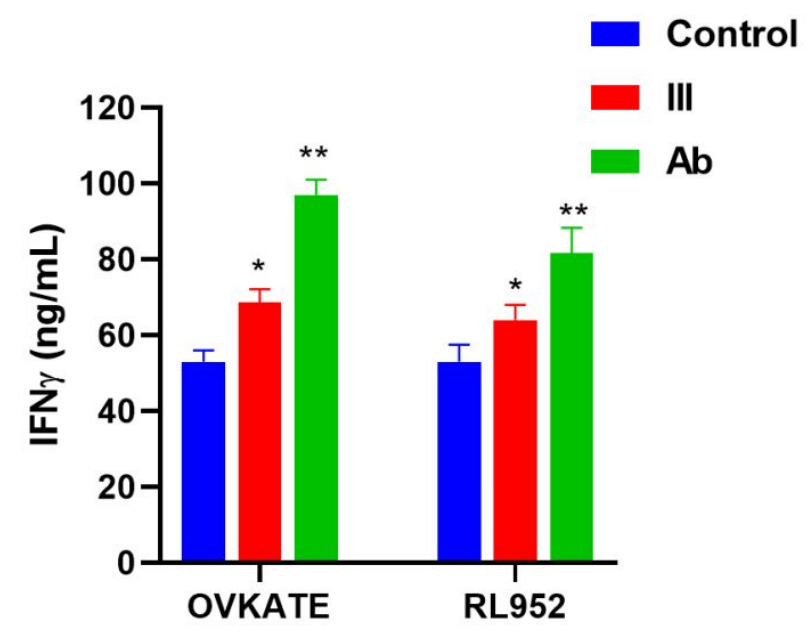

Figure S28. Interferon gamma (IFN $\gamma$ ) concentrations at 24 hours, determined by ELISA, in the supernatant of co-culture of purified T cells from human peripheral blood mononuclear cells (PBMCs) with OVKATE ovarian cancer cell line and RL952 endometrial cancer cell line in the presence of III (5 $\mu \mathrm{M})$ and VISTA Ab $(1 \mu \mathrm{M})$. Error bars represent standard deviation $(n=3) .\left({ }^{* *} p<0.05 ;{ }^{* * *} p<0.005\right.$ relative to untreated control).

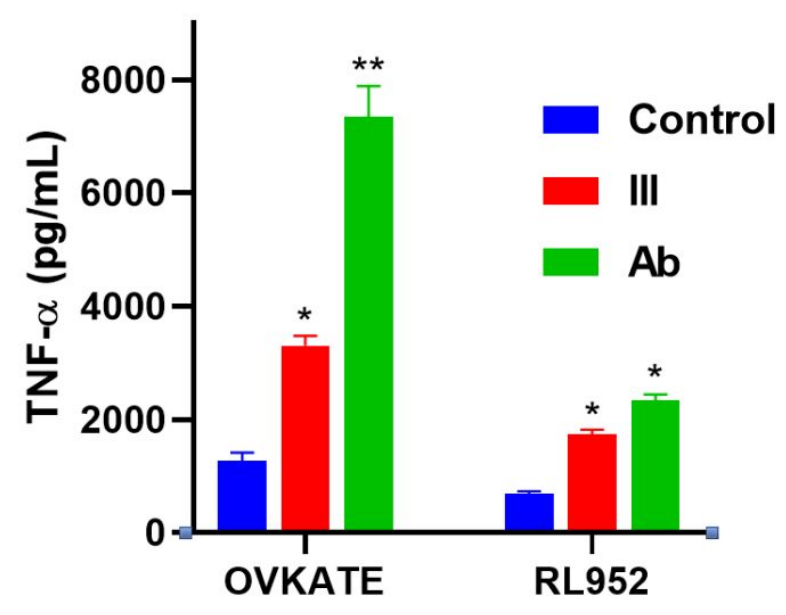

Figure S29. Tumor necrosis factor alpha (TNF $\alpha$ ) concentrations at 24 hours, determined by ELISA, in the supernatant of co-culture of purified T cells from human peripheral blood mononuclear cells (PBMCs) with OVKATE ovarian cancer cell line and RL952 endometrial cancer cell line in the presence of III (5 $\mu \mathrm{M})$ and VISTA Ab $(1 \mu \mathrm{M})$. Error bars represent standard deviation $(\mathrm{n}=3) .\left({ }^{* *} p<0.05 ;{ }^{* * *} p<0.005\right.$ relative to untreated control). 


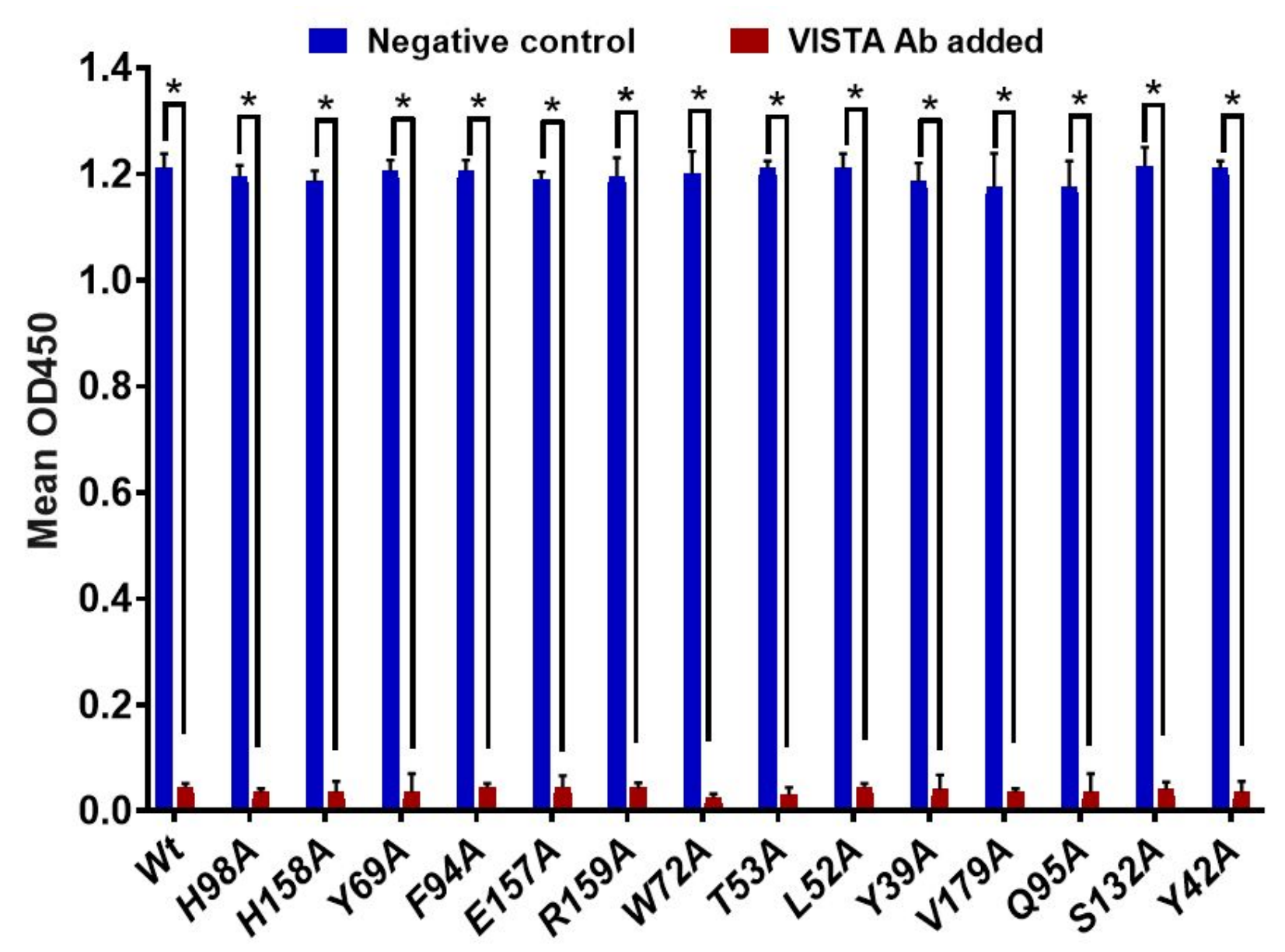

Figure S30. Evaluation of VISTA mutants in competitive ELISA in the absence and presence of $100 \mathrm{nM}$ of VISTA antibody (MAB71263-SP). Error bars represent standard deviation $(n=6) .{ }^{*} p<0.005$ relative to negative control). 


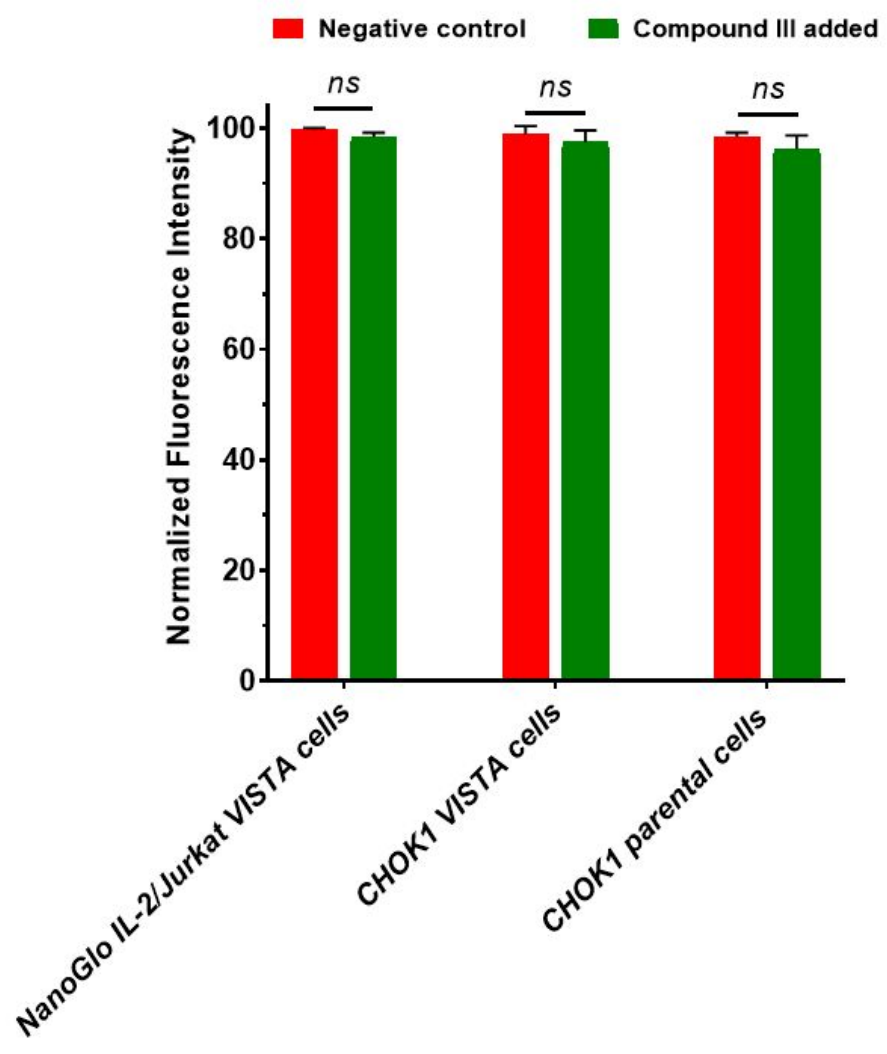

Figure S31. PrestoBlue viability of NanoGlo ${ }^{T M}$ IL-2/Jurkat VISTA, CHOK1 VISTA, and CHOK1 parental cells in the absence and presence of compound III $(10 \mu \mathrm{M})$. Error bars represent standard deviation $(\mathrm{n}=3), \mathrm{ns}$ : not significant. 
Table S1. Inhibition percentages of the hits identified against VISTA in HTS FRET assay.

\begin{tabular}{|c|c|c|}
\hline Compound no. & \% Inhibition & Tested concentration $(\boldsymbol{\mu M})$ \\
\hline $\mathbf{1}$ & 59.1 & 50 \\
\hline $\mathbf{2}$ & 74.3 & 50 \\
\hline $\mathbf{3}$ & 68.2 & 5 \\
\hline $\mathbf{4}$ & 67.5 & 50 \\
\hline $\mathbf{5}$ & 59.7 & 5 \\
\hline $\mathbf{6}$ & 55.2 & 5 \\
\hline $\mathbf{7}$ & 69.2 & 5 \\
\hline $\mathbf{8}$ & 61.2 & 50 \\
\hline $\mathbf{9}$ & 49.6 & 50 \\
\hline $\mathbf{1 0}$ & 52.6 & 50 \\
\hline $\mathbf{1 1}$ & 70.1 & 50 \\
\hline $\mathbf{1 3}$ & 68.3 & 50 \\
\hline $\mathbf{1 4}$ & 61.2 & 50 \\
\hline $\mathbf{1 5}$ & 55.9 & 5 \\
\hline $\mathbf{1 6}$ & 53.4 & 50 \\
\hline $\mathbf{1 7}$ & 46.9 & 50 \\
\hline $\mathbf{1 8}$ & 50.1 & 50 \\
\hline
\end{tabular}


Table S2. GlideScores (kcal/mol) of the hot compound (NSC622608) upon docking to all the predicted binding sites in VISTA crystal structures PDB ID 6OIL and PDB ID 6MVL.

\begin{tabular}{|c|c|}
\hline Binding site & GlideScore (kcal/mol) \\
\hline DoGsiteScorer 1 (6OIL) & -1.35 \\
\hline DoGsiteScorer 2 (6OIL) & -1.75 \\
\hline DoGsiteScorer 3 (6OIL) & -1.70 \\
\hline DoGsiteScorer 4 (6OIL) & -1.16 \\
\hline DoGsiteScorer 5 (6OIL) & -0.87 \\
\hline DoGsiteScorer 1 (6MVL) & -6.84 \\
\hline DoGsiteScorer 2 (6MVL) & -2.61 \\
\hline DoGsiteScorer 3 (6MVL) & -1.96 \\
\hline DoGsiteScorer 4 (6MVL) & -1.13 \\
\hline LIBRA-WA 1 (6OIL) & -1.96 \\
\hline LIBRA-WA 2 (6OIL) & -0.56 \\
\hline LIBRA-WA 3 (6OIL) & -0.47 \\
\hline LIBRA-WA 1 (6MVL) & -2.51 \\
\hline LIBRA-WA 2 (6MVL) & -1.08 \\
\hline LIBRA-WA 3 (6MVL) & -0.31 \\
\hline FT site 1 (6OIL) & -2.98 \\
\hline FT site 2 (6OIL) & -1.87 \\
\hline FT site 3 (6OIL) & -1.20 \\
\hline FT site 1 (6MVL) & -7.19 \\
\hline FT site 2 (6MVL) & -6.65 \\
\hline FT site 3 (6MVL) & -1.51 \\
\hline Prankweb (6OIL) & -2.26 \\
\hline Prankweb (6MVL) & -8.13 \\
\hline DeepSite 1 (6OIL) & -2.53 \\
\hline DeepSite 2 (6OIL) & -2.07 \\
\hline DeepSite 3 (6OIL) & -1.85 \\
\hline DeepSite 4 (6OIL) & -1.64 \\
\hline DeepSite 5 (6OIL) & -1.17 \\
\hline DeepSite 6 (6OIL) & -0.83 \\
\hline DeepSite 1 (6MVL) & -6.47 \\
\hline DeepSite 2 (6MVL) & -2.08 \\
\hline DeepSite 3 (6MVL) & -2.12 \\
\hline
\end{tabular}

*Bold values represent the lowest GlideScores obtained. 


\section{References:}

1. Zhang, J.-H.; Chung, T. D. Y.; Oldenburg, K. R. A simple statistical parameter for use in evaluation and validation of high throughput screening assays. J. Biomol. Screen. 1999, 4, 67-73.

2. Slater, B. T.; Han, X.; Chen, L.; Xiong, Y. Structural insight into T cell coinhibition by PD-1H (VISTA). Proc. Natl. Acad. Sci. USA 2020, 117, 1648-1657.

3. Liu, H.; Zhao, Z.; Zhang, L.; Li, Y.; Jain, A.; Barve, A.; Jin, W.; Liu, Y.; Fetse, J.; Cheng, K. Discovery of low-molecular weight anti-PD-L1 peptides for cancer immunotherapy. J. Immunother. Cancer 2019, 7, 270.

4. Schrodinger Release 2019-1: Induced Fit Docking Protocol; Glide, Schrodinger, LLC, New York, NY, 2019; Prime, Schrodinger, LLC, New York, NY, 2019. 

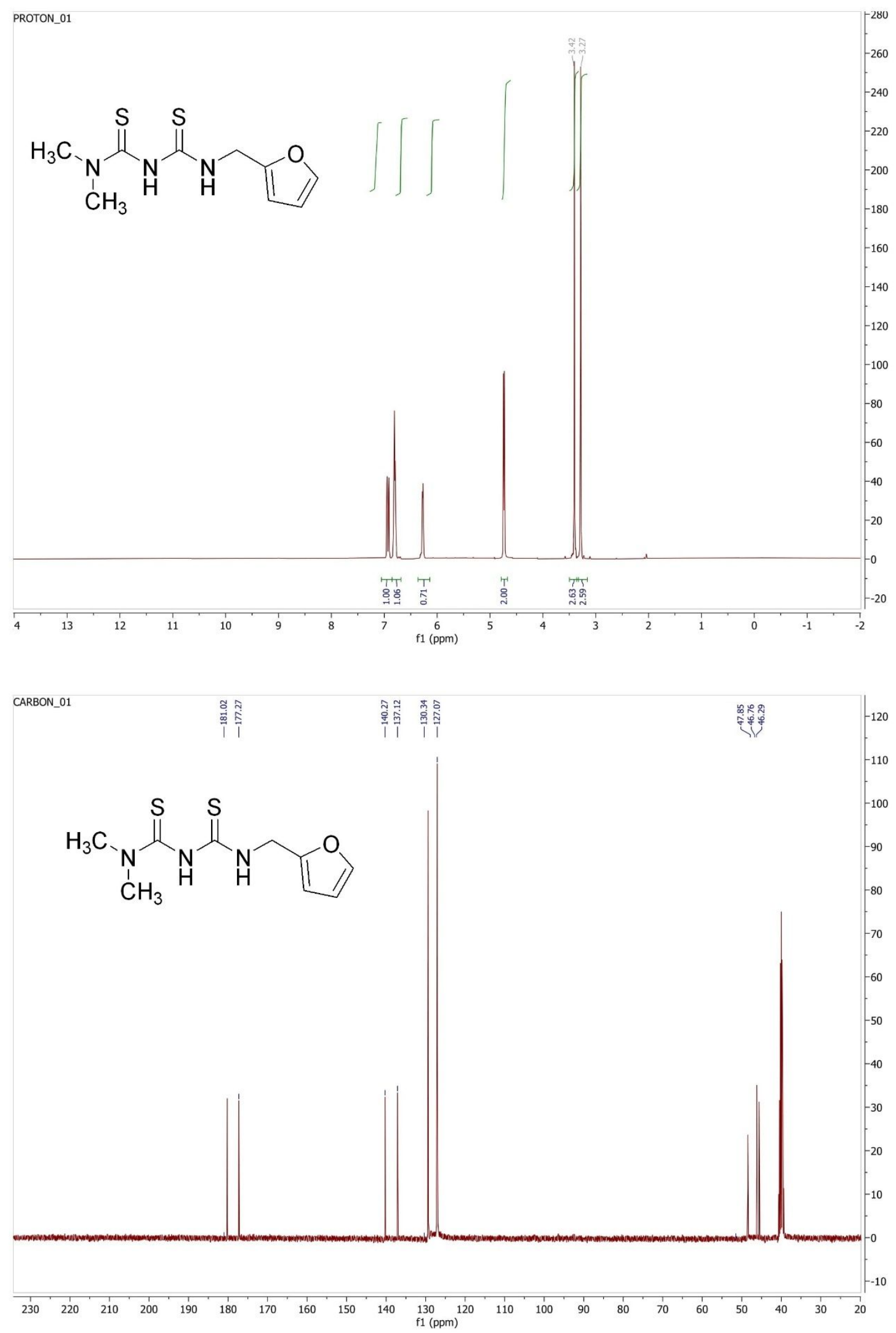

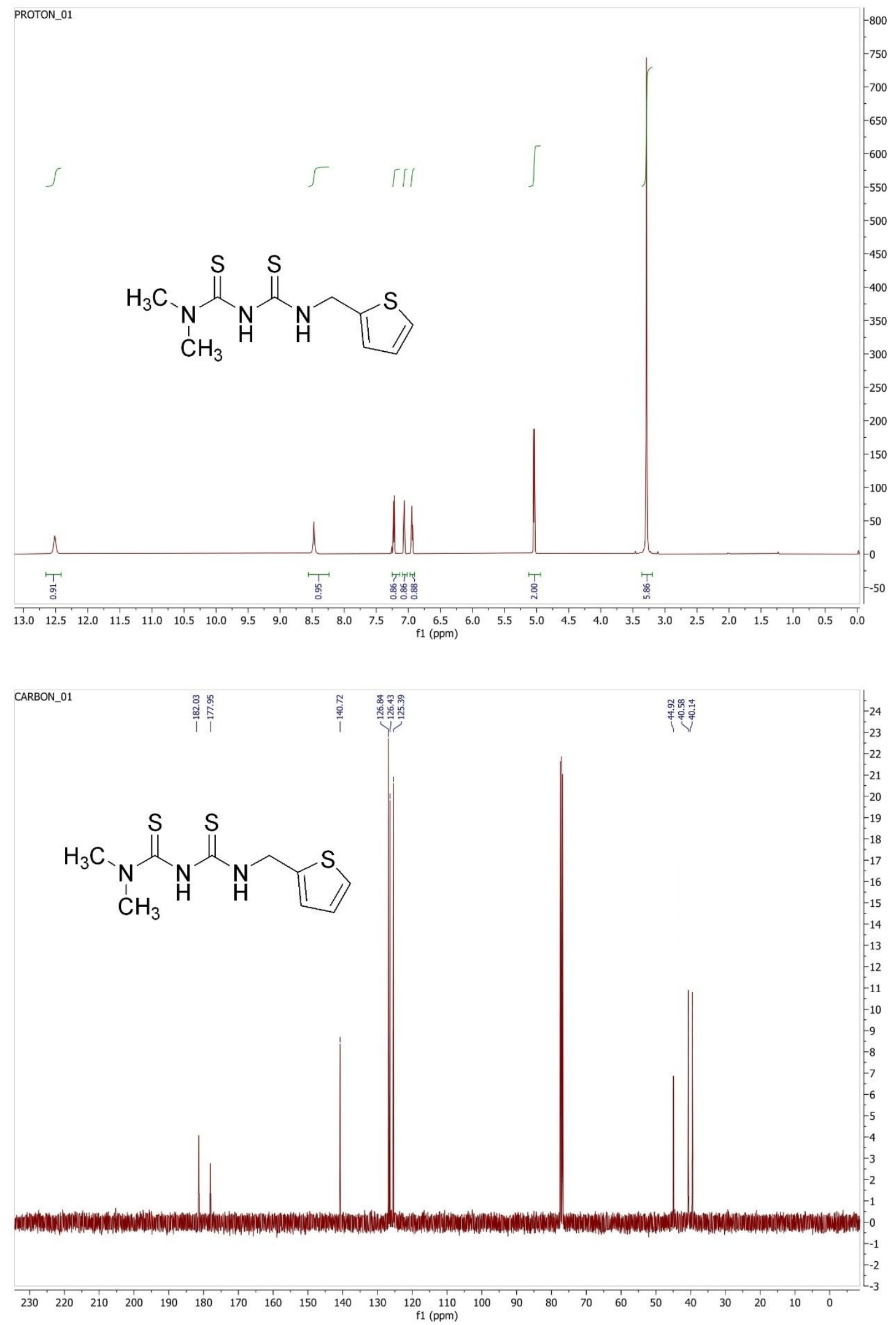

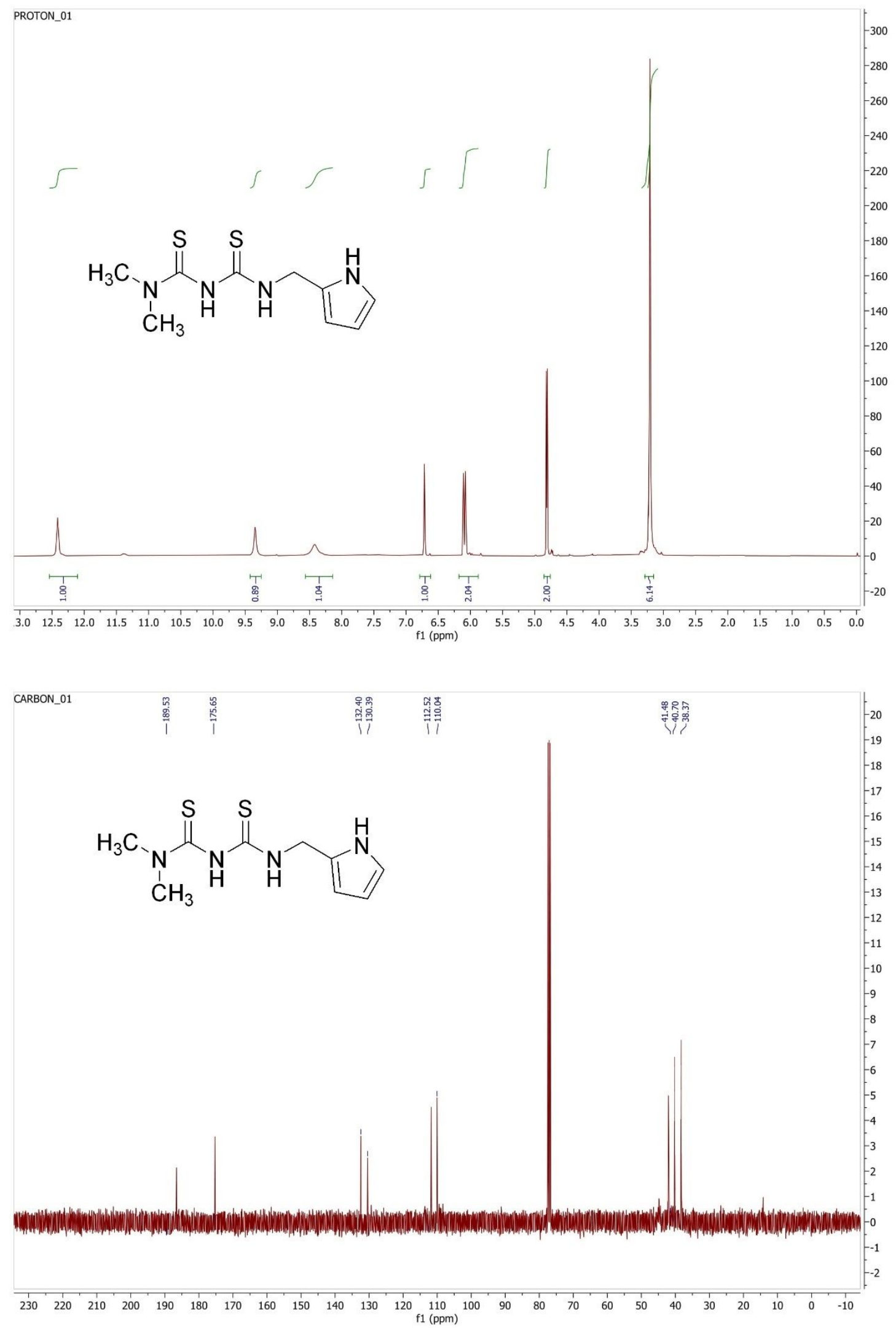

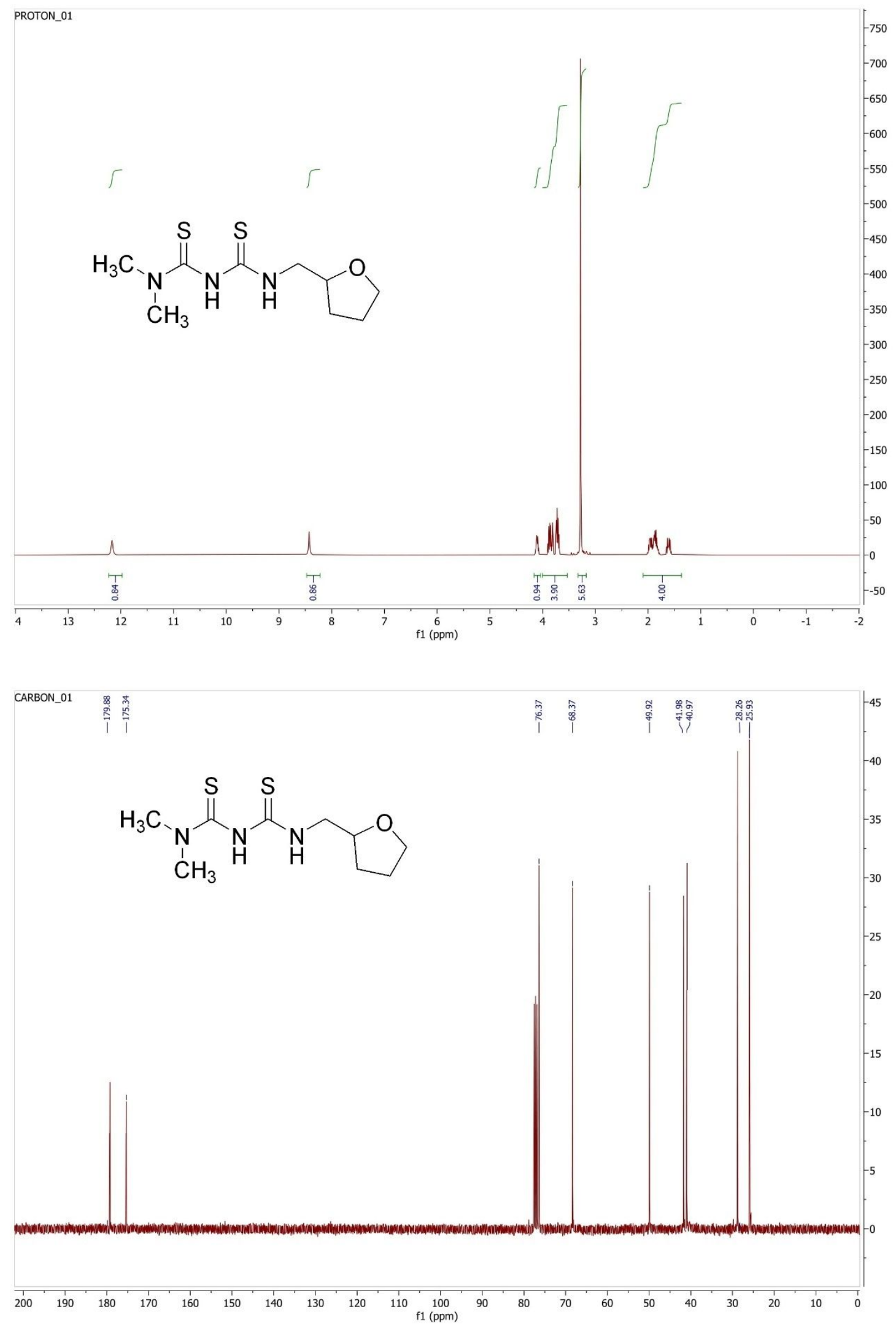

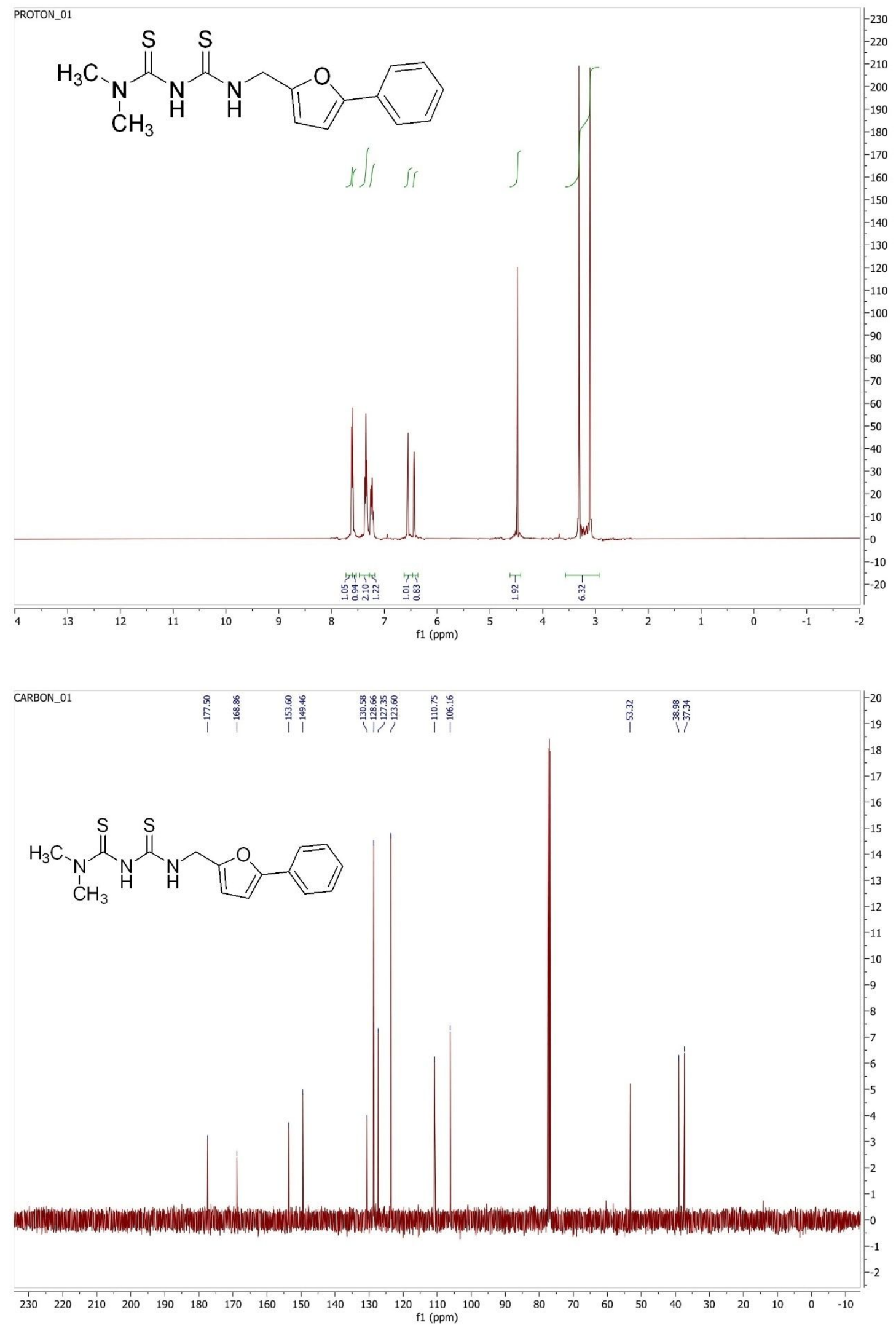

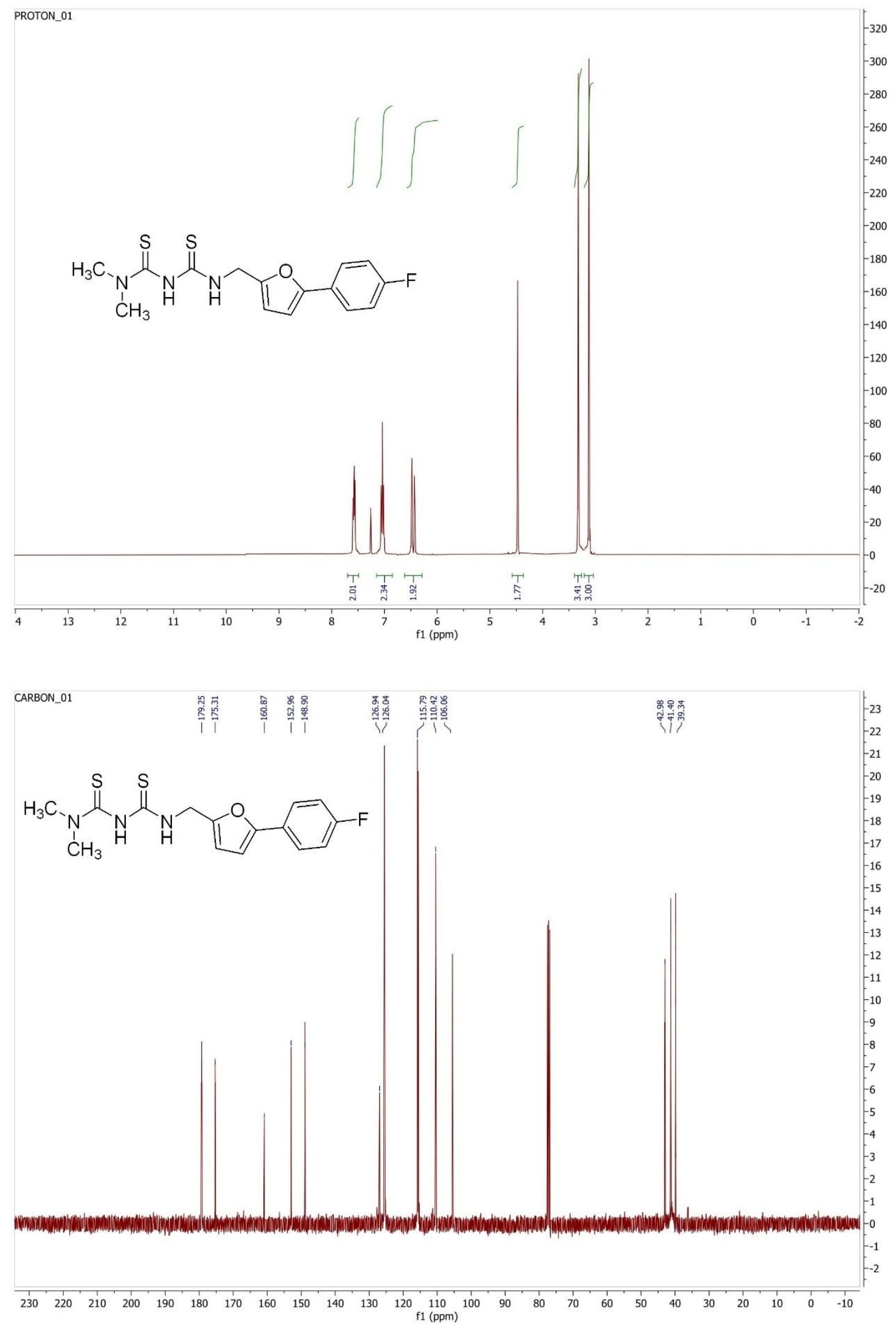

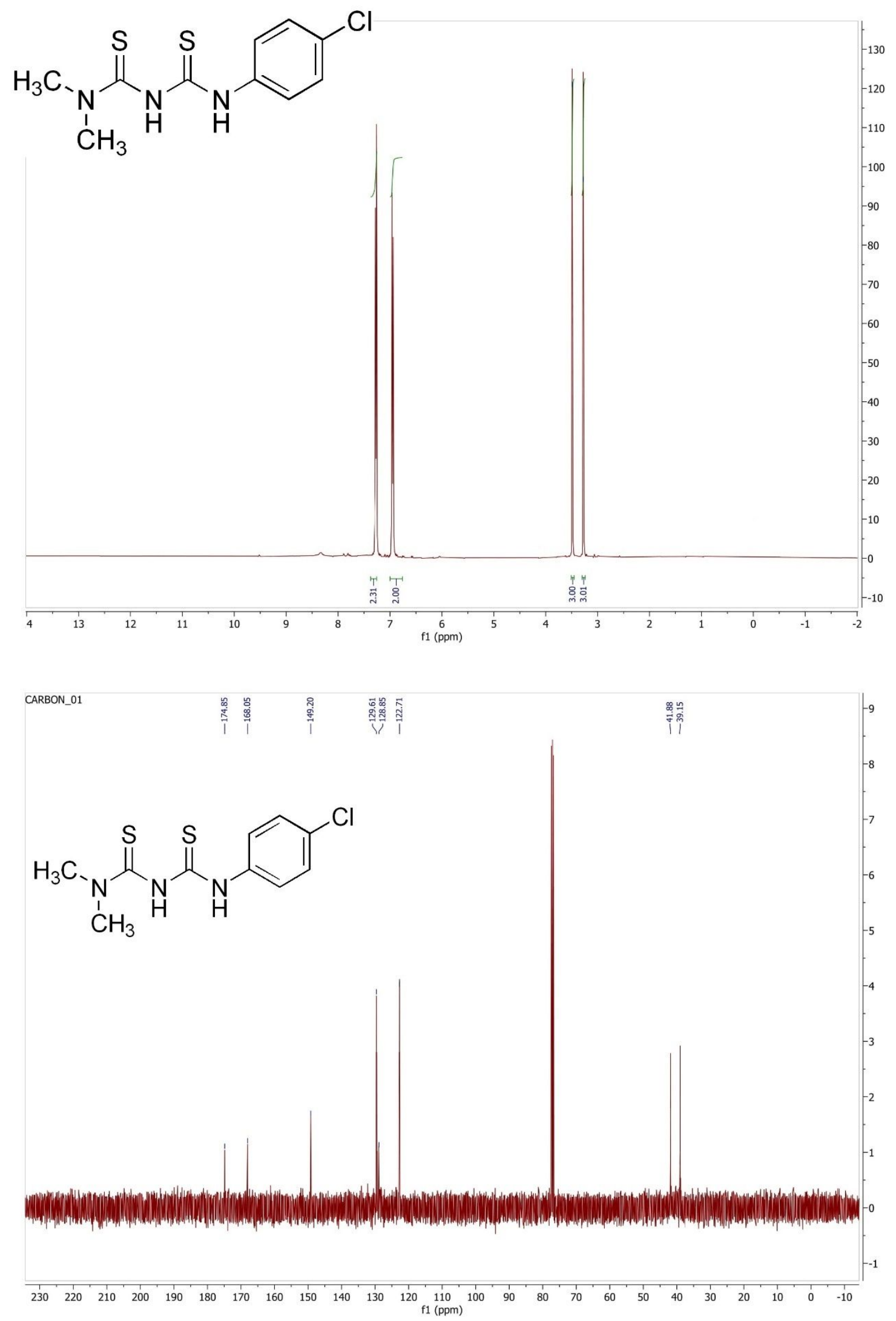

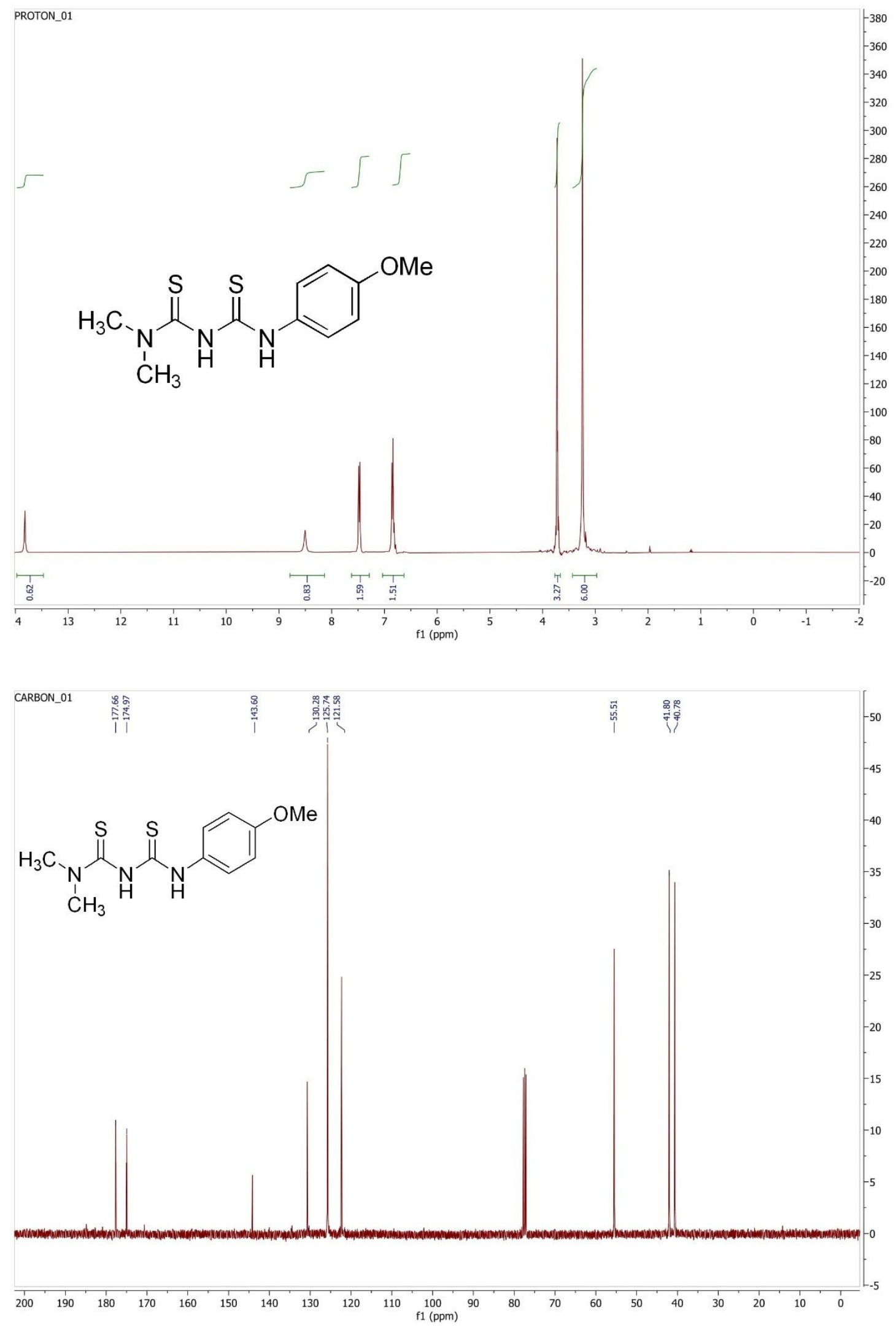

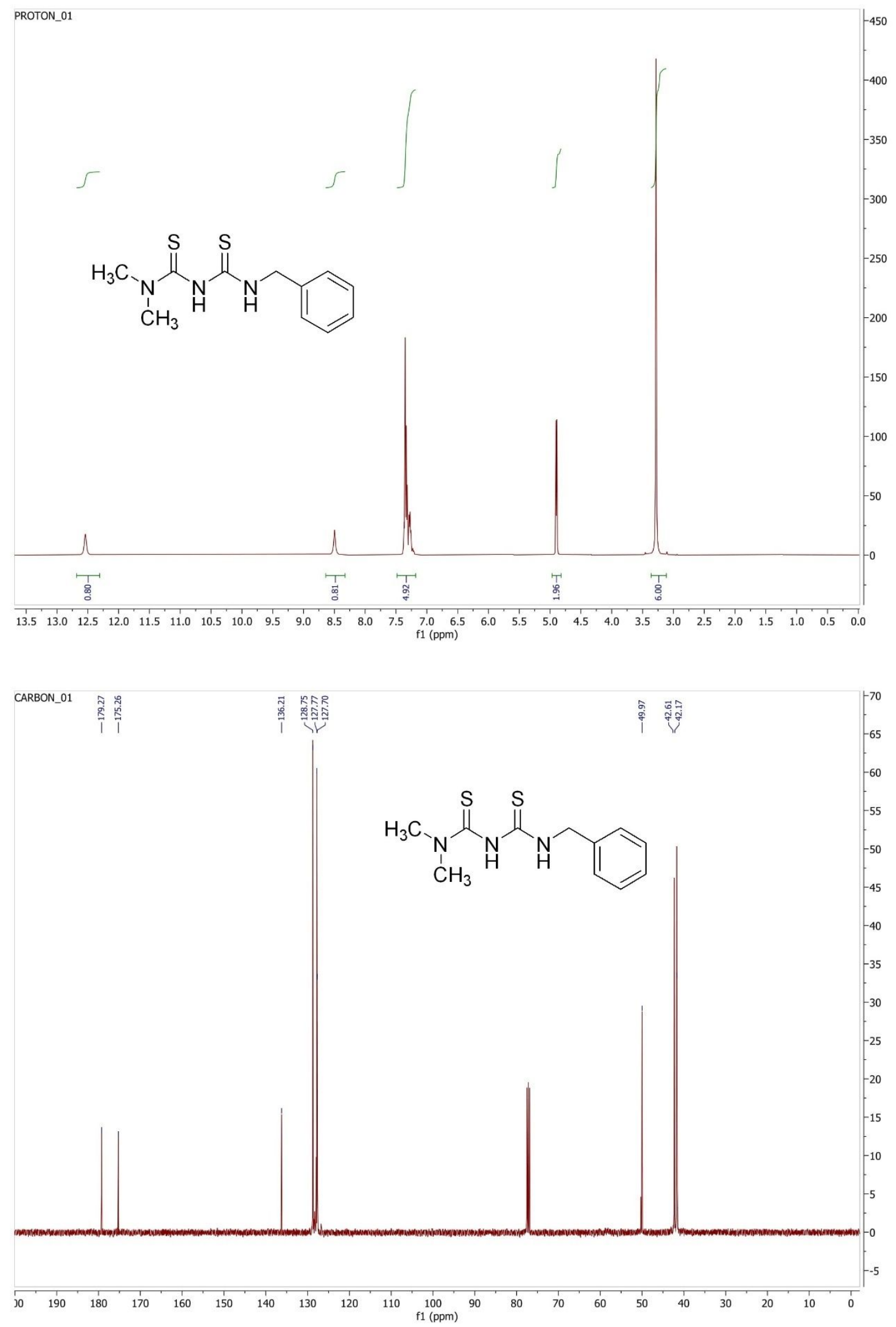

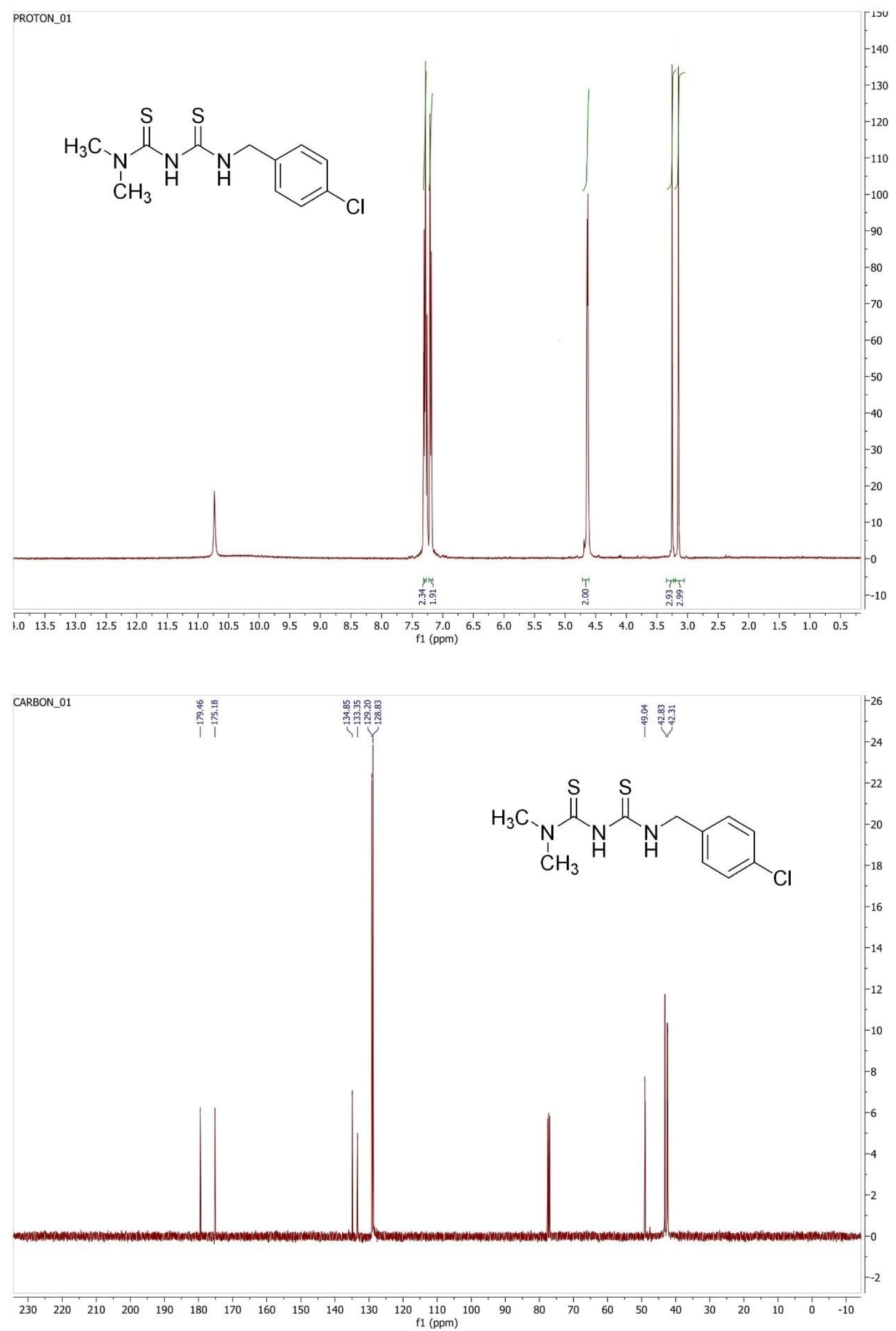

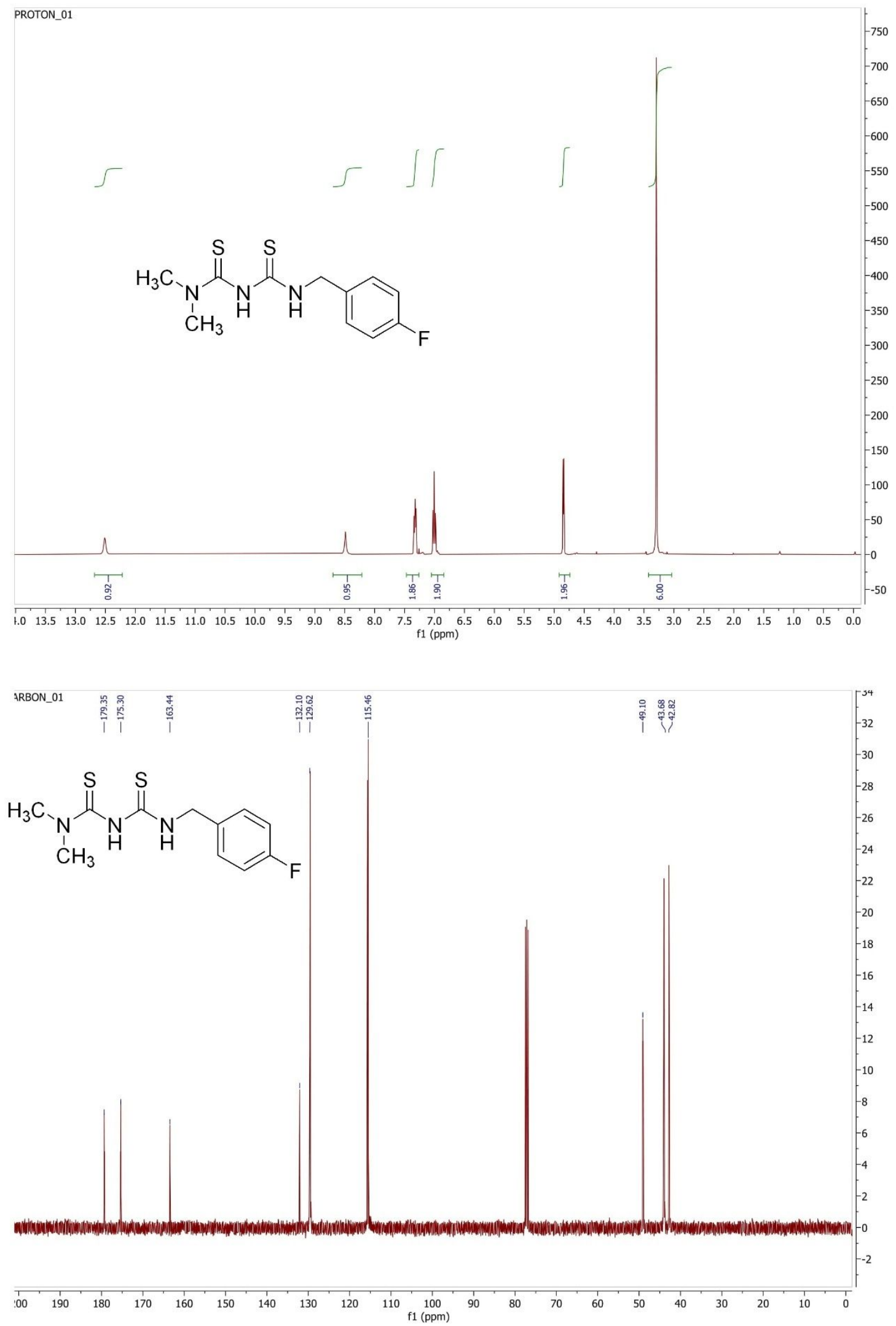

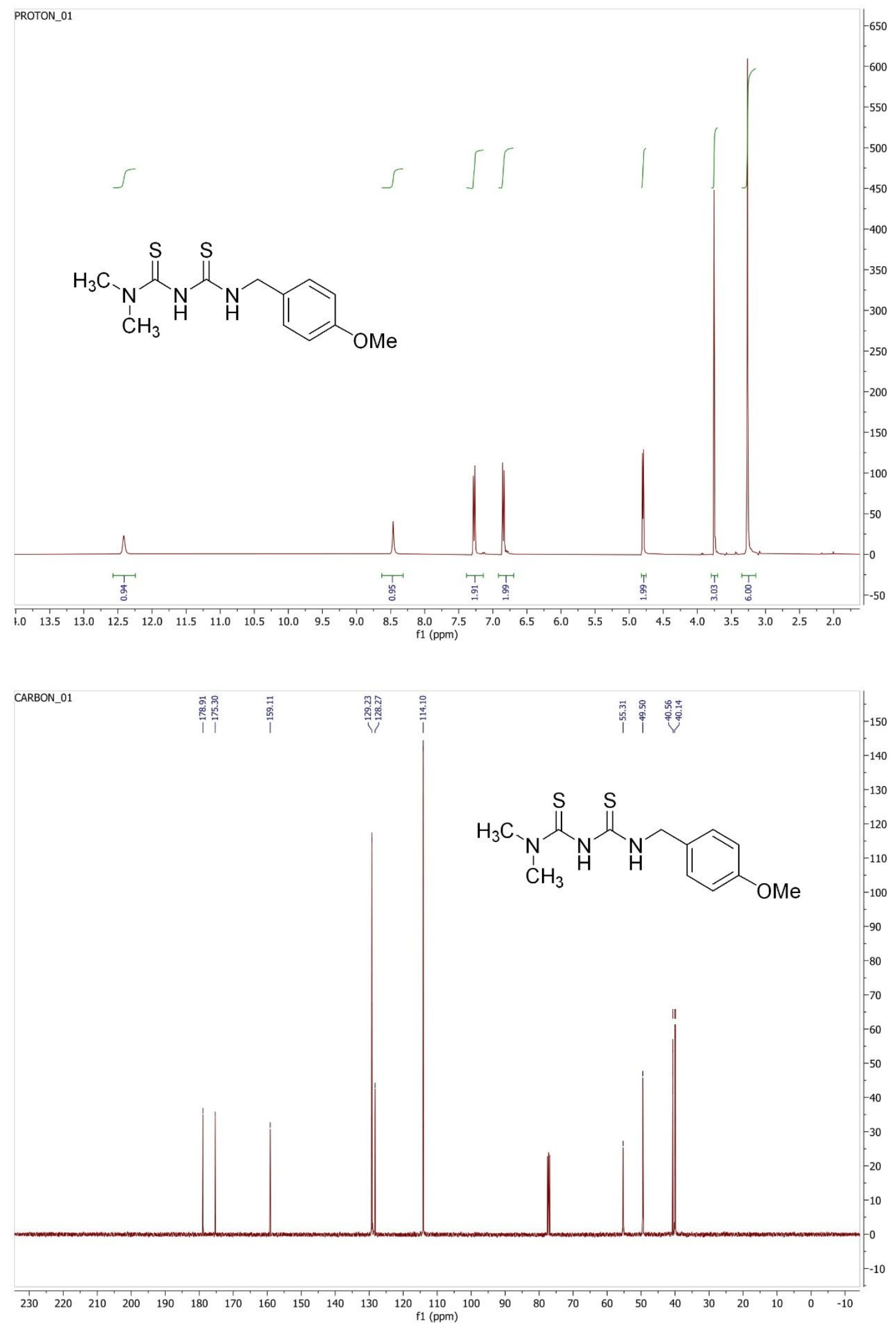

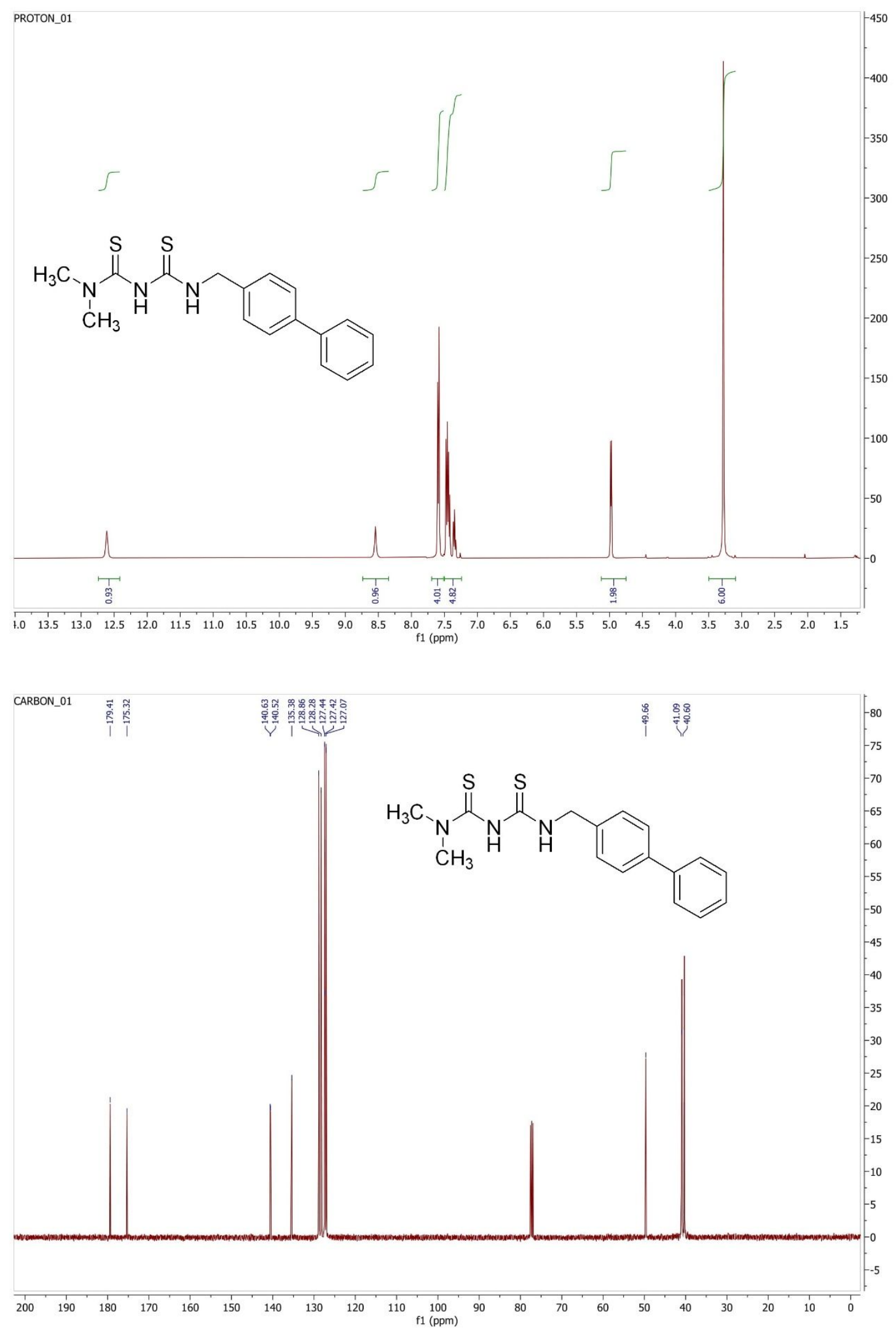

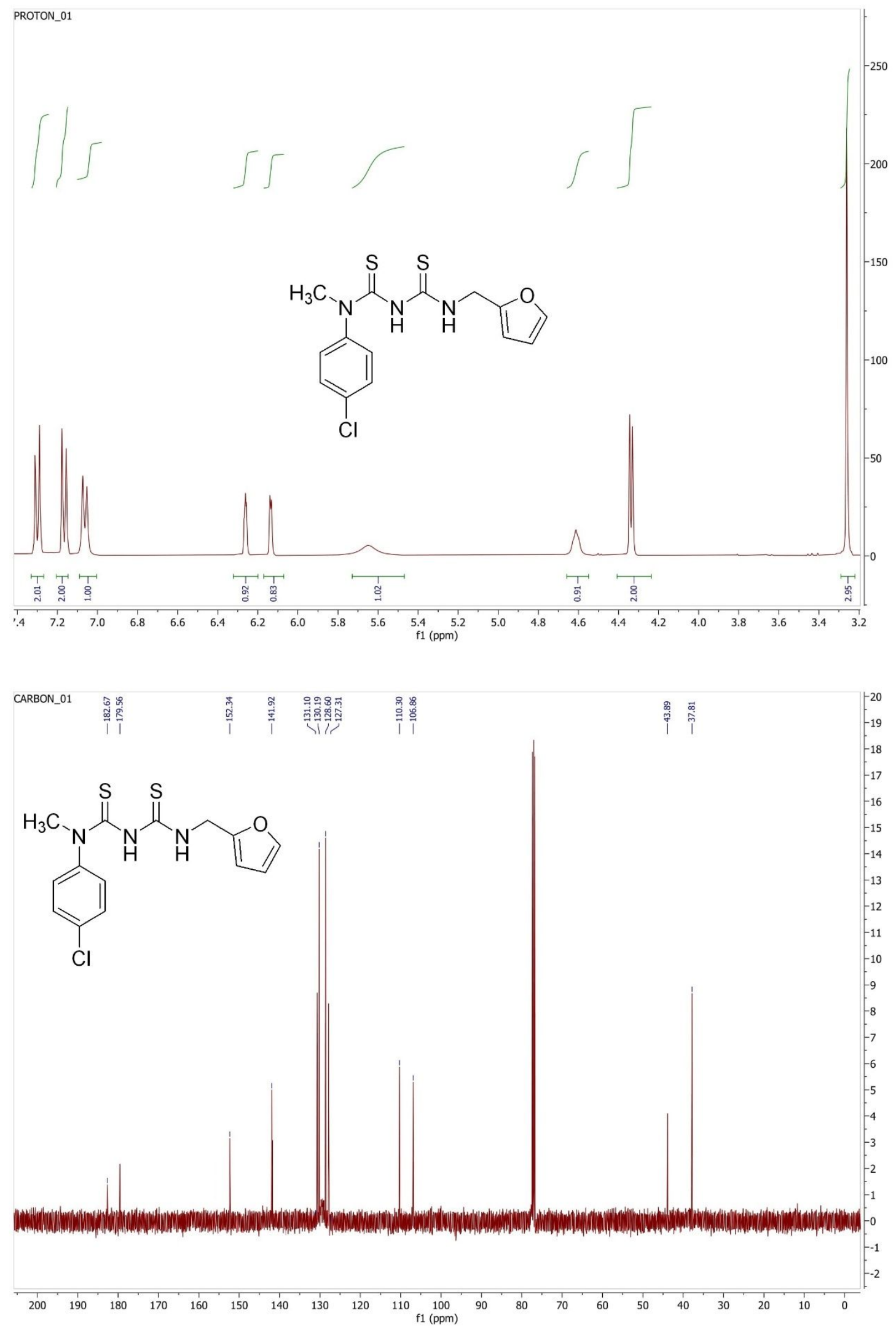

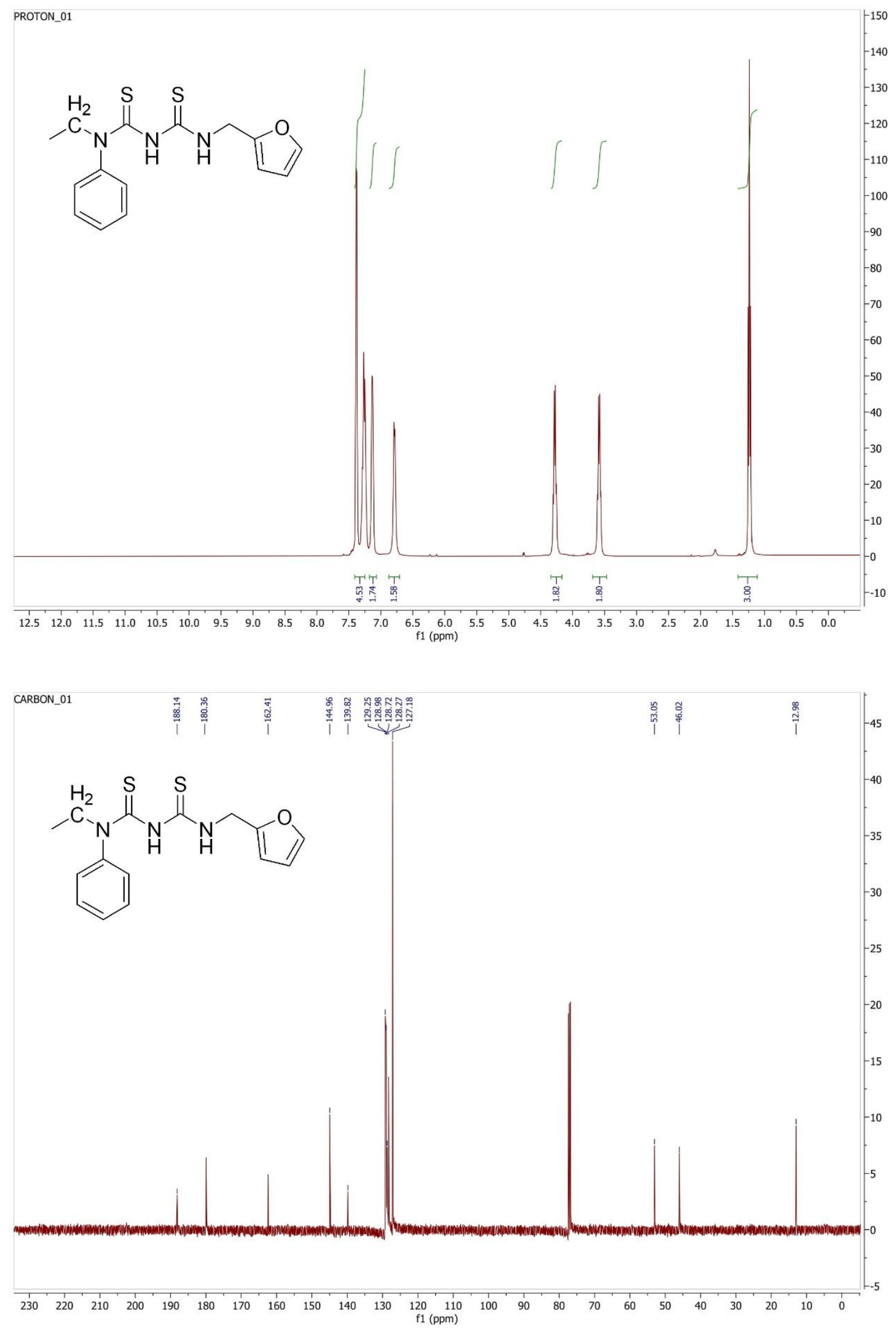

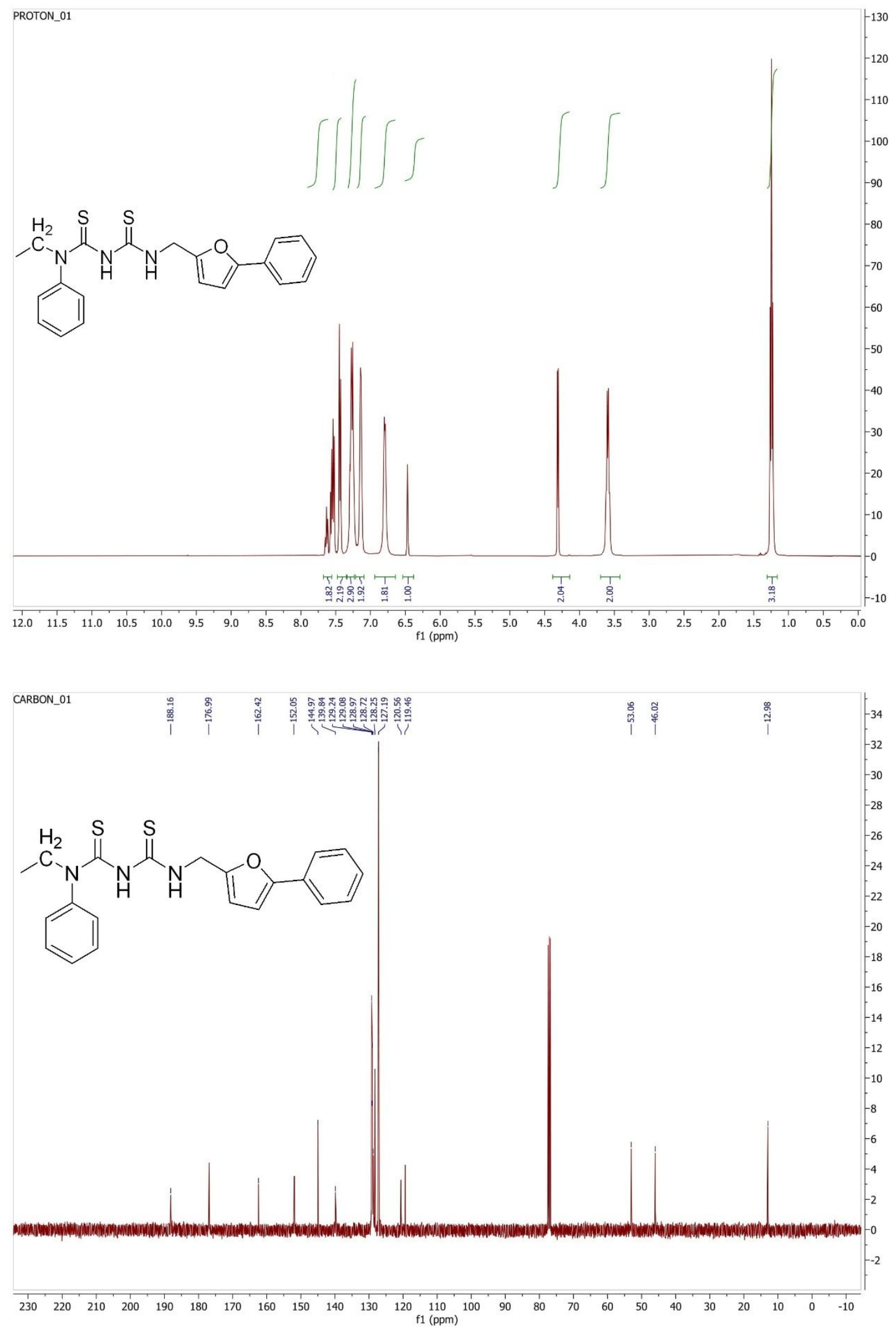


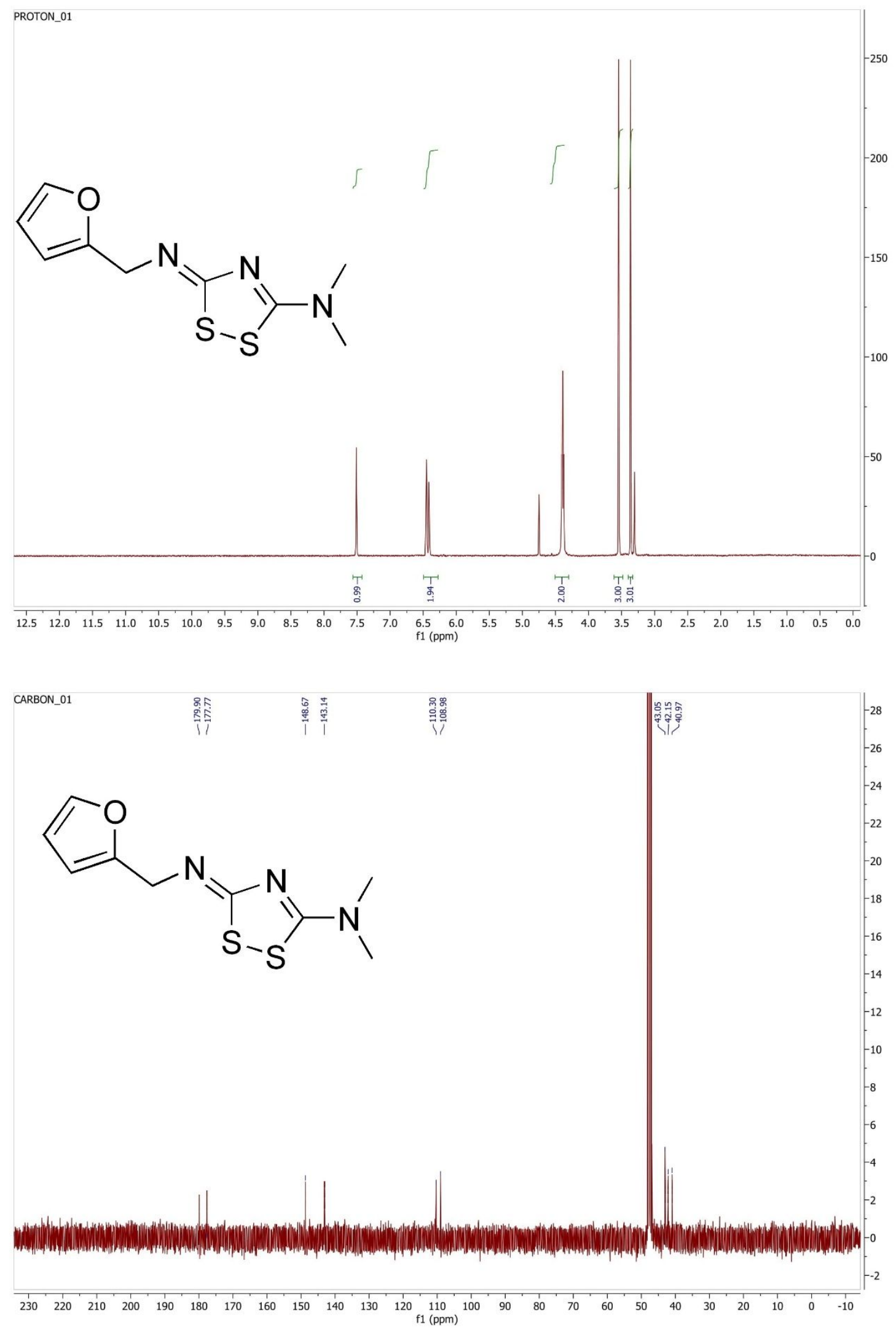



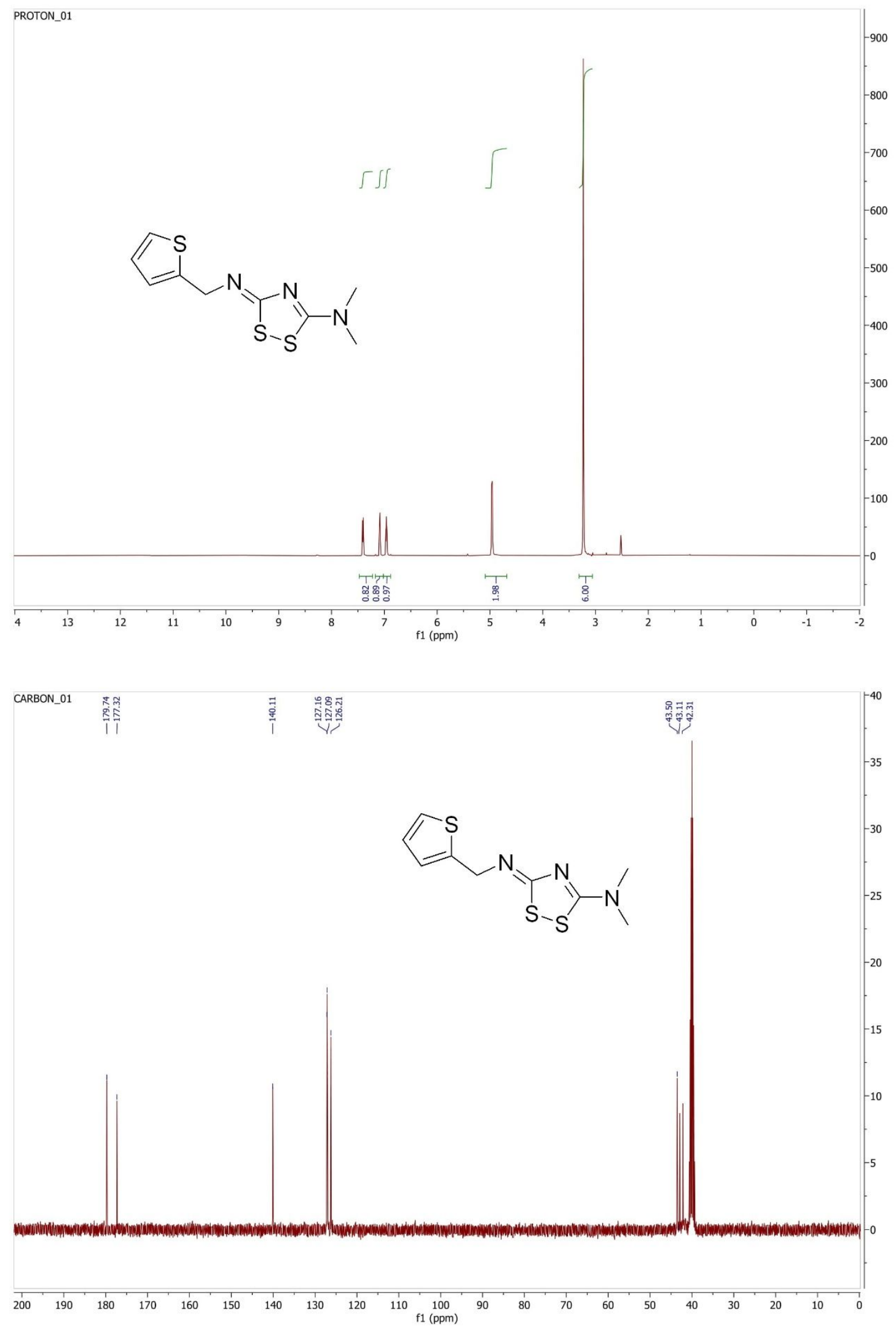


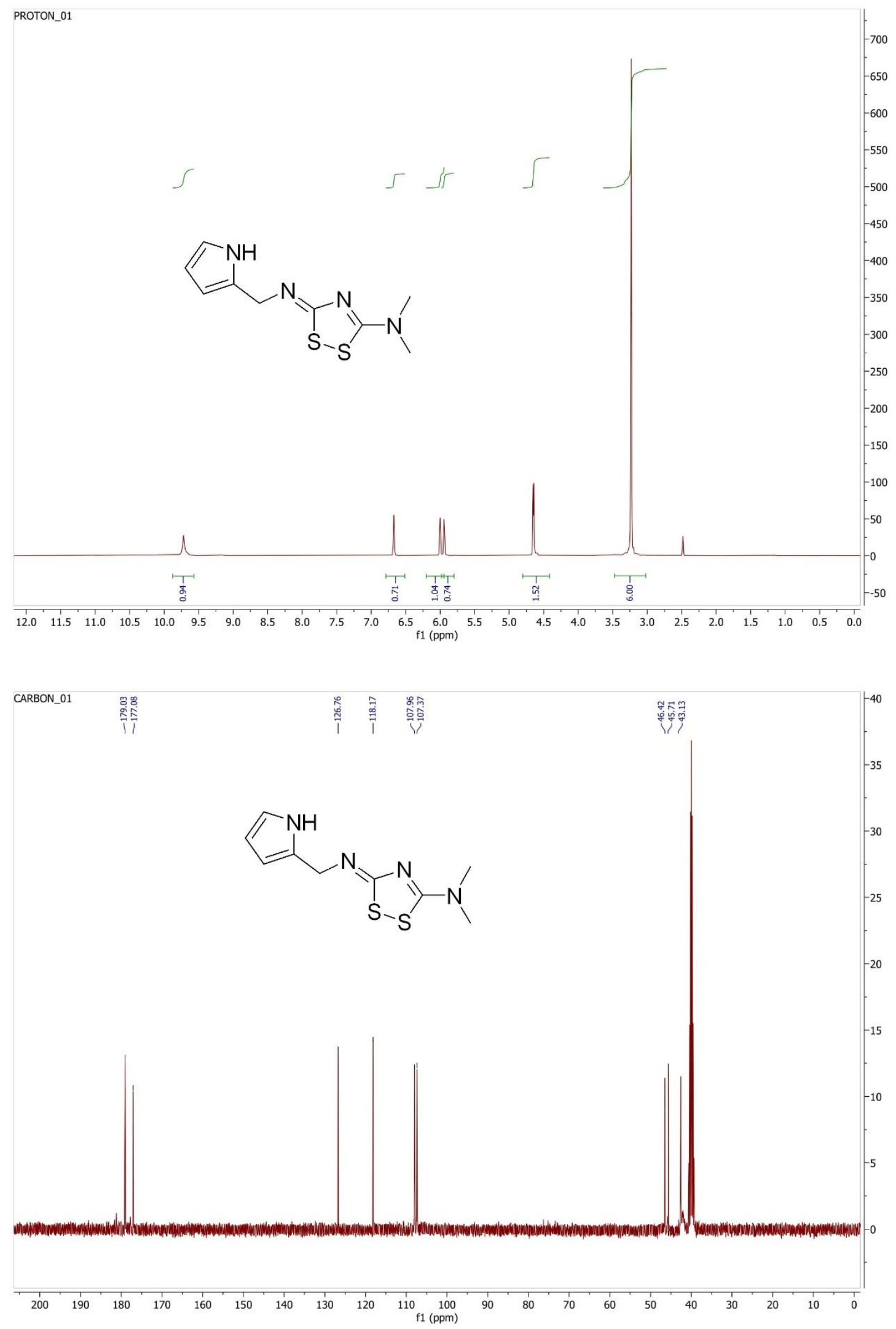



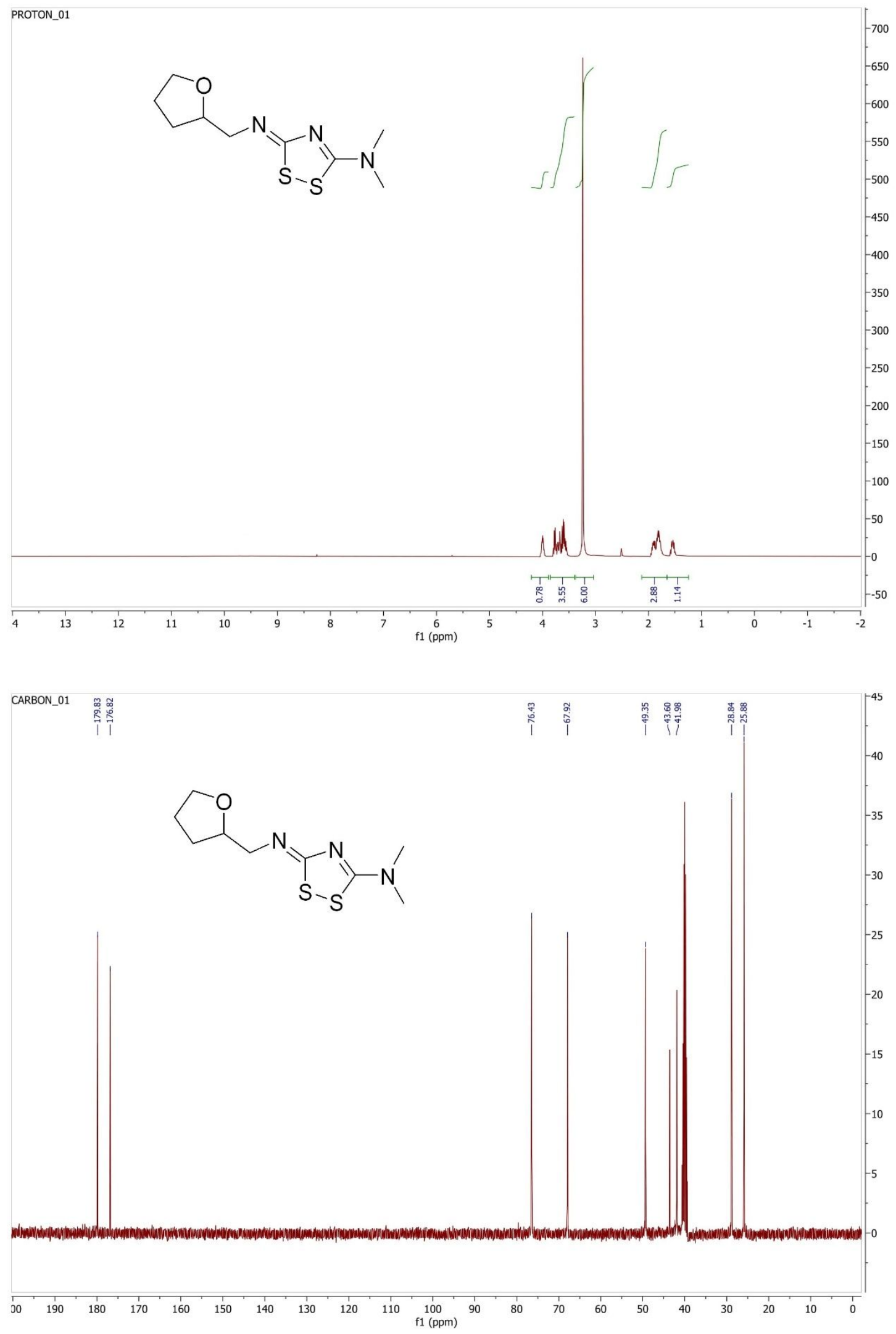

S56 

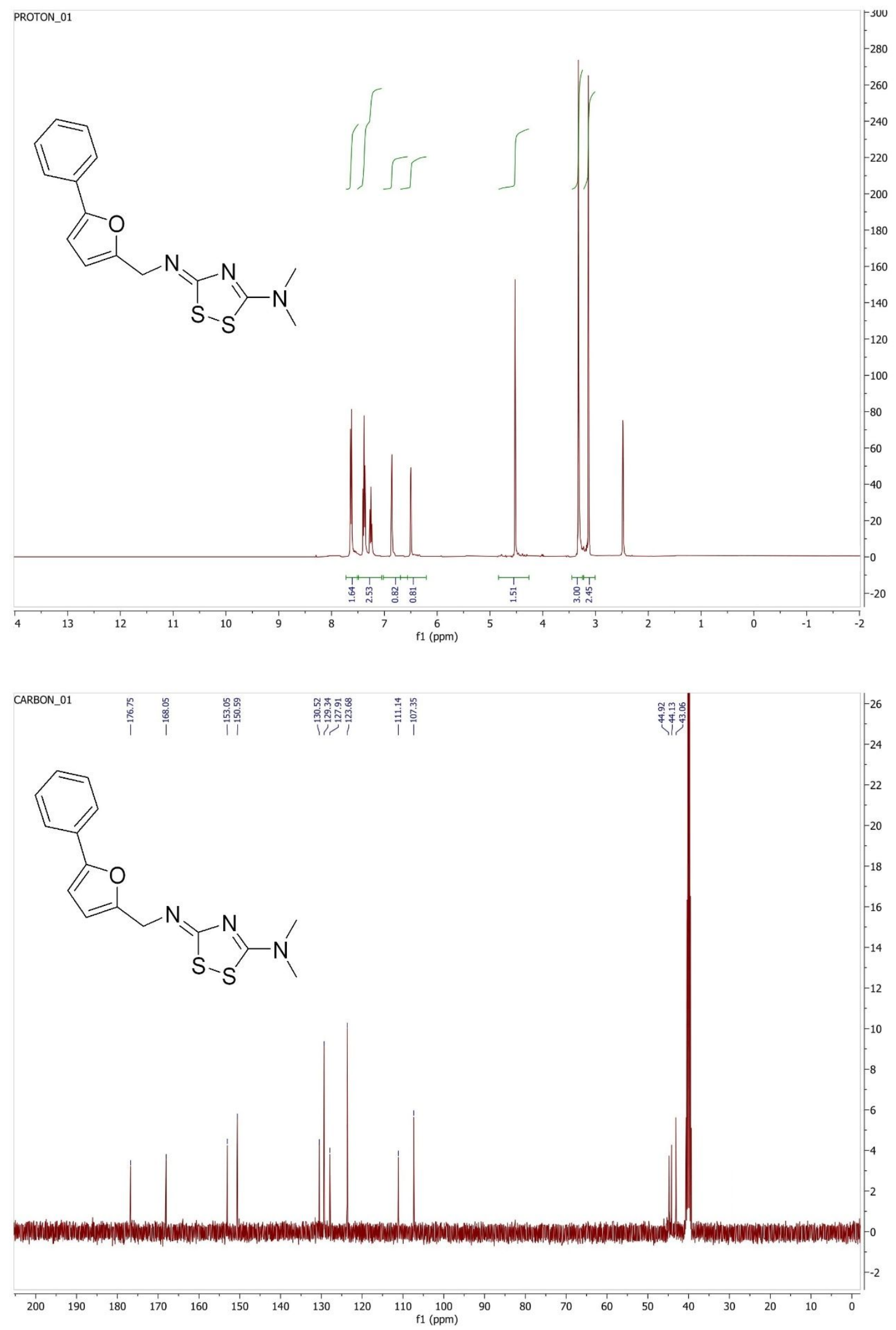

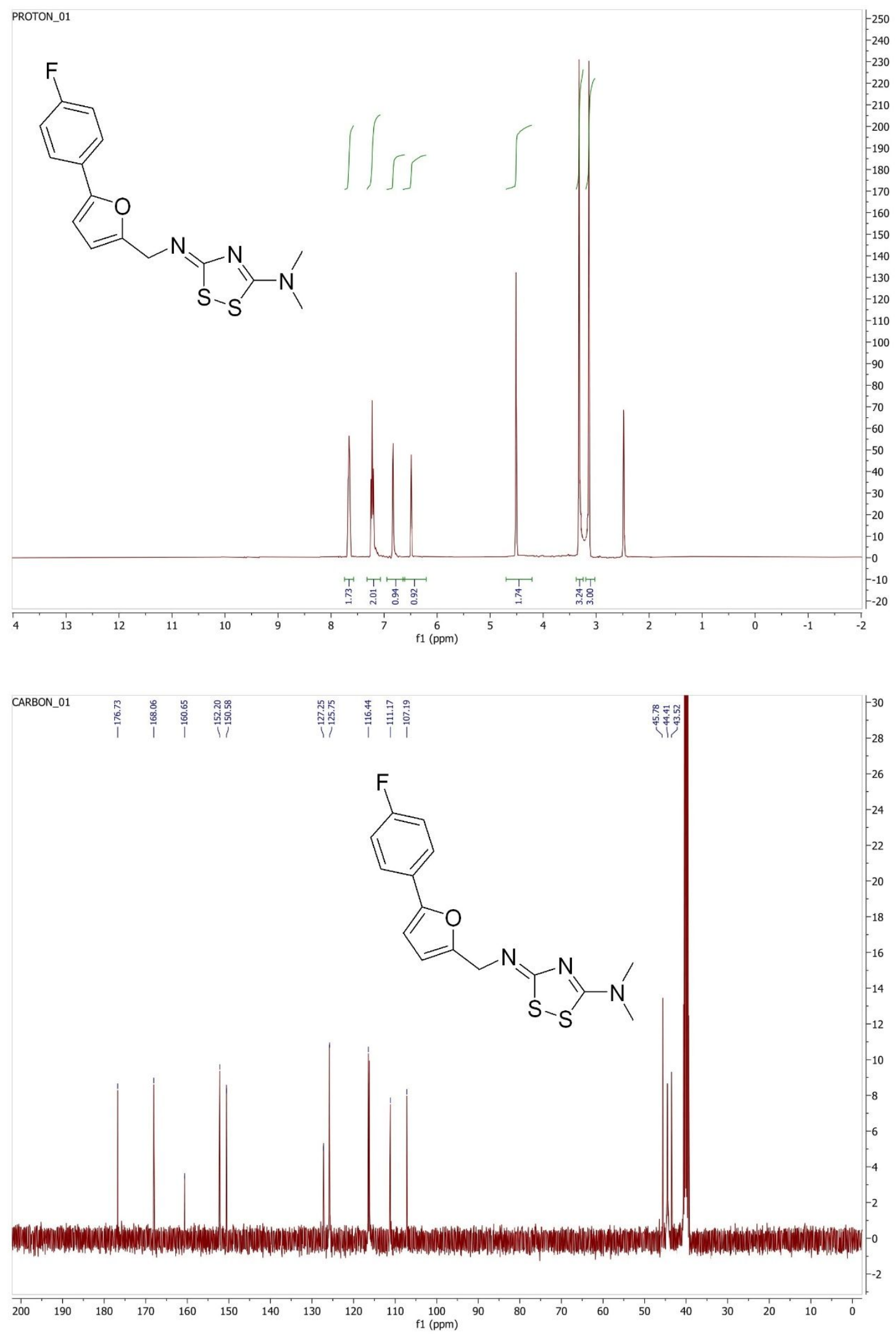

S58 

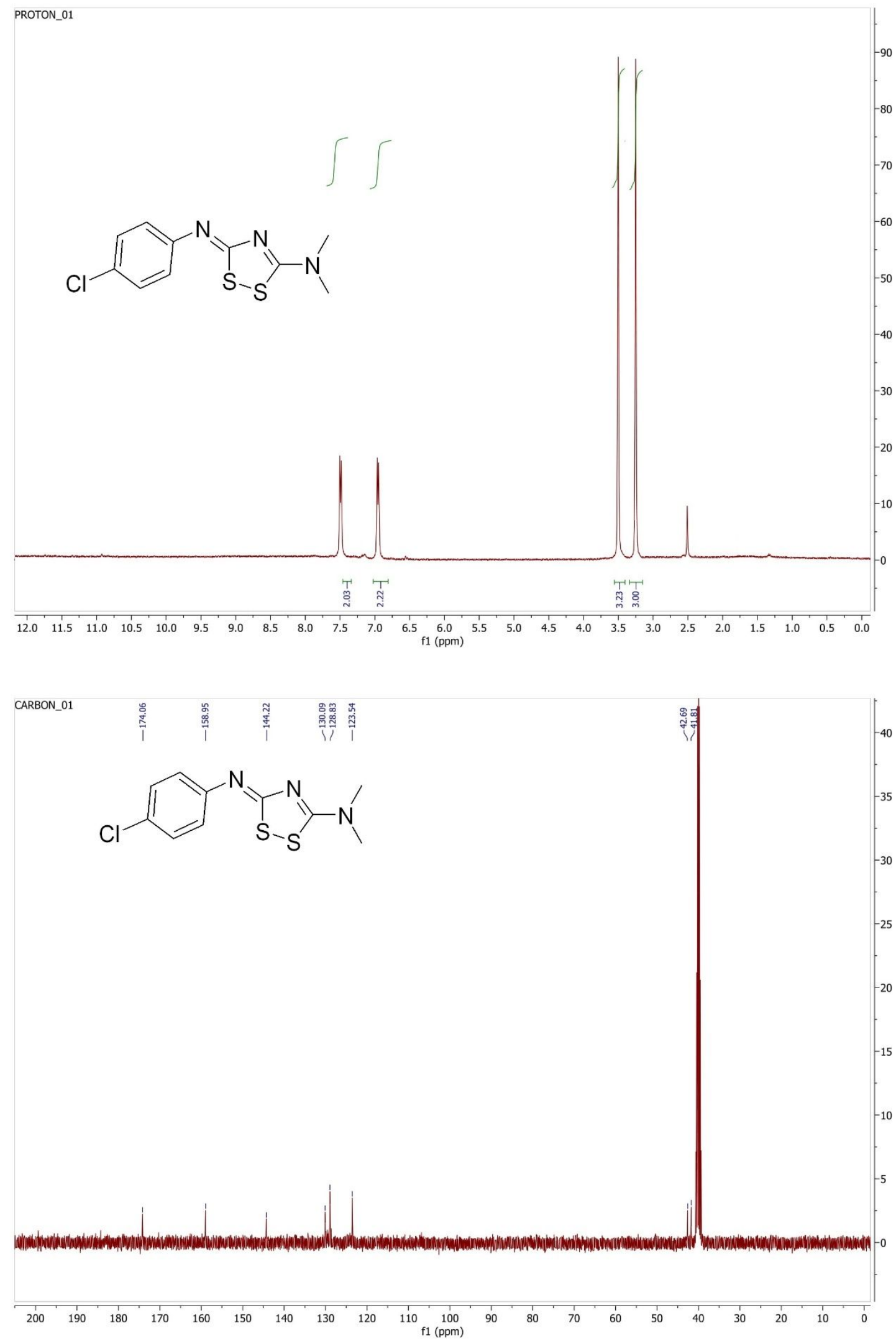

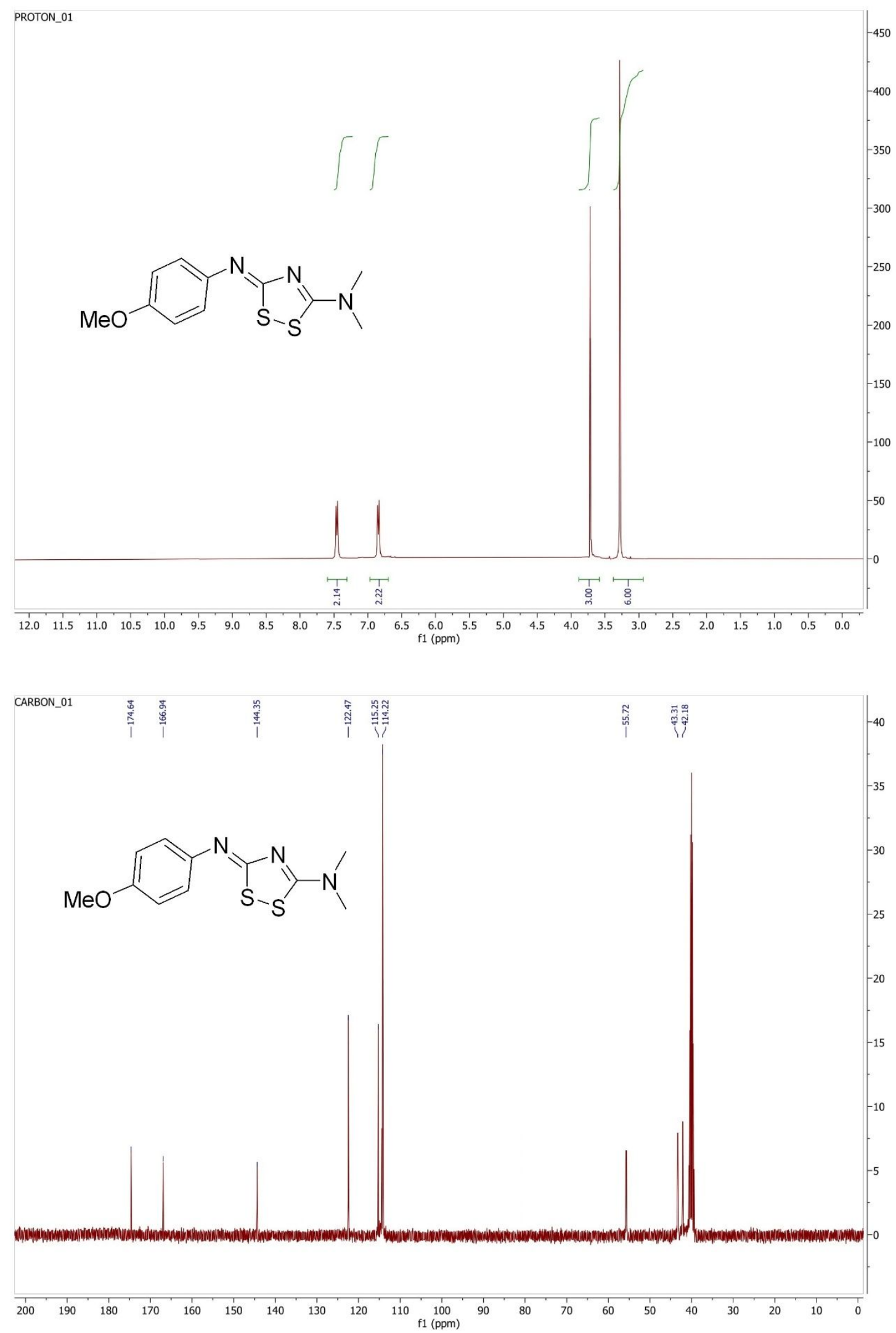

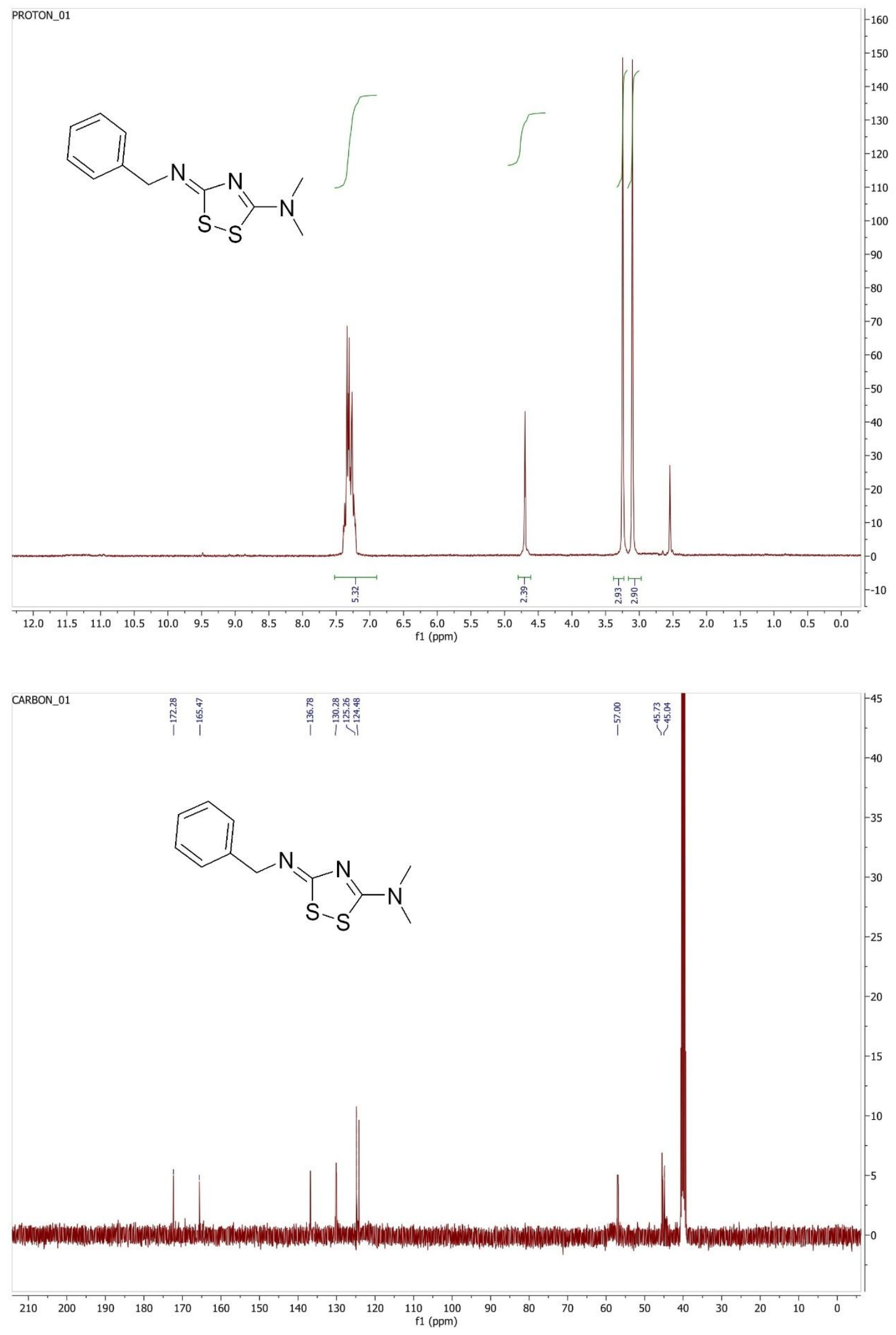

S61 

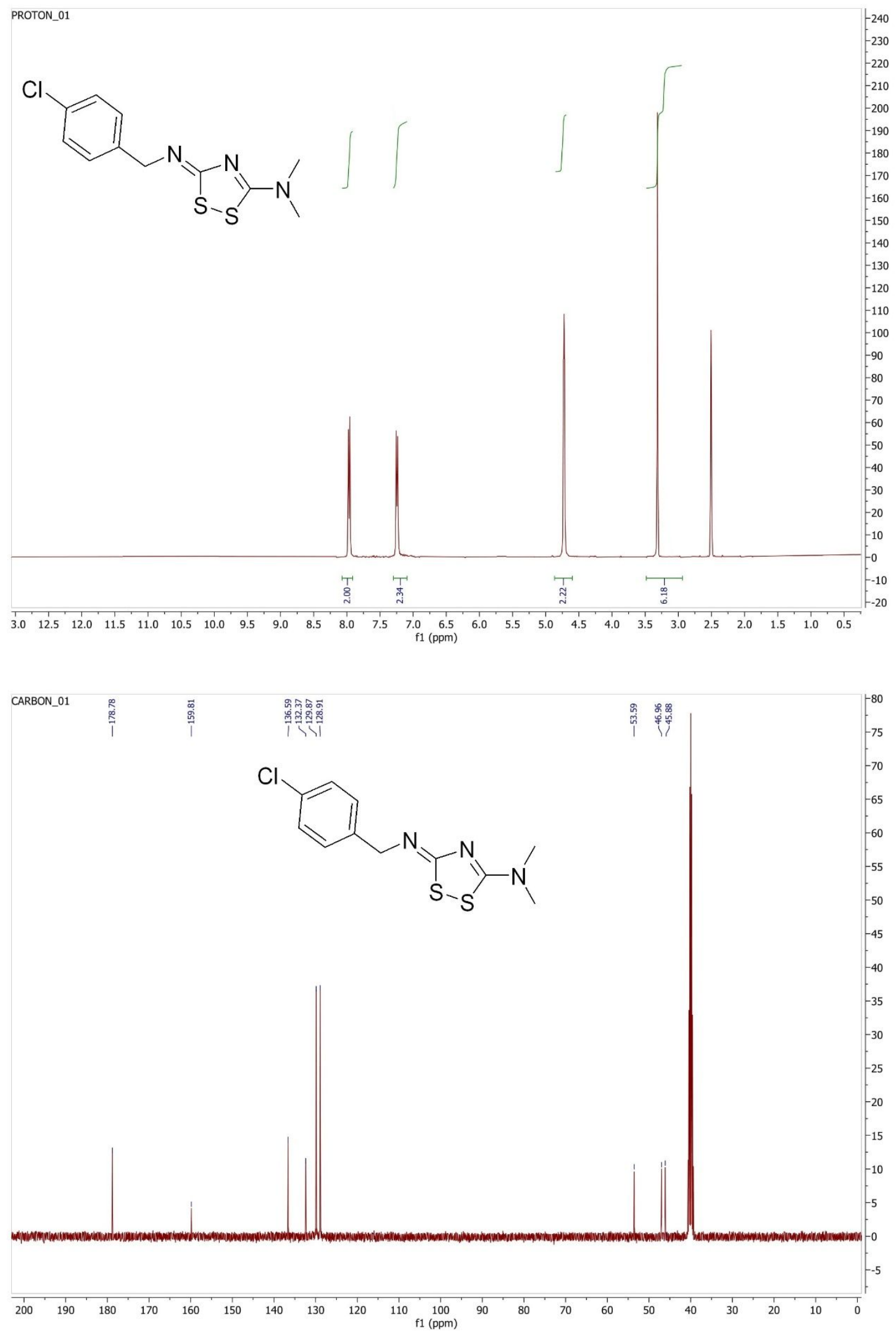

S62 

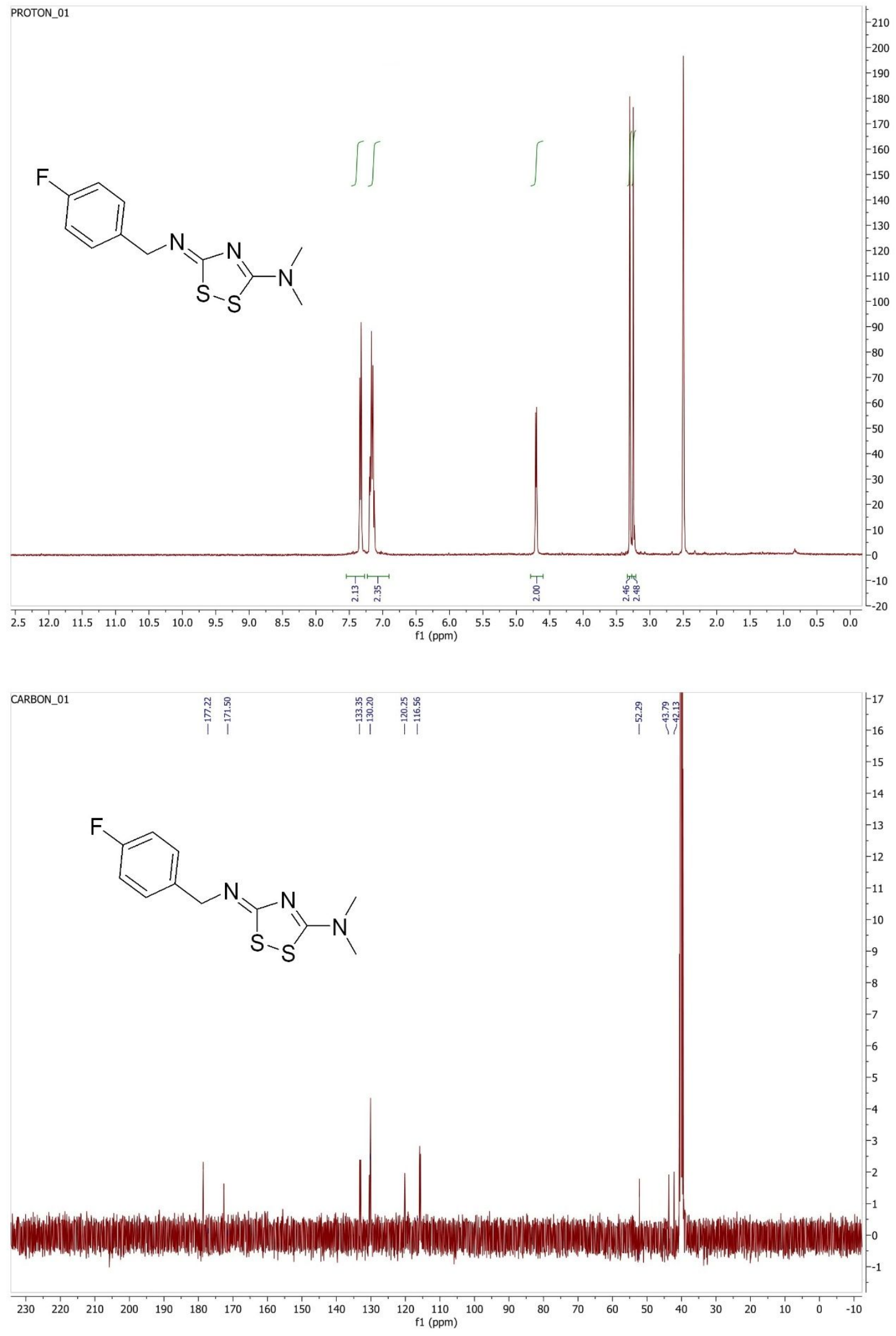

S63 


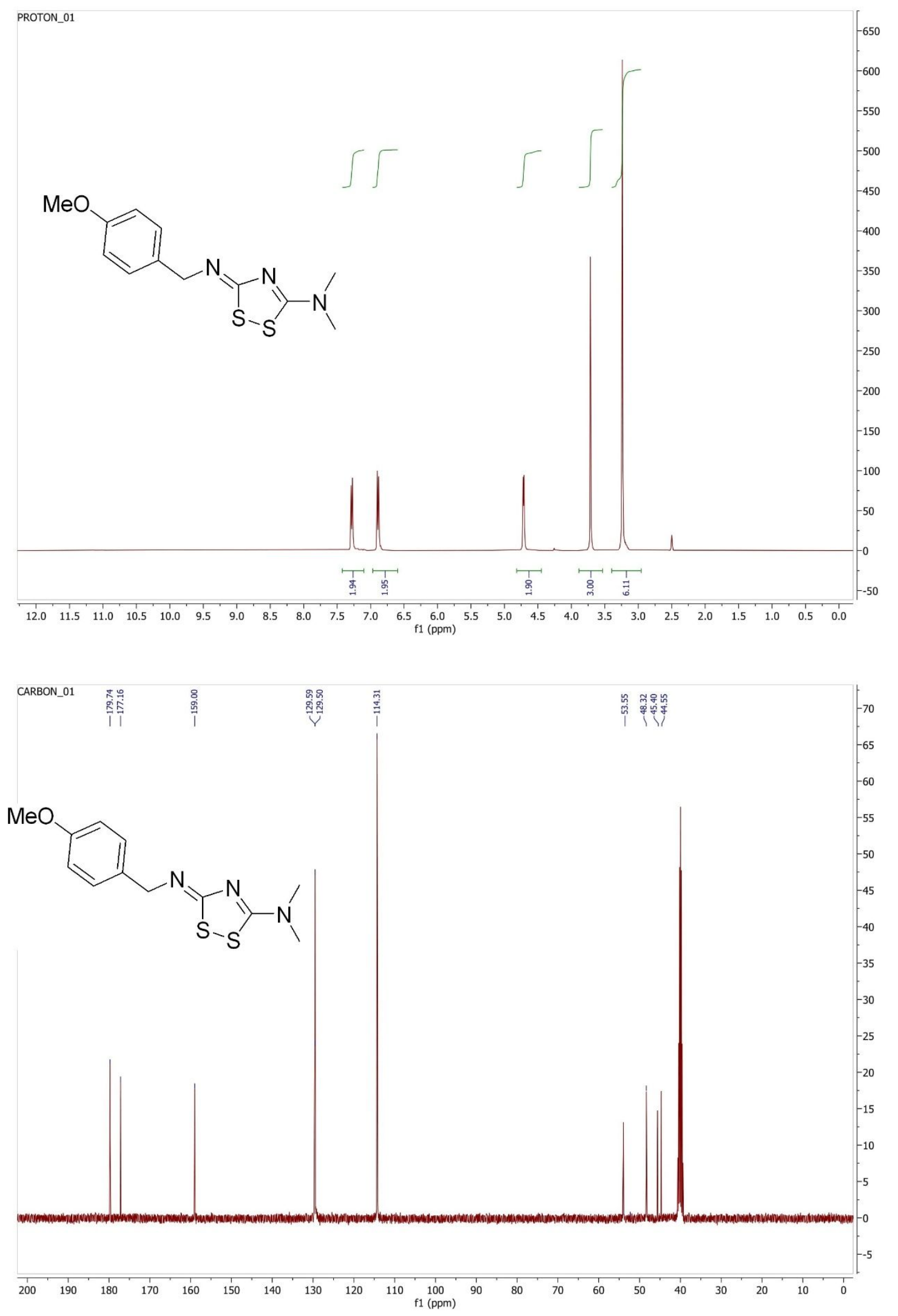




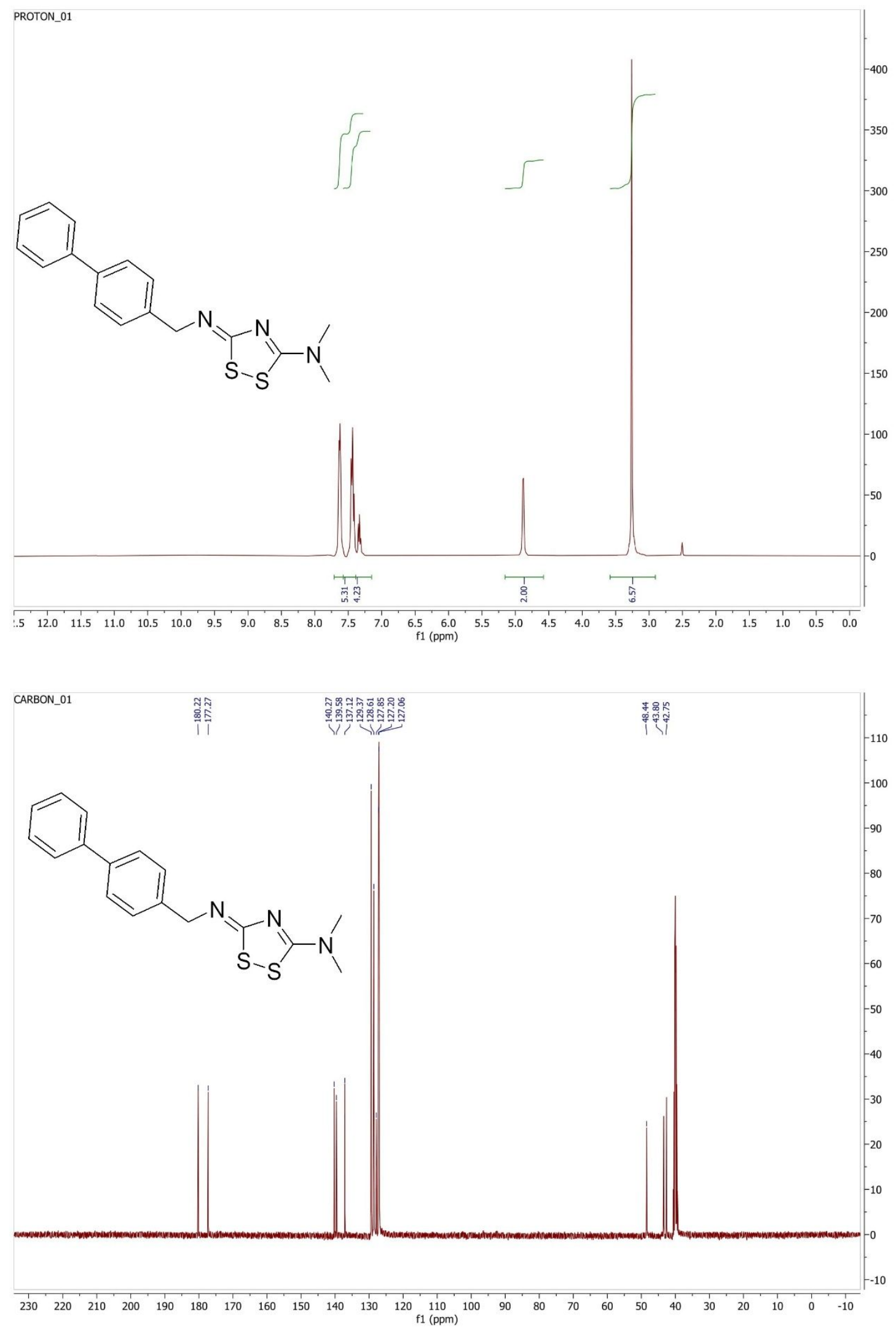



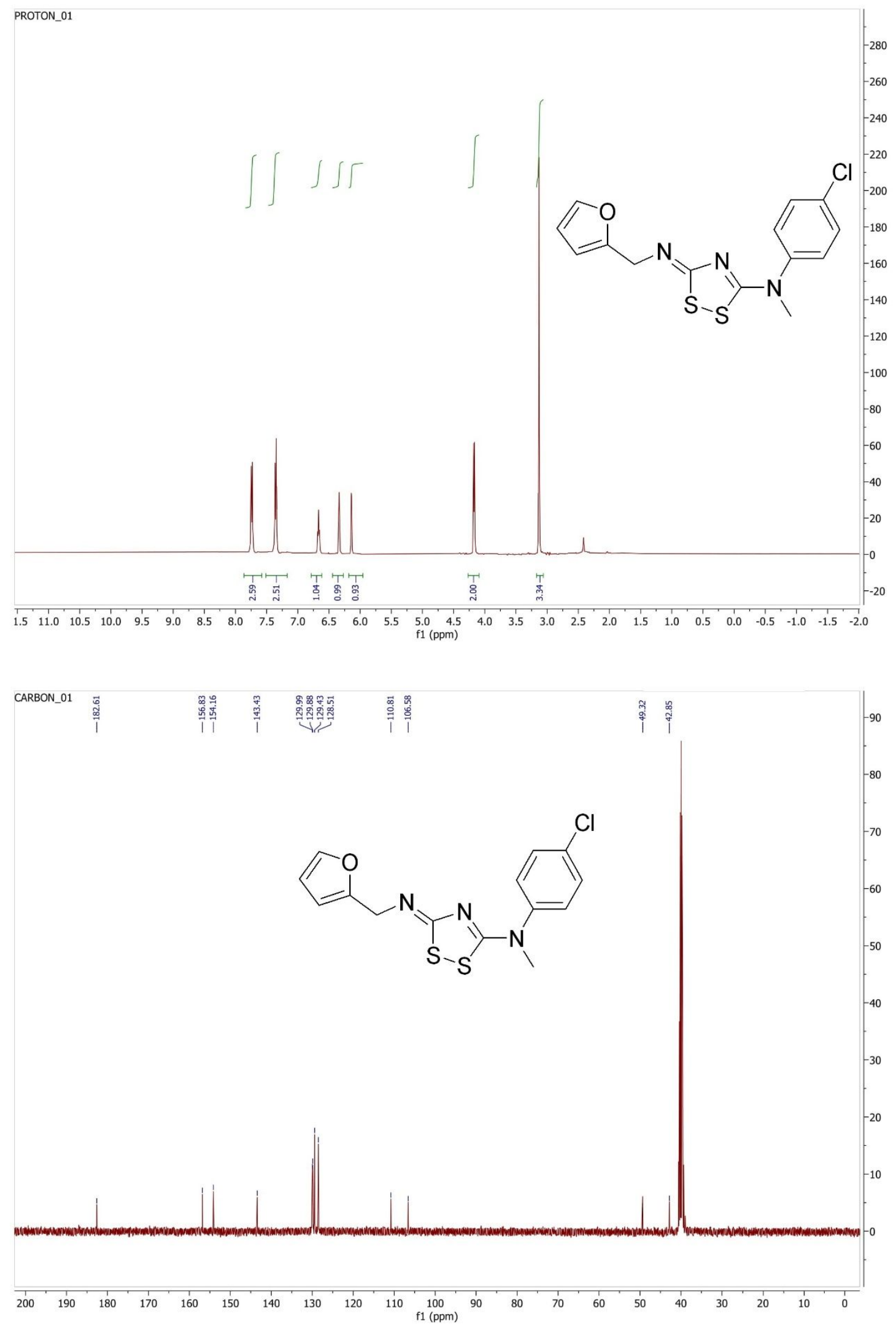

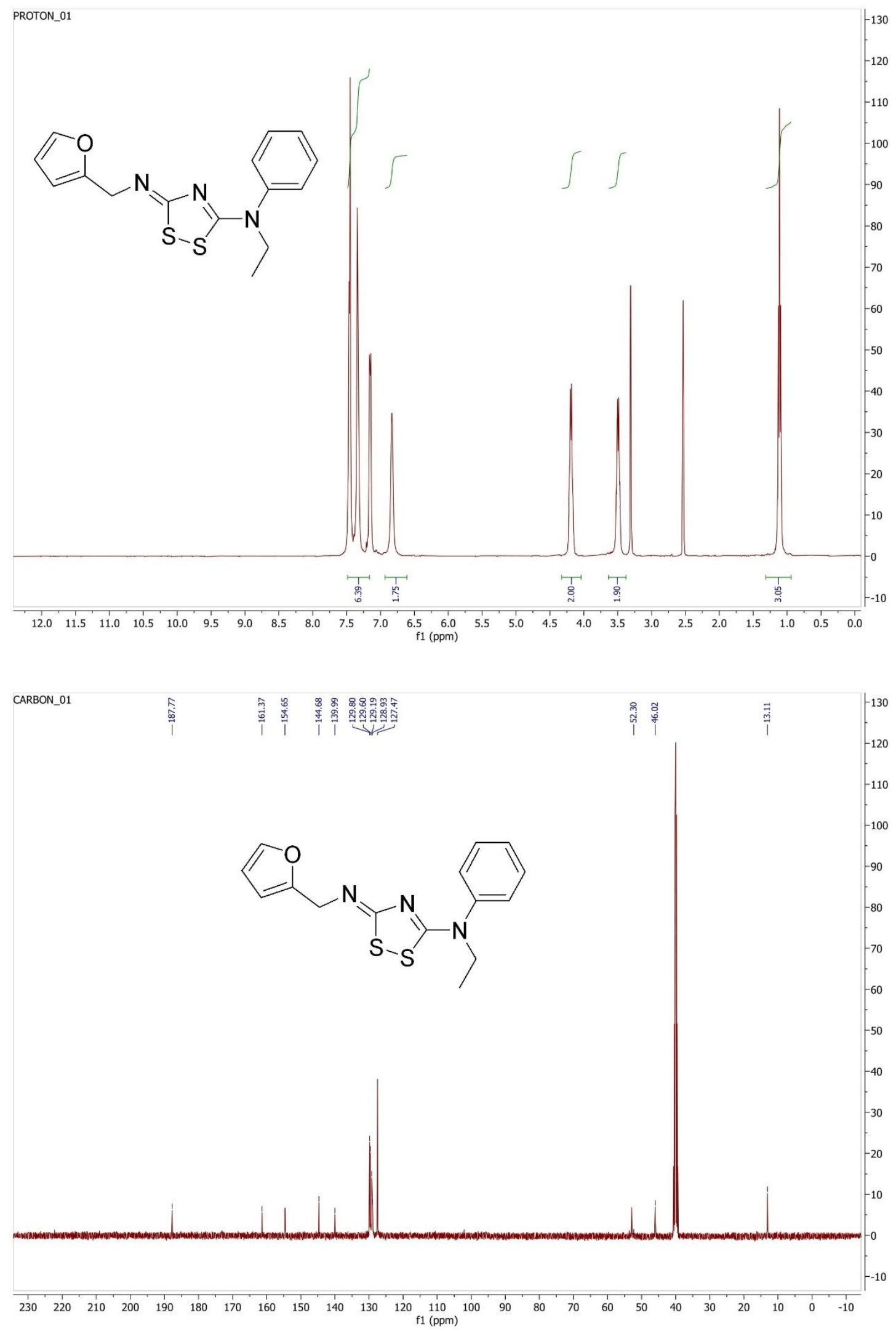

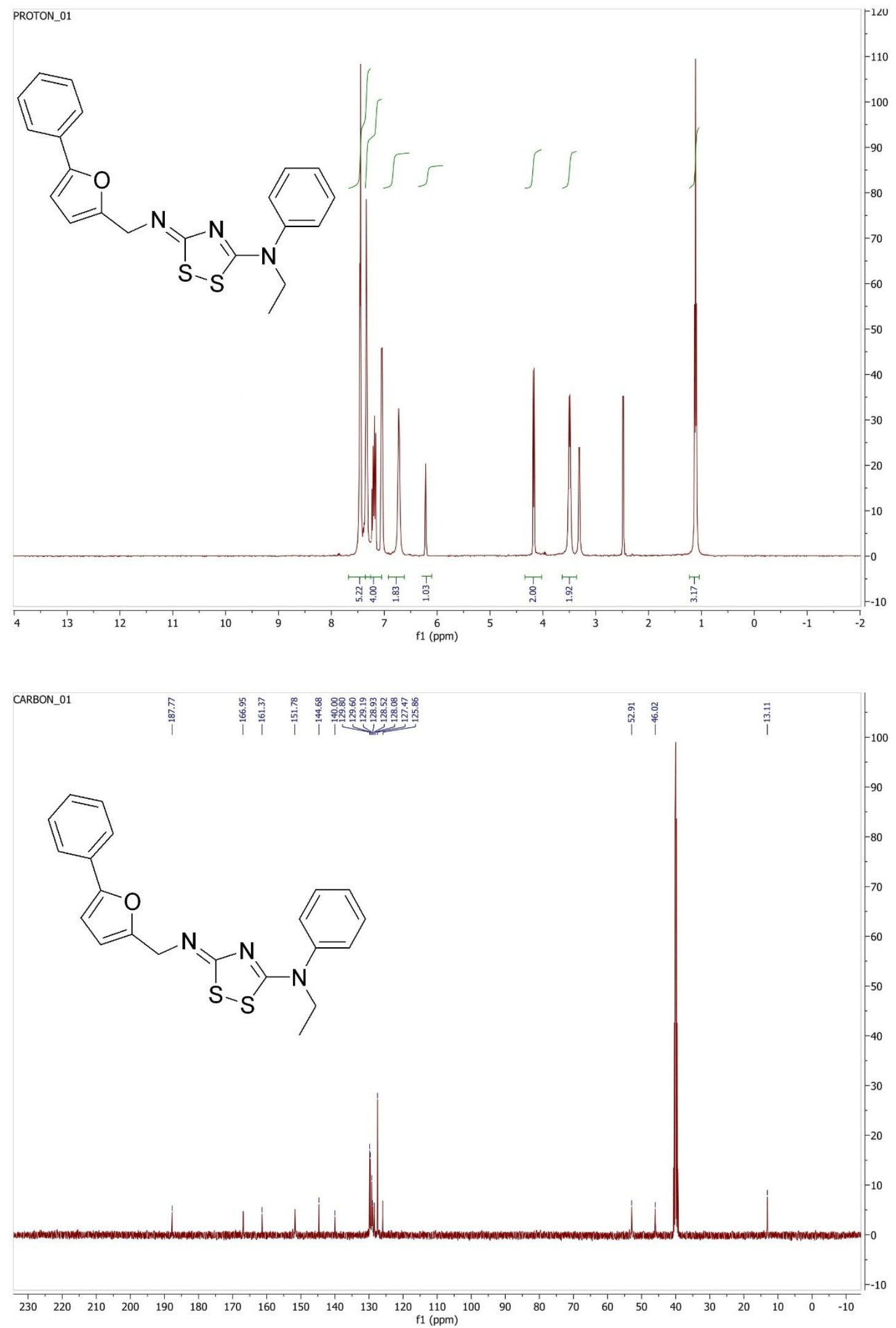